UNIVERSIDADE DE SÃO PAULO

ESCOLA DE ENFERMAGEM

CARACTERIZAÇÃO DO TRABALHO DA ENFERMAGEM

EM LABORATÓRIO DE ANÁLISES CLÍNICAS

ADRIANA MARQUES DA SILVA

SÃO PAULO

2004 
UNIVERSIDADE DE SÃO PAULO

ESCOLA DE ENFERMAGEM

\title{
CARACTERIZAÇÃO DO TRABALHO DA ENFERMAGEM EM LABORATÓRIO DE ANÁLISES CLÍNICAS
}

\author{
Dissertação apresentada à Escola de \\ Enfermagem da Universidade de São Paulo \\ para obtenção do título de Mestre em \\ Enfermagem.
}

ADRIANA MARQUES DA SILVA

ORIENTADORA: Prof $^{\mathrm{a}}$ Dr $^{\mathrm{a}}$ MARINA PEDUZZI

SÃO PAULO

2004 


\section{Silva, Adriana Marques da}

Caracterização do trabalho da enfermagem em laboratório de análises clínicas / Adriana Marques da Silva. - São Paulo: A. M. da Silva; 2004. $189 \mathrm{p}$.

Dissertação (Mestrado) - Escola de Enfermagem da Universidade de São Paulo.

Orientadora: $\operatorname{Prof}^{\mathrm{a}}$. Dr ${ }^{\mathrm{a}}$. Marina Peduzzi.

1. Laboratórios 2. Coleta de amostras 3. Trabalho 4. Enfermagem I. Título. 


\section{DEDICATÓRIA}

A minha mãe, Maria de Lourdes,

uma verdadeira guerreira da luz, que com grande amor, sabedoria e dedicação ensinou-me a ser quem sou

A meu pai, Augusto, "in memoriam"

A minha irmã Cleide, que sempre me acompanhou e auxiliou nos momentos em que mais precisei

A minha irmã Lúcia, que mesmo a distância sempre me apoiou 


\section{AGRADECIMENTO ESPECIAL}

Um agradecimento especial à Profa Dra Marina Peduzzi, orientadora nesta pesquisa, por me aceitar como orientanda, e conduzir-me pelos caminhos da pesquisa com grande competência, amizade e incentivo, acreditando em meu potencial. 


\section{AGRADECIMENTOS}

- A Deus, por acompanhar meus passos e colocar as pessoas certas em meu caminho.

- À Prof ${ }^{\mathrm{a}}$ Dra Paulina Kurcgant que, por meio de seus ensinamentos, contribuiu para o desenvolvimento da sensibilidade de um olhar mais crítico dirigido à dinâmica do trabalho.

- À Fundação Antonio Prudente, pelas oportunidades de desenvolvimento profissional.

- À Prof ${ }^{a}$ Dr $^{a}$ Vanda Elisa Andrés Felli, pelas valiosas contribuições no Exame de Qualificação.

- À Prof ${ }^{a}$ Dra $^{a}$ Cássia Baldini Soares, pelos ensinamentos ainda na fase de elaboração do projeto e no Exame de Qualificação.

- À Enfa Rika Miyahara Kobayashi, grande amiga e incentivadora, pela confiança, paciência e apoio pessoal e profissional, sempre se colocando à disposição, estendendo a mão nas horas mais críticas.

- Ao Profo Dr. Ricardo de Oliveira, que me ensinou a amar o trabalho na área de análises clínicas, e por quem tenho grande admiração e respeito.

- À Enfa Patrícia Gigliotte Kassab, pelo apoio, amizade e reconhecimento profissional.

- À Enfa Andréa Cotait Ayoub, pelo incentivo inicial ao aperfeiçoamento no campo da pesquisa. 
- Ao Profo Dr. José Alexandre M. Barbuto, Prof ${ }^{a}$ Dra $^{a}$ Margareth Ângelo e Prof ${ }^{a}$ Dra $^{a}$ Raquel Rapone Gaidzinsk que, inicialmente, me estimularam a desenvolver esta pesquisa.

- Aos docentes dos Departamentos de Orientação Profissional e Enfermagem em Saúde Coletiva, pela acolhida afetuosa, palavras e ações de estímulo nessa caminhada.

- Aos funcionários do Departamento de Orientação Profissional, da Pós-Graduação e Serviço de Biblioteca e Documentação, pela atenção e dedicação.

- Ao Prof. Dr. Carlos A. C. Sannazzaro da SBAC, Zilda Pereira da Fundação SEADE, Maria Cristina Marques, lara Alves de Camargo e José Geraldo Lupato Conrado do CVS, por contribuírem fornecendo as listagens dos laboratórios de análises clínicas.

- Aos dirigentes dos Laboratórios de Análises Clínicas que aceitaram participar da pesquisa, assim, contribuindo para sua concretização.

- À Equipe de Enfermagem do Centro de Diagnóstico por Imagem e do Departamento de Radioterapia e Braquiterapia da Fundação Antonio Prudente, pela competência do trabalho em equipe.

- Aos auxiliares de enfermagem que compuseram a equipe da Coleta de Exames do Laboratório de Análises Clínicas da Fundação Antonio Prudente, os inspiradores desta pesquisa.

- A Andréa Regina Sanches, pela amizade e partilha dos momentos importantes do mestrado, especialmente, no suporte na manutenção do computador.

- Ao Ricardo Góes, pelo auxílio no sistema de informática. 
- A Nadir Aparecida Lopes, pela realização da revisão bibliográfica.

- A Ivone Borelli, pela revisão de português.

- A Cecília Tsukamoto, pela revisão do inglês.

- A Inês Nobuko Nishimoto e Claudia Benedita dos Santos, pelo auxílio no processo estatístico.

- Aos amigos, que me acompanharam de alguma forma nesse desafio. 


\section{APRESENTAÇÃO}

Após ter concluído o curso de graduação na Escola de Enfermagem da Universidade de São Paulo, fui trabalhar em unidade de internação na Fundação Antonio Prudente, um importante Centro de Referência Tratamento e Pesquisa de Câncer. Mais tarde, fui convidada para atuar no setor de coleta de exames do laboratório de análises clínicas da Fundação.

Assim, no dia-a-dia fui conhecendo e interessando-me por esta área de atuação. Meus grandes professores foram os Auxiliares de Enfermagem, Médicos, Biólogos, Biomédicos e Farmacêuticos-bioquímicos que lá trabalhavam.

Com o passar do tempo, surgiu a necessidade de saber como ocorria o processo de análise da amostra biológica que se iniciava no setor de coleta de exames com a enfermagem.

A fim de desenvolver meu conhecimento técnico-científico neste campo, no ano de 2000, fiz o curso de especialização em análises clínicas da Universidade São Judas Tadeu da capital.

No entanto, persistia ainda uma inquietação. Satisfeita a necessidade do conhecimento técnico específico em análises clínicas, faltava conhecer como era o trabalho desenvolvido pela enfermagem nessa área em outros laboratórios de Análises Clínicas. Desse modo, veio a idéia de realizar este estudo.

Espero que esta pesquisa de caráter exploratório-descritiva possa contribuir para futuros estudos neste campo profissional. 


\section{RESUMO}

Silva AM. Caracterização do trabalho de enfermagem em laboratório de análises clínicas. [dissertação] São Paulo (SP): Escola de Enfermagem de USP; 2004.

Este estudo de caráter qualitativo e quantitativo, tipo exploratóriodescritivo, trata da caracterização do trabalho de enfermagem em laboratórios de análises clínicas. O objetivo geral visa identificar os aspectos da atuação da enfermagem nos laboratórios de análises clínicas, que permitam caracterizar o processo de trabalho da enfermagem. Os objetivos específicos buscaram identificar os trabalhadores da saúde que atuam na coleta de exames; reconhecer as atividades desempenhadas pelos diferentes agentes da enfermagem e conhecer sua inserção na estrutura organizacional. O referencial teórico adotado pautou-se nos estudos do processo de trabalho e de recursos humanos em saúde e em enfermagem. Para a coleta de dados utilizou-se um questionário e a amostra foi composta por 45 instituições. A análise dos resultados revelou que, quanto à caracterização dos laboratórios, $15,6 \%$ não realizam treinamento em serviço e $60 \%$ fazem-no de modo isolado, não continuado; o enfermeiro é o profissional que assume majoritariamente a responsabilidade por essa ação. Quanto aos recursos humanos, $77,8 \%$ são auxiliares de enfermagem, $13 \%$ enfermeiros e 9,1\% técnicos de enfermagem. Evidencia-se a divisão social e técnica do trabalho, no qual os auxiliares executam o cuidado direto, o enfermeiro gerencia o processo e os técnicos desempenham ambas ações, sem diferenças relevantes entre as atividades dos auxiliares e técnicos de enfermagem. Além disso, há outros profissionais que compartilham das mesmas atividades realizadas pela enfermagem e esta se encontra, em grande parte, subordinada a outras áreas de atuação, com escassa autonomia na estrutura organizacional.

Palavras-chave: Laboratório de análises clínicas. Coleta de amostras. Trabalho. Trabalho em enfermagem. Força de trabalho. 


\section{ABSTRACT}

Silva AM. Characteristics of the activities performed by nursing professionals in clinical laboratories. [Master's degree thesis]. São Paulo (SP): School of Nursing at the University of São Paulo; 2004.

This qualitative and quantitative study, an exploratory-descriptive study, examines the characteristics regarding the work performed by nursing professionals in clinical laboratories. The general goal aims to identify roles played by nursing professionals in clinical laboratories that allow us to characterize the nursing work process. The specific goals seek to identify health workers that are responsible for collecting samples, to distinguish the activities played by different nursing professionals and to learn how they are inserted in the organizational structure. The theoretical reference adopted is based on studies regarding work procedures and human resources in health and nursing. A questionnaire was used to collect data and the sample comprised 45 institutions. Regarding the clinical laboratories, result analysis revealed that $15.6 \%$ of them do not offer in-service training and $60 \%$ do not do it on a continuous manner; nurses basically take on the responsibility for training other nursing professionals. Regarding human resources, $77.8 \%$ are nursing assistants, $13 \%$ are nurses, and $9.1 \%$ are practical nurses. There is evidence of a social and technical division of the workload: nursing assistants provide direct care, nurses manage the processes, and practical nurses perform both activities. No relevant differences were observed between the activities played by nursing assistants from those played by practical nurses. Furthermore, there are other professionals that share the same activities played by those nursing professionals. In most cases, nursing professionals are subordinated to other areas and have little autonomy in the organizational structure.

Keywords: Clinical laboratory. Samples collection. Work. Work in Nursing. Workforce. 


\section{SUMÁRIO}

INTRODUÇÃO.

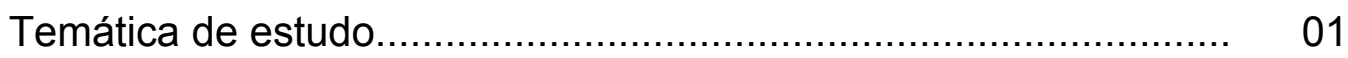

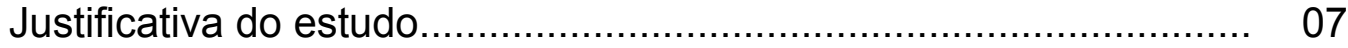

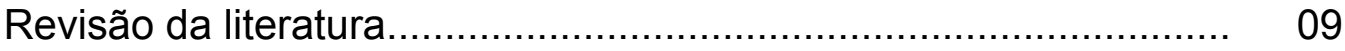

OBJETIVOS DO ESTUDO............................................................ 19

REFERENCIAL TEÓRICO....................................................... 20

METODOLOGIA

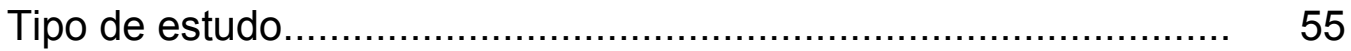

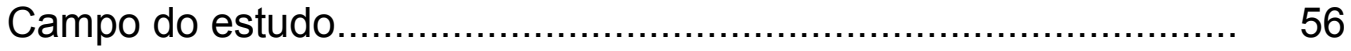

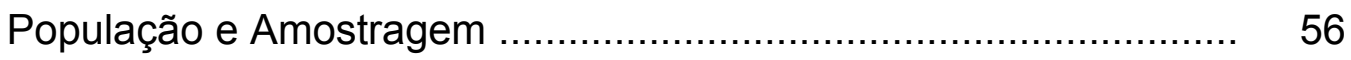

Procedimento de coleta de dados .............................................. 64

Aspectos éticos da pesquisa....................................................... 74

Procedimento de análise de dados................................................. 75

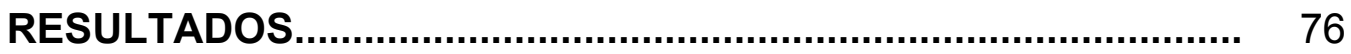

ANÁLISE DE DADOS …........................................................... 105

CONSIDERAÇÕES FINAIS......................................................... 133

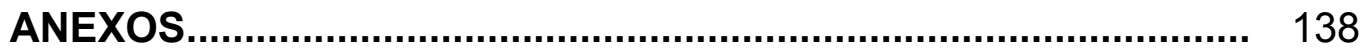

Anexo I - Análise documental................................................. 138

Anexo II - Tabela de dígitos aleatórios.......................................... 165

Anexo III - Instrumento de coleta de dados................................... 171

Anexo IV - Carta de autorização da instituição................................ 174

Anexo V - Termo de consentimento livre e esclarecido................... 175

Anexo VI - Parecer de aprovação da comissão de ética da escola de enfermagem da universidade de São Paulo................ 176

Anexo VII - Carta de apresentação................................................ 177

REFERÊNCIAS BIBLIOGRÁFICAS........................................... 178 
Figura 1 Relação dos motivos das perdas amostrais, segundo seleção amostral. Município de São Paulo, 2003

Figura 2 Núcleo da Área da Saúde, segundo funções e subfunções.

Figura 3 Subfunções específicas da Subárea de 146 Biodiagnóstico, segundo funções e subfunções.

Figura 4 Subfunções específicas da Subárea de Enfermagem, segundo funções e subfunções.

Tabela 1 Distribuição dos laboratórios estudados, segundo categoria profissional dos informantes. Município de São Paulo, 2003

Tabela 2 Distribuição dos laboratórios estudados, segundo tipo de unidade. Município de São Paulo, 2003

Tabela 3 Distribuição dos laboratórios estudados, segundo natureza jurídica. Município de São Paulo, 2003

Tabela 4 Distribuição dos laboratórios estudados, segundo ano de início de funcionamento. Município de São Paulo, 2003

Tabela 5 Distribuição dos laboratórios estudados, segundo regime de atendimento. Município de São Paulo, 2003

Tabela 6 Distribuição dos laboratórios estudados, segundo número aproximado de atendimentos mensais. Município de São Paulo, 2003

Tabela 7 Distribuição dos laboratórios estudados que possuem regime de não internação, segundo período de atendimento do setor de coleta de exames. Município de São Paulo, 2003 
Tabela 8 Distribuição dos laboratórios estudados que possuem regime de internação, segundo período de atendimento do setor de coleta de exames. Município de São Paulo, 2003

Tabela 9 Distribuição dos laboratórios estudados, segundo tipo de cliente. Município de São Paulo, 2003

Tabela 10 Distribuição dos laboratórios estudados, segundo tipo de análises clínicas. Município de São Paulo, 2003

Tabela 11 Distribuição dos laboratórios estudados, segundo 83 outros tipos de análises clínicas. Município de São Paulo, 2003

Tabela 12 Distribuição dos laboratórios estudados, segundo realização treinamento de pessoal de coleta de exames. Município de São Paulo, 2003

Tabela 13 Distribuição dos laboratórios estudados, segundo a carga horária de treinamento de pessoal de coleta de exames. Município de São Paulo, 2003

Tabela 14 Distribuição dos laboratórios estudados, segundo profissional responsável pelo treinamento de pessoal de coleta de exames. Município de São Paulo, 2003

Tabela 15 Distribuição dos laboratórios estudados, segundo realização de coleta de exames domiciliares. Município de São Paulo, 2003

Tabela 16 Distribuição dos laboratórios estudados, segundo profissional responsável pela coleta de exames domiciliares. Município de São Paulo, 2003

Tabela 17 Distribuição dos laboratórios estudados, segundo categoria profissional existente no setor de coleta de exames. Município de São Paulo, 2003

Tabela 18 Distribuição dos laboratórios estudados, segundo realização de atividades do enfermeiro no setor de coleta de exames. Município de São Paulo, 2003 
Tabela 19 Distribuição dos laboratórios estudados, segundo realização de atividades do técnico de enfermagem no setor de coleta de exames. Município de São Paulo, 2003

Tabela 20 Distribuição dos laboratórios estudados, segundo realização de atividades do auxiliar de enfermagem no setor de coleta de exames. Município de São Paulo, 2003

Tabela 21 Distribuição dos laboratórios estudados, segundo realização de atividades de outros trabalhadores sem qualificação técnica formal e regular no setor de coleta de exames. Município de São Paulo, 2003

Tabela 22 Distribuição dos laboratórios estudados, segundo realização de atividades de outros trabalhadores com nível superior no setor de coleta de exames. Município de São Paulo, 2003

Tabela 23 Distribuição dos laboratórios estudados, segundo 101 existência de divisão de atividades assistenciais e gerenciais entre os trabalhadores de enfermagem no setor de coleta de exames. Município de São Paulo, 2003

Tabela 24 Distribuição dos laboratórios estudados com profissionais de enfermagem, segundo divisão de atividades assistenciais e gerenciais entre estes no setor de coleta de exames. Município de São Paulo, 2003

Tabela 25 Distribuição dos laboratórios estudados, segundo 103 inserção da equipe de enfermagem na estrutura organizacional. Município de São Paulo, 2003

Tabela 26 Distribuição dos laboratórios estudados com 104 resposta, segundo a qualificação profissional necessária para atuar no setor de coleta de exames. Município de São Paulo, 2003 


\section{INTRODUÇÃO}

\section{Temática do estudo}

A enfermagem moderna teve sua origem no século $\mathrm{XIX}$, na Inglaterra, decorrente da necessidade de higienizar e disciplinar o espaço hospitalar para transformá-lo de fato em local de cura. Assim, participa do processo de nascimento da clínica com a transformação do hospital, e torna-se um instrumento de cura, cujo objetivo era facilitar a recuperação do corpo doente. Este objetivo veio desenvolvendo-se ao longo dos anos e, hoje, a função peculiar da enfermagem é prestar assistência ao indivíduo sadio ou doente, família e comunidade, no desempenho de atividades para promover, manter ou recuperar a saúde (Almeida, Rocha, 1997).

Pautada neste conceito mais amplo, a enfermagem foi instrumentalizando-se e desenvolvendo-se como área de conhecimento e trabalho, conquistando novos espaços de atuação e mesmo alcançando a categoria de especialidade em alguns campos.

A coleta de exames laboratoriais, seja no paciente em regime de internação nos laboratórios de análises clínicas hospitalares, seja em situação ambulatorial nos laboratórios independentes, é uma atividade que a 
enfermagem desenvolve e que contribui para a promoção, manutenção e recuperação da saúde.

Historicamente, os exames laboratoriais como métodos auxiliares de diagnósticos médicos surgiram a partir da metade do século XIX, em decorrência do progresso da medicina e das áreas de microbiologia, citologia e bioquímica. O trabalho desenvolvido em laboratório de análises clínicas vem passando por intensos aperfeiçoamentos e observa-se que, cada vez mais, são introduzidos métodos mais rápidos e precisos, por meio da automatização, para atender melhor à crescente demanda (Sannazzaro, 1993).

Os exames laboratoriais fornecem dados importantes sobre o estado do paciente/cliente e auxiliam na identificação do diagnóstico clínico, no monitoramento do tratamento e prognóstico. A enfermeira, como os demais membros da equipe de saúde utilizam os resultados dos exames para a tomada da conduta clínica que melhor favoreça $\mathrm{o}$ atendimento às necessidades de saúde do paciente/cliente. Esta é mais uma das razões que fazem com que todas as fases do processo de análise clínica sejam realizadas com responsabilidade e competência técnico-científica.

A sofisticação tecnológica laboratorial exige profissionais especializados nessa área, tanto na análise propriamente dita, como na obtenção da matéria-prima do laboratório: a amostra biológica. A coleta do material biológico pode ser considerada como uma das fases mais importantes do processo de análise clínica, uma vez que se não for bem realizada comprometerá o processo de análise como um todo. Mesmo que o 
equipamento para a análise seja de última geração, não conseguirá minimizar os interferentes ocasionados por uma coleta não adequada ao tipo de exame solicitado (Moura, 1998).

A obtenção de uma amostra biológica de boa qualidade exige do profissional um conhecimento específico sobre os tipos de análise e as diferentes etapas que compõem o processo de análises clínicas, tais como: orientação e preparo para o exame, hora e seleção anatômica do local de coleta, técnica de coleta, materiais e condições para acondicionar e transportar a amostra até o laboratório, bem como a adequação do tempo de demora entre a coleta e a análise propriamente dita.

Além disso, alguns dados relacionados ao paciente/cliente são importantes para um resultado seguro, sendo o melhor momento para a obtenção da maioria das informações aquele em que se obtém o material biológico (Fischbach, 1996). Portanto, a comunicação com o usuário é um importante instrumento de trabalho também no setor de coleta de exames.

Em laboratórios de análises clínicas e mais precisamente na coleta dos exames, a atuação da enfermagem está assegurada pelo Centro de Vigilância Sanitária (CVS) na Portaria do $n^{\circ}$ CVS-01, de 18 de janeiro de 2000, que trata das condições de funcionamento dos laboratórios de análises clínicas, patologia clínica e congêneres. Esta portaria habilita os seguintes profissionais de enfermagem para atuar em setor de coleta: o enfermeiro, o técnico de enfermagem e o auxiliar de enfermagem. A mesma portaria no subitem VI. 3.2, trata que o enfermeiro, também, pode assumir a 
responsabilidade pela coordenação dos programas de coleta domiciliar de material humano (São Paulo, 2000).

A seguir para maior clareza, apresentamos um fragmento da referida portaria:

IV.7.2 - Nos termos da legislação em vigor, nos estabelecimentos de que trata o presente Título, os procedimentos de coleta de material humano poderão ser executados pelos seguintes profissionais legalmente habilitados:

IV.7.2.1- De nível superior:

1. Médicos, enfermeiros;

2. Farmacêuticos, biomédicos, biólogos e químicos, que no curso de graduação e/ou em caráter extracurricular, freqüentaram disciplinas que confiram capacitação para a execução das atividades de coleta.

IV.7.2.2. - De nível técnico: técnicos de enfermagem, assim como técnicos de laboratório, técnicos em patologia clínica e profissionais legalmente habilitados que concluíram curso em nível de ensino de $2^{\circ}$ grau, que, no curso de graduação e/ou em caráter extracurricular, freqüentaram disciplinas que confiram capacitação para a execução das atividades de coleta.

IV.7.2.2.1. Os profissionais de que trata o subitem anterior, poderão executar todas as atividades técnicas relacionadas às etapas de tratamento pré-analítico, mediante prévio treinamento.

É indispensável prévio treinamento para os técnicos de laboratório e técnicos em patologia clínica.

IV.7.2.3 - De nível intermediário (médio): auxiliares de enfermagem, assim como profissionais 
legalmente habilitados que concluíram curso em nível de ensino de $1^{\circ}$ grau, que, no curso de graduação e/ou em caráter extracurricular, freqüentaram disciplinas que confiram capacitação para a execução das atividades de coleta.

IV.7.2.3.1- Os profissionais de que trata o subitem anterior, poderão executar todas as atividades auxiliares relacionadas às etapas de tratamento préanalítico, mediante prévio treinamento.

IV.7.3 - Durante o período de transição, poderão continuar executando as atividades de coleta, mediante supervisão de profissional de nível superior, os funcionários que o vem fazendo há mais de 01 (um) ano e que foram submetidos a treinamentos específicos voltados para a execução de tais atividades, sendo que, nestes casos, os Responsáveis Técnicos pelos estabelecimentos de que trata o presente Título deverão:

IV.7.3.1 - Apresentar, às autoridades sanitárias competentes, os comprovantes de conclusão de curso de qualificação profissional destes funcionários, em nível de ensino de $1^{\circ} \mathrm{grau}$, em conformidade com o prazo estabelecido por esta Norma.

IV.7.3.2 - Os cursos de qualificação profissional a que se refere o sub-item anterior, deverão se enquadrar no disposto no sub-item IV.7.2.3 desta Norma (São Paulo, 2000, p. 22).

Além disso, o Conselho Federal de Enfermagem (COFEN), pela Resolução COFEN -195 de 18 de fevereiro de 1997, confere ao enfermeiro atuante no setor de saúde pública a autonomia para a solicitação dos 
exames de rotina e complementares, previstos pelos programas do Ministério da Saúde (COFEN, 1997).

Da mesma forma, a Resolução COFEN -146, de 1 de junho de 1992 preconiza a presença/responsabilidade de um enfermeiro nos locais onde existem ações de enfermagem sendo executadas (COFEN,1992).

Destaca-se que esta resolução aplica-se aos laboratórios de análises clínicas em que haja auxiliares e/ou técnicos de enfermagem realizando ações de enfermagem, como: punção venosa, sondagens, coleta de secreções de feridas e drenos, em geral; curativos em feridas após a realização da coleta, manipulação de cateteres centrais e periféricos, orientações sobre o preparo e coleta dos exames, administração de medicação, auxílio a outros profissionais em procedimentos mais complexos, entre outras atividades.

O profissional enfermeiro, paulatinamente, está inserindo-se nessa área de atuação e, em decorrência de sua formação, contribui para a garantia da qualidade da assistência prestada, bem como se responsabiliza pelo gerenciamento dos recursos humanos e materiais do laboratório, propiciando a promoção de uma interação multidisciplinar. Assim, encontrase em condições de desenvolver as ações relativas à coleta de material biológico.

A atuação da enfermagem em laboratório de análises clínicas já constitui alvo da elaboração de cursos voltados ao nível médio abordando, também, os aspectos envolvidos na coleta dos exames e em cursos de 
análises clínicas em que o enfermeiro tem um espaço aberto de participação e de ampliação dos conhecimentos específicos na área.

Uma vez regulamentada a atuação neste campo, cabe à enfermagem aperfeiçoar-se tanto técnica como cientificamente, incluindo o desenvolvimento de pesquisas relacionadas ao tema, a fim do profissional tornar-se qualificado e necessário no mercado.

A portaria citada habilita outros profissionais para executarem a coleta dos exames de diferentes subáreas da saúde.

\section{JUSTIFICATIVA DO ESTUDO}

Os distintos processos de trabalho que ocorrem no laboratório de análises clínicas despertaram-me interesse para conhecer as características do setor de coleta: suas especificidades, quem são os trabalhadores atuantes nesse setor, que funções desempenham, qual seu preparo acadêmico, a qual profissional respondem e como estão inseridos dentro da instituição de saúde, destacando-se o pessoal de enfermagem onde ele existir.

Desse modo, conhecendo-se os trabalhadores nesse campo, esperase poder caracterizar a atuação da enfermagem em laboratórios de análises clínicas.

Os resultados produzidos com base nesta investigação inserem-se na produção da linha de pesquisa "Gerenciamento de Recursos Humanos em 
Saúde e em Enfermagem“, contribuindo com o conhecimento a respeito da gerência e, particularmente, dos processos de trabalho em enfermagem.

Nesta pesquisa, parte-se do pressuposto que a coleta de exames laboratoriais contempla a execução de ações de enfermagem e que na literatura há uma escassa produção teórica sobre o processo de trabalho da enfermagem nesse campo.

O estudo do processo de trabalho tem por base os pressupostos do materialismo histórico-dialético, porém, recortado em um plano mais microscópico, centrado no exercício cotidiano do trabalho, investiga os objetos de intervenção, os saberes fundantes da ação, os agentes que as executam e a finalidade ou racionalidade que preside estes pressupostos, em sua sempre peculiar configuração, a depender do objeto de estudo (Almeida, Mishima, Peduzzi, 2000). 


\section{REVISÃO DA LITERATURA}

A intenção inicial do levantamento bibliográfico foi identificar o que existe na literatura brasileira sobre a atuação da enfermagem relacionada aos exames laboratoriais, por isso o período temporal da consulta não foi limitado e os bancos de dados inicialmente consultados foram restritos à língua portuguesa.

Na primeira fase do levantamento dos dados, foram selecionados os unitermos "laboratório"; "exames laboratoriais"; "laboratório enfermagem" e foi feita uma consulta on-line no Banco de Dados de Enfermagem (BDENF) dentro da BIREME/OPAS/OMS - Biblioteca Virtual em Saúde. Outros bancos de dados foram consultados e outros unitermos selecionados, ampliando a busca no sentido de localizar o profissional da enfermagem inserido no contexto de trabalho dos laboratórios de análises clínicas.

Os unitermos selecionados foram: "laboratório clínico"; "patologia clínica"; "medicina laboratorial"; "trabalho laboratório clínico"; "enfermagem laboratório clínico"; "profissionais laboratório clínico"; "exames"; "coleta de exames"; "coleta de amostras biológicas"; "enfermagem laboratorial"; "laboratoristas"; "atividades enfermeiro".

Os bancos de dados consultados foram o DEDALUS, LILACS, AdSaúde, SciELO. 
Poucos trabalhos foram encontrados, por isso no SciELO foram consultados unitermos também em inglês e foi incluído o Banco PubMed na busca. Ambos com as seguintes palavras-chave: "clinic pathology"; "clinic analysis"; "laboratory clinic nursing"; "collect biologic sampling nursing"; "collect biologic specimens"; " workers clinic laboratory"; "laboratories analysis"; "nursing laboratory functions"; "professionals clinic laboratory".

Na literatura nacional e internacional, os trabalhos identificados foram classificados pela temática predominante, conforme segue:

\section{- TRABALHO/ATIVIDADES DA ENFERMAGEM}

O unitermo "atividades de enfermagem" foi selecionado para identificar as ações relativas aos exames laboratoriais que são descritas dentro das várias atividades que a enfermagem desenvolve em seu dia-a-dia.

Nos bancos de dados consultados, o único trabalho reconhecido foi o de Kurcgant et al. (1993), que parte dos relatos dos enfermeiros de unidades de internação sobre as atividades que desenvolvem no cotidiano. Nesses relatos, não existem informações relativas às coletas de exames de laboratório. Assim, entende-se que essa atividade não é percebida pelo enfermeiro como parte de suas práticas no ambiente de trabalho (Kurcgant et al., 1993), talvez, porque essa função, em alguns serviços, é desempenhada pela equipe do próprio laboratório, ou porque não é considerada de grande importância frente às demais ações desenvolvidas no dinâmico trabalho da enfermagem nas unidades de internação. 
- CONHECIMENTOS / ATIVIDADES RELACIONADAS À COLETA DOS EXAMES

A enfermagem aparece relacionada à execução do procedimento técnico, tanto na literatura nacional como na internacional. Mesmo os trabalhos escritos por enfermeiros que evidenciam as atividades de enfermagem na coleta de exames, referem-se aos aspectos técnicos do exame, a seus interferentes, à técnica de coleta propriamente dita, à indicação do exame, aos cuidados antes e depois da coleta, ao significado clínico do exame e sua importância à enfermagem. Destaca-se que tais trabalhos foram escritos sob a forma de manuais (Souza, 1978; Heckler, et al., 1985; Treseler, 1995; Malarkey, McMorrow, 1996; Barbosa, Barbosa, Valera, 2000).

Outros estudos citam que as amostras coletadas pela enfermagem apresentaram uma boa qualidade quando comparadas às obtidas pelo próprio paciente ou por outros profissionais da equipe de saúde (Oliveira, Vinha,1982; Oliveira,Vinha, Van Grieken, 1983; Kottke, Trapp, 1998).

Algumas pesquisas relacionadas ao ensino/treinamento do enfermeiro e da equipe de enfermagem para a coleta dos exames foram encontradas como as de Silvieri, Paula (1968), Ricardi et al. (1990), e ainda, um estudo a respeito do que o paciente internado sabe sobre seus exames e quem the forneceu as orientações dentro da equipe de saúde (Santos, 1973). Neste último estudo, quem mais ofereceu informações ao paciente foi o médico, e, dentro da equipe de enfermagem, o profissional que mais orientou $\mathrm{o}$ paciente, foi o auxiliar de enfermagem. 


\section{LABORATÓRIO GERAL}

Dentro dos trabalhos voltados ao laboratório como um todo, estão os aspectos ligados aos trabalhadores do laboratório, sua saúde, biossegurança, sistemas de qualidade. Estas pesquisas nem sempre abordam o setor de coleta especificamente e, quando o fazem, aparecem os termos "trabalhadores", "profissionais" ou "pessoal da coleta", sem uma referência exata sobre a categoria profissional a que estão se referindo, bem como não são precisos quanto à discriminação das funções nos distintos níveis técnicos dos "coletores". Nestes trabalhos, a enfermagem não é citada (Martins et al., 1997).

Hirata, Monteiro, Magliari (2002) mencionam o técnico de laboratório como o trabalhador que, geralmente, faz a coleta, bem como processa, guarda e transporta a amostra.

A atuação no laboratório clínico representa um campo relativamente novo aos profissionais da enfermagem verificou-se que existe pouca literatura a respeito do tema e as que foram encontradas datam de anos atrás. Assim, a mais antiga foi escrita em 1968 (Silvieri, Paula, 1968), o que demonstra que a preocupação pelo assunto é antiga. Observa-se que os primeiros passos para a produção científica nesse campo da atuação foram iniciados pela academia.

$\mathrm{Na}$ literatura consultada, a enfermagem, sobretudo, a enfermeira, aparece vinculada especificamente à execução das técnicas de coleta das amostras biológicas para a realização dos exames laboratoriais, no entanto, 
os depoimentos dos profissionais não fazem referência a esse vínculo, conforme citado anteriormente (Martins et al., 1997).

Considerando nossa experiência de trabalho no setor de coleta de exames, além da técnica propriamente dita, existem outras atividades desenvolvidas pela enfermagem neste campo, como a assistência ao paciente mais debilitado em nível ambulatorial, a participação no teste de novos materiais para a coleta dos exames, orientações a outros profissionais.

Além dessas funções, cabe ao enfermeiro a administração dos recursos materiais e humanos da coleta dos laboratórios, o treinamento e a educação em serviço dos membros da equipe de enfermagem e de outros profissionais no setor de coleta, a promoção de intercâmbio e de auxílio entre o laboratório e as unidades de internação, a manutenção do diálogo entre os setores de análises e a enfermagem visando o benefício do paciente/cliente.

Nesta área, atuação necessita de um conhecimento técnico-científico especializado, assim, assinalamos alguns aspectos que, possivelmente, estejam relacionados com a baixa produção teórica do tema:

1) o número reduzido de profissional enfermeiro atuando nos laboratórios de análises clínicas, visto que cabe a ele a realização de pesquisa, dentro da equipe de enfermagem; 2) o fato de ser um profissional que acarreta maiores custos para os laboratórios por receber melhor remuneração que o pessoal de nível médio; 3) ou, ainda, por tratar-se de 
uma ação de suporte à assistência propriamente dita, o que atrai pouco os enfermeiros, de modo geral.

No entanto, trata-se de um trabalho que permite ao enfermeiro a ampliação da visão a respeito do paciente/cliente e a análise dos resultados dos exames sobre o quadro clínico, facilitando a tomada de conduta, especialmente, se as alterações nos valores laboratoriais apontarem sinais de risco à vida do paciente/cliente.

Em razão disso, surgiu a necessidade de maior compreensão das habilidades e competências do profissional para atuação em setor de coleta de exames biológicos e optou-se por realizar uma análise documental (Anexo I) sobre os Referenciais Curriculares Nacionais para a Educação Profissional de Nível Técnico da Área de Saúde, nas quais são observadas semelhanças, especificidades e interfaces das subáreas de Biodiagnóstico e de Enfermagem, já iniciadas na formação profissional (Ministério da Educação e Cultura, 2000).

O cenário da subárea de Biodiagnóstico possui um quadro de recursos humanos composto por trabalhadores pertencentes ao nível médio e fundamental, também chamado de intermediário, na Portaria $n^{\circ}$ CVS-01, de 18 de janeiro de 2000 , sem formação especifica a respeito da subárea, pois são treinados em serviço pelos responsáveis técnicos do setor onde atuam ou vão atuar (São Paulo, 2000).

Semelhante ao que ocorre com a subárea de Biodiagnóstico relacionada ao contingente de pessoal sem formação específica, existem, 
também, na Enfermagem trabalhadores sem qualificação técnica formal e regular, usualmente, denominados atendentes de enfermagem.

Segundo dados obtidos por Noca (1999), no COFEN e Associação Brasileira de Enfermagem (ABEn), em 1985, havia 41\% dos atendentes que não concluíram o ensino fundamental; mais de $80 \%$ que não chegaram a concluir o ensino médio; $22,3 \%$ que não tiveram qualquer treinamento específico e $10 \%$ que atuavam sem capacitação em serviço na área de enfermagem e sem o ensino fundamental.

Aguiar (2001) obteve dados da Secretaria Municipal de Saúde de São Paulo, datados de 1989, citando um número de 4.000 atendentes de enfermagem existentes nos serviços de saúde, e 46\% não possuíam ensino fundamental completo. A autora cita que o COFEN contabilizou, em 1998, um total de 134.590 atendentes de enfermagem, equivalendo a $23,6 \%$ do pessoal de enfermagem.

Entretanto, nota-se uma melhora na escolarização e na profissionalização da força de trabalho de saúde e de enfermagem, visto que, em 1983, a categoria atendentes representava cerca de $63,8 \%$ do total dos trabalhadores de enfermagem (COFEN, 1985), e, em 1998, havia sido reduzida para 35\% desse total (Ministério da Saúde, 1999).

Desse modo, persiste a existência de um contingente de trabalhadores de enfermagem sem qualificação técnica formal e regular atuando em serviços de saúde. Mas vale destacar que a enfermagem brasileira e o próprio Ministério da Saúde vêm buscando superar essa situação e garantir a qualificação profissional a todos os trabalhadores de enfermagem no País, 
desde 2000, especialmente, por intermédio do Projeto de Profissionalização dos Trabalhadores da Área de enfermagem (PROFAE) (Castro, 2002).

Nesse sentido, cabe lembrar que a Portaria $n^{\circ}$ CVS-01, de 18 de janeiro de 2000 faz menção a trabalhadores, que já estejam executando as atividades de coleta, há mais de um ano sob supervisão e treinamento específico. Assim, no setor de coleta de exames, há agentes sem qualificação técnica específica para o desenvolvimento desse trabalho (São Paulo, 2002).

Convém salientar que, além da educação profissional própria, o treinamento em serviço é essencial ao bom desempenho de todos os profissionais. Na Enfermagem, embora o técnico de enfermagem desenvolva a subfunção coleta de amostras biológicas, os aspectos específicos do setor são aprendidos no dia-a-dia, contribuindo, para seu aperfeiçoamento profissional.

O técnico de laboratório e de patologia clínica têm como objeto de trabalho a obtenção e processamento de amostras biológicas de forma que sua ênfase está na precisão do processamento das mesmas, chegando a uma eficácia técnica.

Por sua vez, o técnico de enfermagem tem seu objeto de trabalho centrado no cuidado de enfermagem, com ênfase na execução de técnicas permeadas pela interação, o que permite o reconhecimento das múltiplas dimensões das necessidades de saúde do paciente/cliente, chegando à eficácia do cuidado. 
Quanto às delimitações e interfaces destas subáreas, evidenciam-se disciplinas básicas em comum advindas das ciências naturais, como a biologia, microbiologia, parasitologia, química, física e matemática, além das presentes nas ciências humanas: a psicologia, a sociologia e a filosofia.

Na subárea de biodiagnóstico, há a citologia, disciplina essencial à identificação celular na leitura de lâminas sob microscopia, técnica rotineira no laboratório de análises clínicas; já na subárea de enfermagem, as disciplinas anatomia, fisiologia humana e higiene estão presentes, pois são importantes ao bom desempenho da ação "cuidar".

Nestes Referenciais Curriculares, as subáreas em questão possuem subfunções, habilidades e competências comuns a todos os profissionais da saúde. Especificamente relacionado ao laboratório de análises clínicas, ambas subáreas exercem a subfunção de coleta de amostras biológicas/ preparação e acompanhamento de exames diagnósticos que habilitam os técnicos de enfermagem, de laboratório e de patologia clínica para atuarem no setor de coleta dos exames laboratoriais.

Esta preparação diferencia o trabalho comum do especializado, caracterizando nova divisão social do trabalho.

Vale a pena ressaltar que atividades originariamente realizadas pela enfermagem, como punção venosa para coleta de sangue, coleta de outras amostras biológicas, administração de medicação para realização de provas funcionais, entre outras, vão sendo apropriadas por outros profissionais na dinâmica da divisão técnica e social do trabalho. Aspectos atinentes a esse processo serão analisados na pesquisa aqui proposta. 
A subárea Biodiagnóstico faz interface apenas com as subáreas de hemoterapia e enfermagem; a Enfermagem, por sua vez, interage com a quase totalidade das subáreas da Saúde, uma vez que seu processo de trabalho abrange o cuidar/cuidado em todos os seus aspectos, considerando as necessidades do ser humano, o conceito de saúde e os pressupostos do Sistema Único de Saúde (SUS) (Noca, 1999). 


\section{OBJETIVO GERAL}

Identificar os aspectos da atuação da enfermagem nos laboratórios de análises clínicas, que permitam caracterizar seu processo de trabalho nesse setor.

\section{OBJETIVOS ESPECÍFICOS}

- Identificar os trabalhadores da saúde que atuam na coleta de exames dos laboratórios de análises clínicas;

- Reconhecer as atividades desempenhadas pelos diferentes agentes da equipe de enfermagem nesse setor;

- Conhecer a inserção da enfermagem na estrutura organizacional. 


\section{REFERENCIAL TEÓRICO}

\section{TRABALHO EM SAÚDE E EM ENFERMAGEM}

Nesta pesquisa, o referencial teórico adotado advém dos estudos do processo de trabalho em saúde e em enfermagem, destacando-se a categoria divisão do trabalho e dos estudos sobre recursos humanos em saúde.

O plano de investigação foi recortado na dimensão mais microscópica do trabalho relacionada aos aspectos do exercício cotidiano do trabalho, ou seja, seus elementos constituintes (os objetos de intervenção, os saberes fundantes da ação dos agentes que as executam e a finalidade dos processos), destacando-se a esfera da ação humana e da prática concreta.

Para Liedke (1997a), o conceito de processo de trabalho foi desenvolvido por Marx em sua obra intitulada O Capital, em que define o trabalho como um processo, no qual os seres humanos atuam sobre as forças da natureza, submetendo-as a seu controle e transformando os recursos naturais em bens e serviços úteis à vida humana, social e individual. Ao modificar a natureza, o trabalhador aciona suas energias físico-musculares e mentais (Liedke, 1997a, 1997b). 
O trabalho constitui, então, de uma mediação entre o homem e a natureza, operando transformações requeridas por necessidades humanas (Peduzzi, 1998).

Conseqüentemente, o trabalhador transforma também a si mesmo, pois deposita no material manuseado um projeto idealizado previamente que o homem traz em mente, desde o início do processo, atribuindo um significado a seu próprio trabalho (Liedke, 1997a; Peduzzi, 2001a). Trata-se da implementação de um projeto concebido previamente e que traduz a intencionalidade do trabalho (Peduzzi, Anselmi, 2002).

Inicialmente, o trabalho caracteriza-se pela intencionalidade e pelo cumprimento de uma dada finalidade, presentes em todos os elementos constituintes do processo. Esta característica pode facilmente ser identificada pela capacidade humana de separar o momento de concepção e de execução do trabalho, possibilitando a construção e armazenamento dos instrumentos de trabalho em separado do momento da utilização dos mesmos (Peduzzi, 2001b).

O trabalho é uma ação racional teleológica, visto que se dirige a um fim, abarcando a ação instrumental, que é orientada por regras técnicas apoiada no saber, e a ação estratégica, que também visa uma relação de utilidade para determinados fins, orientada por máximas e valores. 0 trabalho como ação instrumental e/ou ação estratégica busca êxito ou sucesso na obtenção de determinado resultado (Peduzzi, 1998; Peduzzi, 2001b; Peduzzi, Anselmi, 2002). 
Outra característica do trabalho pode ser verificada na relação intrínseca entre o próprio trabalho (produção) e as carências humanas/sociais (consumo). Os processos de trabalho e as necessidades compõem estruturas recíprocas relacionadas e presentes no conjunto da vida social, de modo que o primeiro consiste em um processo sistemático reiterado de atendimento das necessidades (Peduzzi, 1998).

Esta última característica do processo de trabalho, também, é apontada por Liedke (1997a), ao referir que se trata de uma atividade que visa à produção de valores de uso para a satisfação das necessidades humanas, assim, possui um caráter qualitativo, relacionado à obtenção do resultado frente ao carecimento que the deu origem.

No entanto, sob a perspectiva do capitalismo e da reprodução do capital, o produto e o processo de produção conferem ao trabalho um significado quantitativo, pressupondo determinadas condições sociais nas quais o trabalho é realizado (Liedke, 1997a).

Ainda Liedke (1997a, p.182) ao retomar Marx, destaca que:

O processo de trabalho capitalista é, essencialmente, processo de produção da mais valia e não de produção simples de mercadorias; produz e reproduz a relação capitalista, que é aquela entre classes sociais: de um lado, o capitalista, e de outro, o assalariado.

O salário é definido como o preço do trabalho, determinado pelo mercado e dependente da relação entre oferta e procura. Desta forma, quando o indivíduo vende a sua força de trabalho para o capitalismo, o 
processo de trabalho volta-se, não mais para a produção de utilidades, de valores de uso, mas, para o valor de troca, como processo capitalista de produção de mercadorias, baseado na valorização do valor, ou seja, da mais valia (Liedke, 1997a).

Liedke (1997b) citando Marx faz uma distinção entre as noções de trabalho, força de trabalho e trabalhador que consiste no fato de que, no mercado de trabalho, o capitalista compra a força de trabalho, a capacidade de trabalho, não o trabalho realizado. Na sociedade capitalista, a força de trabalho torna-se uma mercadoria, mas, o trabalhador, não. A quantidade de trabalho depende de como o processo produtivo está organizado, a fim de promover a cooperação do trabalhador e desestimular atitudes de resistência ao trabalho (Liedke, 1997b).

$\mathrm{Na}$ área da saúde, as pesquisas sobre trabalho iniciaram-se, nos anos 60 do século XX, na América Latina com Juan César Garcia, e, no Brasil, nos anos 70 do século XX, com Maria Cecília Donnangelo e Sérgio Arouca. Além destes, estudiosos como Ricardo Bruno Mendes Gonçalves, Lilia Schraiber, Emerson Elias Merhy, Gastão Wagner Souza Campos e outros, produziram uma interlocução com os conceitos marxistas (marxiano), buscando uma melhor compreensão das dimensões e elementos do processo de trabalho em saúde, considerando a historicidade das práticas.

Estes autores têm contribuído para a análise da organização tecnológica do trabalho em saúde, embora apresentem peculiaridades em seus estudos. 
Na enfermagem, a introdução da abordagem teórico-metodológica iniciou-se nos anos 80 do século XX, com os estudos de Maria Cecília Puntel de Almeida sobre o saber da enfermagem, que a considerou na formação social capitalista, destacando sua gênese e evolução histórica na sociedade brasileira. Vale assinalar que outros autores também vêm dedicando-se à investigação nesta vertente (Almeida, Mishima, Peduzzi, 2000; Peduzzi, 2001a, 2001b; Peduzzi, 1998).

Estas abordagens permitem a análise e compreensão do foco de atenção/cuidado, que é o objeto de trabalho das práticas de saúde, em sua dimensão individual e coletiva, bem como dos instrumentos utilizados para execução do cuidado, configurando-se este último como o resultado ou produto da ação que, por sua vez, é imediatamente incorporada pelo cliente que recebe esse cuidado.

Tais abordagens permitem a compreensão das relações que se estabelecem no desenvolvimento do processo de trabalho e da articulação deste com os processos políticos, sociais, culturais e econômicos. Estas dimensões fazem parte do processo de trabalho e guardam uma relação recíproca entre si (Almeida, Mishima, Peduzzi, 2000). 
Elementos constituintes do processo de trabalho

O processo de trabalho tem como elementos constituintes a atividade adequada a um fim, que é o trabalho propriamente dito; o objeto de trabalho é a matéria a ser transformada, que pode estar em seu estado bruto ou ser resultante de um trabalho prévio, como as matérias-prima. Os meios de trabalho são os instrumentos utilizados pelo trabalhador. As condições sociais e o período histórico em que o trabalho está sendo desenvolvido são distinguidos pelos instrumentais disponíveis. (Almeida, Rocha, 1997; Liedke, 1997a; Peduzzi, 1998).

Quanto aos elementos do processo de trabalho em saúde, Peduzzi e Anselmi (2002) relatam que os agentes constituem um dos elementos desse processo e, por isso, devem ser analisados no interior das relações recíprocas entre o objeto de trabalho, instrumentos e atividades, bem como no interior do processo da divisão do trabalho (Peduzzi, 2001a, 2001b).

Por meio da ação do agente, é possível observar e expressar a existência concreta, mas, nem sempre evidente de uma dinâmica entre objetos, saberes, instrumentos materiais e atividades do processo de trabalho. Este agente não apenas é o instrumento de viabilização concreta desse processo, inserindo ferramentas entre ele próprio e o objeto com uma dada finalidade, e colocando-se como portador de um projeto específico, mas também é sujeito, conforme traz para dentro do trabalho, outros projetos de caracteres coletivos e pessoais (Peduzzi, 1998). 
Outro componente do processo de trabalho que deve ser destacado é o objeto do trabalho, configurado como o aspecto específico recortado da realidade sobre o qual incide a atividade do trabalho. Assim sendo, não existe como objeto de intervenção em si mesmo, apenas como expressão de um 'olhar' que contém um projeto em mente e procede a um certo recorte das necessidades sociais que dão origem àquele peculiar trabalho.

Peduzzi (1998); Almeida, Rocha, (1986), destacam, também, que o objeto de trabalho demanda instrumentos adequados a ele e estes instrumentos só podem ser aplicados aos objetos que the correspondam, determinando uma relação de reciprocidade entre ambos. Assim, os instrumentos possibilitam uma aproximação e transformação do objeto, bem como as características do objeto e a finalidade do trabalho determinam as características de seus meios (Almeida, Rocha, 1986; Peduzzi, 1998).

Os instrumentos de trabalho podem ser simples, como a utilização da força animal, mecânica, elétrica, hidráulica, bem como mais complexos, como semicondutores e outras tecnologias existentes. O conhecimento científico é percebido como constitutivo dos meios de produção que, por sua vez, determinam o potencial de desenvolvimento atingido pelo processo de trabalho em uma determinada época histórica (Liedke, 1997a).

Peduzzi, Anselmi (2002) quando se referem aos instrumentos de trabalho abordam que estes são construídos historicamente pelo sujeito que, assim, amplia sua possibilidade de intervenção sobre o objeto. No trabalho em enfermagem e em saúde, encontramos instrumentos materiais e 
intelectuais, tais como, os saberes técnicos que informam e fundamentam imediatamente a ação realizada (Peduzzi, 2001a; Peduzzi, Anselmi, 2002).

O trabalho pode ser caracterizado como um processo de transformação que ocorre porque o homem tem necessidades que devem ser satisfeitas. Na saúde, sua finalidade é atender às carências de saúde. Nessa perspectiva, entende-se que, no campo da enfermagem, os objetos de trabalho são o cuidado de enfermagem e seu gerenciamento. Cuidado este, concebido como um conjunto de ações de acompanhamento contínuo do usuário/população, no transcorrer das doenças ou ao longo de processos sociovitais (saúde da criança, do adolescente, da mulher, do idoso, entre outros), visando a promoção, prevenção e recuperação da saúde (Peduzzi, Anselmi, 2002).

Divisão do trabalho

Nos estudos do trabalho, outro aspecto importante é sua divisão técnica e social que advém de um processo historicamente construído.

Em meados do séc XVI e o último terço do séc XVIII, o modo de produção capitalista dá início à manufatura. Antes desta, a característica central do trabalho artesanal é o domínio do artesão sobre todo o processo de trabalho, desde a concepção do produto ao conhecimento de todas as etapas necessárias à sua execução (Peduzzi, 1998).

A autora citada refere que a manufatura: 
origina-se a partir do artesanato, de duas maneiras: a) surge da combinação de ofícios diversos e independentes, por cujas mãos tem de passar um produto até o acabamento final, com o que os antigos artesãos perdem sua independência no trabalho e passam a constituir apenas operações parciais do processo de produção de uma única mercadoria; b) surge da decomposição de um ofício em suas diferentes operações particulares, isolandoas e individualizando-as para tornar, cada uma delas, função exclusiva de um trabalhador parcial. Ora introduz a divisão do trabalho num processo de produção ou a aperfeiçoa, ora combina ofícios anteriores distintos (Peduzzi, 1998, p.26).

Assim a manufatura contribui para a específica modalidade da divisão técnica do trabalho, é a separação do trabalhador de seus instrumentos de trabalho, bem como a cisão das dimensões intelectuais e manuais do trabalho. Esta separação permite a distinção entre os diversos graus de complexidade dos trabalhos parciais ou especializados que requerem diferentes graus de formação do trabalhador (Peduzzi, 1998).

Introduz-se, portanto, a divisão técnica do trabalho, representada pelo parcelamento dos processos, que determinam as várias etapas de produção de um dado produto, executadas por distintos trabalhadores. Essa modalidade de divisão tem como característica central o fato do trabalhador parcial não produzir nenhum produto por completo isoladamente, sendo necessária a participação de vários trabalhadores especializados ou, em outros termos, resultado da atividade de um trabalhador coletivo (Peduzzi, 1998). 
De acordo com Peduzzi (2001b), essa divisão técnica do trabalho introduz o fracionamento de um processo de trabalho originário do qual derivam outros trabalhadores parcelares. Além disso, introduz, também, os aspectos de complementaridade e de interdependência entre os trabalhadores especializados atuantes em uma mesma área de produção.

Transportando-se para o campo da saúde, Peduzzi (1998) cita que a divisão do trabalho verifica-se de forma processual e complexa, pois cada trabalho individualiza-se pela necessidade histórica de sua peculiar atuação especializada, configurando saberes e ações que lhes são próprios e singulares. Reflete, assim, o desenvolvimento científico-tecnológico, bem como a própria dinâmica social das práticas de saúde que gera subdivisões sistemáticas dos trabalhos, assim como os parcelamentos das tarefas interiores a cada área de atuação, que vão sendo cada vez mais recortadas, tornando-se mais manuais e delegadas sucessivamente para meros agentes executores (Peduzzi, 1998).

Essa dinâmica amplia o número de trabalhadores parciais e especializados, que abrange desde o médico e demais profissionais universitários ao pessoal auxiliar de nível médio, tanto na enfermagem como na área de apoio diagnóstico e terapêutico, até os trabalhadores empíricos, sem formação formal e regular específica para o setor saúde, treinados em serviço. Nesse processo de divisão, não apenas a divisão técnica e pormenorizada de trabalhos é reproduzida, mas, a desigual valoração social desses trabalhos (Peduzzi, 1998). 
A valorização diferenciada dos trabalhos é sentida na saúde pela distinção e elitização do trabalho do profissional médico em relação aos demais profissionais de saúde, pois, ao médico, é atribuído o maior valor social, decorrente da hegemonia do modelo biomédico determinado historicamente. A hegemonia do trabalho médico pauta-se no fato de ter sido a medicina a responsável por introduzir os conhecimentos gerais sobre saúde e doença, fundamentada cientificamente, e por ter legitimado esse trabalho como competência exclusiva da área médica (Peduzzi, 1998).

Assim, o profissional médico apropria-se do momento mais intelectual do trabalho (diagnóstico e terapêutica), tornando-se o agente hegemônico do processo de produção em saúde, como já foi dito anteriormente. As outras práticas que se agregam, são igualmente necessárias, mas, a exemplo de como os homens reproduzem a estrutura de classe social do trabalho, a medicina garante o espaço do poder sobre o conjunto dos outros trabalhos (Almeida, Rocha, 1997).

No processo de divisão, uma das particularidades é a forma como vão se fragmentando as dimensões intelectual e manual dos processos de trabalho, embora, sempre seja preservado um certo caráter de reflexão, visto que 0 trabalho humano não se automatiza por completo em nenhuma situação de produção.

Portanto, a combinação entre intelectual e manual difere de um trabalho para o outro, com maior legitimidade social aos trabalhos mais intelectuais, visto que o poder é garantido pelo controle sobre esta dimensão, ou seja, da concepção do processo de trabalho (Peduzzi, 1998). 
Neste contexto, a enfermagem destaca-se como profissão, pois, também, sofreu a divisão social do trabalho, tanto externa, quando divide o espaço de atuação com o médico nos hospitais como internamente pelo parcelamento do cuidado e do aparecimento de distintas categorias de trabalhadores de enfermagem.

Historicamente, a enfermagem teve sua origem independente da medicina, pois suas atividades eram desvinculadas das ações, ordens e planos terapêuticos do médico. A partir do Cristianismo até o final do Feudalismo na Idade Média, o cuidado de enfermagem não era direcionado ao corpo doente ou à doença, mas, de cunho religioso. Assim sendo, a enfermagem e a medicina, cujas origens eram independentes, existiram por séculos sem muito contato, porque o objeto de trabalho da enfermagem era o ambiente, e do médico, o corpo doente. (Almeida, Rocha, 1986; Peduzzi, 1998).

A partir do final do séc XVIII e início do XIX, o hospital que, inicialmente, fora criado para isolar da sociedade as pessoas doentes e indigentes e para abrigar viajantes, sofre uma disciplinarização de seu espaço, permitindo sua medicalização e, posteriormente, sua transformação em espaço de cura que se derivou das mudanças do saber e da prática médica que encontraram no hospital seu espaço privilegiado de experiência, transformando-o em instrumento terapêutico.

O hospital moderno desenvolveu-se sob a necessidade do capitalismo curar seus feridos em guerras, visto que se tratava de soldados treinados no manuseio dos armamentos, cujas baixas acarretavam um alto custo. Assim, 
o hospital tornou-se o local onde acontecia a produção e a transmissão do saber, reprodução das relações de classe entre os trabalhadores da saúde, pois a organização da atenção médica implicou necessariamente nessa divisão (Melo, 1986).

Diante do processo de transformação do hospital, emerge a enfermagem moderna, constituindo uma hierarquia entre as ladies-nurses, que eram provenientes de famílias de classe alta da sociedade e que assumiam as funções de educação e supervisão, e as nurses, de nível socioeconômico inferior que se ocupavam do cuidado direto ao doente. Assim, instala-se, desde a origem da enfermagem profissional moderna, uma divisão do trabalho que se perpetua até os dias atuais (Almeida, Rocha, 1986; Melo, 1986; Silva, 1986).

No capitalismo, do final do século XVIII e início do XIX, o aumento da burguesia e sua instalação como classe social dominante, especialmente, na Inglaterra, influenciam a enfermagem no sentido de adotar o modelo vocacional de atuação.

Em meados do século XIX, ocorre a institucionalização da enfermagem sob o comando de Florence Nightingale. Surgem as primeiras escolas de enfermagem a fim de agregar conhecimento científico à enfermagem (Almeida, Rocha, 1986; Melo, 1986).

Almeida e Rocha (1986) analisam que as técnicas de enfermagem constituem a primeira forma organizada do saber na enfermagem e, posteriormente, esse saber traduz-se pela sistematização dos princípios 
científicos que as fundamentam e, recentemente, pela busca da construção de teorias.

A fundamentação científica está pautada nas ciências naturais, como anatomia, fisiologia, patologia, microbiologia, tratando-se de uma prática imbricada no saber médico e apóia-se nas ciências sociais, sociologia e psicologia, constituindo, assim, o cuidado como objeto de trabalho.

A enfermagem moderna surgiu como uma divisão do trabalho médico, pois as tarefas consideradas "manuais" passaram a ser desempenhadas pela enfermagem, revestidas, agora, por um aparato técnico, mas ainda sob a hegemonia médica (Melo, 1986).

Para Peduzzi (1998), na dinâmica de trabalho entre medicina e enfermagem, instala-se uma divisão de trabalho, na qual a ação de curar, por meio do diagnóstico e da terapêutica, cabe ao profissional médico garantindo-lhe a hegemonia e as ações de cuidado, ou seja, o acompanhamento do paciente no transcorrer do agravo à saúde é próprio dos agentes da enfermagem, estabelecendo-se a dualidade curadorcuidador.

No Brasil, as ações de cuidado de enfermagem são divididas entre múltiplos agentes - auxiliar de enfermagem, técnico de enfermagem, enfermeiro e trabalhadores de enfermagem sem qualificação técnica formal e regular. $\mathrm{O}$ enfermeiro assume as atividades mais intelectuais de ensino e gerenciamento do cuidado e/ou dos serviços, enquanto o pessoal de enfermagem de nível médio, cujo trabalho tem um caráter mais manual, 
responde pela maioria das atividades assistenciais (Almeida, Rocha, 1986; Melo 1986; Peduzzi, 1998; Peduzzi, Anselmi, 2002).

Segundo Melo (1986, p.54), no século XX, a divisão do trabalho na enfermagem desenvolveu-se com o avanço tecnológico que:

ao lado das políticas de saúde, sob o capitalismo, amplia a divisão social do trabalho e criam novas categorias encarregadas do cuidado direto ao doente. Entretanto, o enfermeiro com curso superior se apropria do trabalho de supervisão e controle, solidificando o seu papel de trabalhador intelectual da enfermagem...

Nesse mesmo sentido, Peduzzi (1998, p.36) destaca que:

No interior desse intenso processo de divisão do trabalho, observamos diferenças técnicas e desigualdades sociais. As primeiras dizem respeito as diferenciações $e$ especializações dos saberes e das intervenções técnicas, entre as variadas áreas profissionais. As segundas referemse à existência de valores e normas sociais hierarquizando e disciplinando as diferenças técnicas entre as profissões. Ou seja, correspondem distintas autoridades técnicas e legitimidades sociais, às diferentes áreas profissionais. Isso significa que algumas profissões são "superiores" às outras e que há relações hierárquicas ou relações de subordinação entre os profissionais. Portanto, as diferenças técnicas transmutam-se em desigualdades sociais entre os agentes do trabalho, e a equipe multiprofissional expressa tanto as diferenças como as desigualdades entre ás áreas. 


\section{RECURSOS HUMANOS EM SAÚDE}

Como foi assinalado, inicialmente, os estudos sobre recursos humanos em saúde também foram usados como referencial nesta pesquisa.

A vertente de investigações sobre recursos humanos em saúde iniciou-se nos anos de 1960 e 70, predominando as pesquisas sobre a formação universitária e oferta de pessoal de saúde, seguidas da introdução da abordagem histórico-estrutural das práticas de saúde. Este enfoque vai dar origem ao estudo da organização social das práticas e do trabalho em saúde, no interior do qual tem destaque o agente do trabalho, ou seja, os recursos humanos.

Nesta perspectiva, os recursos humanos são abordados como agentes, tal como referido acima ou como força de trabalho. Este conceito vai fundamentar os estudos sobre força de trabalho em saúde, na qual se destacam as pesquisas de autores como Roberto Passos Nogueira, André Médici, Elza Paim, Maria Helena Machado e Sábado Girardi, que permitem a análise do mercado de trabalho e da dinâmica do emprego em saúde e a identificação de tendências estruturais e conjunturais que determinam o espaço de manobra da formação e utilização do pessoal de saúde (Nogueira, 1992; Paim, 1994; Peduzzi, Schraiber, 2000).

Schraiber, Peduzzi (1993) apresentam um panorama das pesquisas em recursos humanos em saúde com base em um estudo bibliográfico que englobou as décadas de 1970 e 1980, e demonstram haver seis categorias para a classificação da produção teórica encontrada que são: profissionais de saúde, formação/capacitação de recursos humanos em saúde, 
administração de recursos humanos em saúde, mercado de trabalho em saúde, políticas de recursos humanos em saúde e agentes do trabalho em saúde.

Só nos anos de 1980, inicia-se a institucionalização das investigações sobre recursos humanos, com a consolidação da linha de pesquisa sobre a força de trabalho, num recorte metodológico quantitativo, embora a categoria de análise seja originária das ciências sociais, bem como dos estudos sobre processo de trabalho.

A temática recursos humanos vem merecendo destaque nas investigações no campo da saúde, desde diferentes perspectivas. Isto pode ser observado nas considerações apresentadas por Peduzzi, Schraiber (2000) ao citarem que nas questões relacionadas aos recursos humanos no cotidiano dos serviços de saúde, há aspectos relevantes que devem ser considerados, como a formação e a incorporação dos profissionais aos serviços, o planejamento em saúde, a gerência em saúde, a avaliação dos serviços, a organização do trabalho e o modelo de atenção à saúde, entre outros.

Além disso, de um lado, há os recursos humanos como fatores estratégicos para o sucesso dos resultados na prestação de serviços de saúde e, por outro lado, estes são diluídos entre uma infinidade de fatores, reiterando-lhes a visibilidade necessária para investimentos permanentes, tanto no exercício cotidiano do trabalho como na formação ou na investigação. 
Tratando-se do tema recursos humanos, convém ressaltar que, no final do século XIX, o acúmulo de capital pelos dos lucros das transações realizadas no mercado pelos proprietários das fábricas, comerciantes ou advindos dos aluguéis e/ou vendas pagos aos donos das terras pelos assalariados que dispunham apenas de sua força de trabalho, deu origem a três classes fundamentais na sociedade: os proprietários fundiários, empresários e os trabalhadores (Liedke, 1997b).

Assim, o conceito de força de trabalho remete à análise de aspectos gerais da divisão de trabalho, a aspectos específicos da dinâmica do emprego nas sociedades capitalistas, ao mercado de trabalho, relações de trabalho, trabalho formal e assalariado, entre outros, bem como introduz, sob o ponto de vista analítico, o conceito de força de trabalho específica de uma dada coletividade, pertencente a uma parte da população economicamente ativa (Nogueira, 1992, 2002).

Ao longo do século XX, houve a consolidação da produção em massa e em série pelas linhas de montagens que intensificam o parcelamento do trabalho e a fragmentação das funções, bem como a separação entre elaboração e execução do processo de trabalho, entre outras (Antunes, 1995; Cherchiglia, 1999).

A década de 1980, constituiu-se em um período de profundas transformações no mundo do trabalho nos países capitalistas, relacionadas às formas de inserção na estrutura produtiva e às formas de representação sindical e política. Foi um período de grande salto tecnológico, em que a automação, a robótica e a microeletrônica invadiram o universo fabril, 
inserindo-se e desenvolvendo-se nas relações de trabalho e produção de capital.

O novo modelo de organização do trabalho origina-se no quadro de recessão que se inicia na primeira metade dos anos 70 do século $\mathrm{XX}$, após três décadas de desenvolvimento e crescimento pós - Segunda Guerra Mundial (Peduzzi, 1998).

Estas transformações influenciaram diretamente a organização do trabalho, em especial, na indústria, mas também na produção em serviços, inclusive no setor saúde. Nesse sentido, Peduzzi (1998) e Antunes (1995) destacam alguns aspectos que sintetizam as mudanças em curso:

a) a produção sustenta-se em um processo produtivo flexível, uma vez que está voltada e conduzida pela demanda para atender às exigências mais individualizadas do mercado, no melhor tempo e com melhor qualidade;

b) a flexibilização da produção e o alto ritmo da mudança técnica requerem a especialização flexível do trabalhador;

c) a existência de uma combinação de diferentes processos produtivos, articulando o "fordismo" da produção em massa com processo flexíveis e "artesanais";

d) a necessidade de um trabalhador polivalente e multifuncional, que se integra em uma equipe de trabalho, atuando frente a um complexo sistema de máquinas automatizadas; e

e) as crescentes inovações e incorporações tecnológicas levando à diminuição do tempo de trabalho necessário à produção e ampliação das dimensões mais qualificadas e intelectuais do trabalho. 
Esses aspectos articulados, por um lado, reduzem o operariado industrial e fabril e, por outro, aumentam o subproletariado, o trabalho precário, com contratos temporários, parciais, subcontratos e terceirizações, ampliando a desvalorização do trabalho e o desemprego.

Por outro lado, esse mesmo processo de mudanças no mundo do trabalho faz crescer a demanda pelo trabalho de cunho intelectual a ser desenvolvido por profissionais com maior qualificação técnica. Isso decorre da acentuada incorporação tecnológica, sobretudo, da microeletrônica. Observa-se, portanto, um processo tenso e contraditório no que se refere à força de trabalho.

Relacionado aos serviços, Nogueira (1989) cita que, seguindo o modelo capitalista de organização, os serviços também passam por uma radical integração à economia que se manifesta em múltiplas direções, conforme se pode constatar, com exemplos da área da saúde apresentados pelo autor, como segue:

a) a base técnica do serviço, embora dependente ainda em maior ou menor extensão do consumo de trabalho vivo, amplia-se com o uso de mercadorias na forma de instrumentos ou insumos efêmeros: os serviços de saúde tornam-se um dos braços mercantis do setor industrial produtor de medicamentos e equipamentos;

b) há uma especialização dentro da divisão social do trabalho em serviço, ou seja, o serviço integra-se com outros serviços: o hospital contrata empresas de limpeza, alimentação, de segurança, auditoria, etc.; 
c) o serviço de consumo estende-se à órbita da produção de mercadorias: uma empresa de medicina de grupo, que antes atendia segurados individuais, estabelece um convênio com indústrias para segurar seus trabalhadores em regime de pré-pagamento;

d) as formas de organização autônoma são gradualmente deslocadas ou subordinam-se como linha auxiliar das formas coletivas: o médico, como produtor isolado pode ser credenciado pelo sistema previdenciário para aumentar a cobertura potencial da medicina institucionalizada;

e) as formas populares ou não organizadas incorporam-se como discreto apêndice do sistema legitimado: a "medicina natural", já pode ser encontrada em um centro de saúde oficial e até fazer parte dos recursos utilizados dentro do lema "saúde para todos".

Ainda tomando como referência este autor, Nogueira (1989) menciona que as atividades de prestação de serviços caracterizam-se, segundo a utilidade que possuem: primeiramente, servem para recuperar um bem, para preservar um conjunto de bens, para tornar melhor alguma coisa que já se possua, estabelecendo uma relação de exterioridade com o usuário. Em segundo lugar, o sentido de utilidade está condicionado estreitamente por valores e comportamentos sociais reconhecidos, como os serviços de um médico, por exemplo, servindo, portanto, ao usufruto mais pessoal em uma relação direta com a personalidade do usuário. 
Mercado de trabalho em saúde

Nogueira (1992) relata que, quando cerca de $4 \%$ da capacidade de trabalho total de um país (como é o caso do Brasil), diz respeito à prestação de serviços de saúde, justifica-se uma visão que considere a dinâmica empregatícia desse setor em relação aos ramos do comércio, indústria, etc.

Girardi, Carvalho (2002) citam que, tomando-se por base as estatísticas da Relação Anual de Informações Sociais (RAIS) do Ministério do Trabalho e Emprego, cerca de 5,6 milhões de vínculos formais de emprego estão em estabelecimentos direta ou indiretamente vinculados à economia da saúde, dos quais 1,7 milhões correspondem a postos de trabalho assalariados em hospitais, clínicas e serviços diagnósticos e terapêuticos, e os maiores empregadores são as instituições hospitalares, que, no levantamento realizado entre os gestores hospitalares, apresentaram uma tendência de mais de $90 \%$ de preferência por contratações de salários típicos para enfermeiros e pessoal auxiliar de enfermagem.

No entanto, segundo os autores, o peso dos estabelecimentos hospitalares com fins lucrativos e os hospitais vinculados ao terceiro setor encontram-se subdimensionados.

Além disso, verificam-se fora da relação salarial típica um conjunto heterogêneo de arranjos, a exemplo dos contratos de trabalho heterônimos precarizados, dos ocupados por "conta própria" ou "auto-empregados" de pequena e baixa qualificação (ocupações não regulamentadas), de trabalho 
autônomo "liberal", de trabalho autônomo cooperado, dos autônomos contratados para a prestação de serviços, das pequenas empresas de profissionais de saúde subcontratadas do setor organizado (sociedade de quotas limitadas e sociedades civis de profissões regulamentadas), dos profissionais "irregulares" e alternativos, etc. (Girardi, Carvalho, 2002).

Girardi, Carvalho (2002, p.34): apontam ainda que:

\begin{abstract}
Um aspecto que talvez deva ficar realmente ressaltado com relação à detenção pelos profissionais de posições não assalariadas no mercado diz respeito aos diferentes significados de trabalho "frágil" para as diversas categorias de trabalhadores e profissionais de saúde. Com efeito, estar excluído da relação salarial tem um significado completamente diferente para um trabalhador de uma profissão com prerrogativas de auto-regulação que, para dizer o mínimo controla importantes aspectos de seu mercado de trabalho - como a medicina ou a odontologia - e para um trabalhador de uma ocupação não regulamentada, que tem seu mercado de trabalho controlado quase que totalmente pelas organizações empregadoras ou pelo movimento da oferta e demanda nos mercados.
\end{abstract}

A respeito das configurações do mercado de trabalho dos assalariados em setor saúde no Brasil; os autores concluem que mais de $10 \%$ da ocupação assalariada no mercado formal de trabalho está no setor saúde; $16 \%$ dos empregos regulamentados estão vinculados ao setor público municipal; $12 \%$ ao setor público ligado à União; $16 \%$ a 
instituições do terceiro setor e, aproximadamente, $3 \%$ a atividades empresariais lucrativas encontram-se na área da saúde.

Segundo os autores mencionados, para os profissionais do setor saúde a participação no setor público aumentou, provavelmente, em decorrência da transferência das responsabilidades com relação à atenção à saúde para os municípios pelo SUS ao longo da década de 1990. Há uma distribuição mais ou menos equilibrada entre os vínculos assalariados entre as instituições do setor público $(51,3 \%)$ e do setor privado $(25,6 \%$ em entidades empresariais e 18,8\% em entidades do terceiro setor). A ocupação assalariada em profissões de saúde cresceu mais que a de outros profissionais da economia talvez pelo crescimento do número de egressos dos cursos superiores, com exceção dos médicos entre os quais os autores não observaram esse crescimento.

Os autores citam que a conversão de vínculos do regime Consolidação das Leis Trabalhistas $(C L T)$ para o regime estatutário está entre as reconfigurações mais notáveis ocorridas no mercado de trabalho em saúde, nos anos 1990, ainda que este movimento tenha se destacado nos anos finais da década. Houve uma reclassificação dos vínculos assalariados dos profissionais da saúde que passaram a serem registrados na RAIS sob as denominações ocupacionais próprias dos serviços públicos, como "funcionários públicos", "agentes da administração pública", "analistas da saúde", entre outros, conforme Girardi, Carvalho (2002).

Girardi, Cherchiglia e Araújo (2003) em seus estudos a respeito dos recursos humanos nos hospitais sem fins lucrativos, apontam que os 
hospitais filantrópicos concentram $57 \%$ da força de trabalho assalariada dos hospitais privados do País e cerca de $60 \%$ dos vínculos formais de médicos do setor privado.

Além disso, dentre o setor hospitalar não lucrativo, os serviços tecnológicos de maior oferta correspondem aos serviços de laboratório $(90,6 \%)$ dos hospitais que oferecem esse serviço; radiologia $(74,9 \%)$, ultrasonografia $(69,1 \%)$ e anatomia patológica, com taxa de oferta de $59,4 \%$. Por outro lado, os serviços com menor cobertura pelos hospitais filantrópicos foram os de medicina nuclear (3,2\%); ressonância magnética $(5,8 \%)$ radioterapia e urodinâmica (ambos com 6,6\%). Os hospitais filantrópicos que atendem exclusivamente ao SUS ofertam bem menos serviços tecnológicos, quando comparados aos que possuem planos próprios.

Quanto à forma de contratação dos agentes, a maioria dos Serviços de Apoio Diagnóstico e Terapêuticos (SADT) dos hospitais filantrópicos é operada por pessoal não próprio, ou seja, o vínculo de trabalho ocorre com o terceiro que é, por sua vez, proprietário do serviço e não com o hospital. Esse resultado reflete a proeminência da terceirização dos serviços ofertados pelas instituições filantrópicas, especialmente, para obtenção dos serviços de apoio diagnóstico (como laboratório, radiologia, etc.) ou terapêutico especializado (a exemplo da hemodiálise e da hemoterapia, entre outros) (Girardi, Cherchiglia, Araújo, 2003).

Quando comparadas às outras profissões de saúde, nos hospitais filantrópicos, algumas categorias são essencialmente assalariadas como os auxiliares de enfermagem (97,5\%); enfermeiros (93,1\%); nutricionistas 
$(85,1 \%)$ e farmacêuticos $(77,4 \%)$. Os fonoaudiólogos, dentistas e fisioterapeutas têm um alto índice como autônomos (48,2\%; 45,8\% e 45,5\% respectivamente), apesar de ainda se encontrarem em níveis menores quando relacionados aos médicos. A terceirização é relevante aos bioquímicos $(34,7 \%)$; fisioterapeutas $(23,1 \%)$ e fonoaudiólogos $(18,8 \%)$. No entanto, aos profissionais de enfermagem esses índices são baixíssimos, pois $96,6 \%$ possuem a forma de emprego assalariado (Girardi, Cherchiglia, Araújo, 2003).

Mercado de trabalho na enfermagem

Conforme relatam Peduzzi, Anselmi (2002), para se conhecer as práticas de enfermagem é necessário proceder a uma análise de sua força de trabalho. As autoras fazem referência a um estudo desenvolvido pelo Ministério da Saúde, em 1998, que estima um contingente de quase 225.000 agentes de enfermagem atuando sem qualificação técnica. Segundo esta pesquisa, à época o País contava com 70.933 (12,7\%) enfermeiros, 70.740 $(12,6 \%)$ de técnicos de enfermagem; $222.794(39,7 \%)$ de auxiliares de enfermagem e 196.186 (35\%) de trabalhadores com outras denominações e sem o nível básico de profissionalização em enfermagem.

Informações da pesquisa de Assistência Médico-Sanitária do Instituto Brasileiro de Geografia e Estatística (IBGE) apontam para um total de 541.567 trabalhadores de enfermagem no mercado formal de trabalho no ano de 1999, distribuídos como segue: 70.157 (13\%) enfermeiros, 49.604 
$(9,1 \%)$ técnicos de enfermagem, $339.766(62,8 \%)$ auxiliares de enfermagem, $82.040(15,1 \%)$ atendentes de enfermagem e similares (Ministério da Saúde, 2002; Silva, Peduzzi ,2003).

Por outro lado, dados do Conselho Federal de Enfermagem (COFEN), de 2003, mostram um contingente expressivamente superior de trabalhadores de enfermagem que alcança o total de 771.742 agentes, ou seja, $103.688(13,4 \%)$ enfermeiros, $144.834 \quad(18,8 \%)$ técnicos de enfermagem, 486.382 (63\%) auxiliares de enfermagem e $36.312(4,7 \%)$ atendentes e 526 parteiras (Ministério da Saúde, 2002; Silva, Peduzzi, 2003).

Observam-se divergências nos dados sobre a força de trabalho da enfermagem apresentados pelas distintas fontes, o que pode ser atribuído a diferenças nos procedimentos de levantamento de informação. A pesquisa conduzida pelo Ministério da Saúde buscava identificar o real contingente de trabalhadores de enfermagem sem qualificação técnica formal e regular inseridos efetivamente nos serviços de saúde públicos e privados. A pesquisa do IBGE coleta dados sobre os empregos formais, com carteira assinada e o COFEN registra todos os profissionais de enfermagem formados independente de sua inserção no mercado de trabalho (Silva, Peduzzi, 2003)

Pierantoni, Varella (2002) apontam que, no setor saúde, os dois segmentos que empregam o maior volume de pessoal de enfermagem são os dos serviços médicos, odontológicos e veterinários, com cerca de 91 mil instituições e um estoque de quase um milhão de empregos, e a 
administração pública, direta e indireta, cobrindo quase 720 mil empregos nas três esferas do governo.

Mas a maioria dos empregos de enfermagem está localizada nos serviços médicos e odontológicos, especialmente, nos serviços classificados como de atendimento hospitalar de urgência e emergência. $O$ setor privado emprega $58,9 \%$ do pessoal de enfermagem, enquanto o público, $41,1 \%$. Todas as categorias de enfermagem estão setor privado, com exceção dos visitadores sanitários, no qual 57,9\% estão empregados no setor público.

Os autores citados ainda observam que a remuneração é praticada, segundo o nível de escolaridade, ou seja, as ocupações de menor escolaridade têm salários menores e a especialização do enfermeiro ainda é pouco aceita no mercado de trabalho, visto aquelas mais tradicionais, pois o Conselho aponta a existência de 37 especialidades, porém a Classificação Brasileira de Ocupações (CBO) só reconhece 16.

No que se refere ao nível técnico e auxiliar de enfermagem, a CBO indica haver 13 e 7 especializações, respectivamente. Estes números podem ser indicativos de uma tendência ao desenvolvimento de competências e à especialização desses agentes.

Vale esclarecer que a CBO consiste em uma importante fonte de informações sobre as ocupações existentes no mercado de trabalho brasileiro, sendo o documento que reconhece, nomeia e codifica títulos e conteúdos das ocupações do mercado de trabalho brasileiro. Sua finalidade é servir como referencial às políticas de emprego, formação profissional, 
plano de cargos e salários, estudos ocupacionais, censos demográficos, estatísticas de mercado e orientação de investimentos.

Os autores ressaltam que o novo cenário que se apresenta com a implantação da estratégia saúde da família contribuiu para o aparecimento de duas ocupações emergentes: o agente comunitário e o cuidador de crianças, jovens, adultos e idosos. Mas, no campo da saúde, existe a preocupação de que o agente comunitário e a modalidade de cuidador poderiam representar uma nova versão dos atendentes de enfermagem, apresentando uma baixa regulação do exercício profissional acompanhada de uma inserção desregulamentada ou flexibilizada no mercado decorrente da baixa qualificação e remuneração (Pierantoni, Varella, 2002).

O surgimento de novas ocupações com o requerimento de distintas competências é para os autores citados decorrente das transformações do mundo do trabalho, envolvendo as inovações tecnológicas e novas formas de organizar e gerenciar o processo produtivo que resultam, por sua vez, na emergência de distintos setores, novas formas de fornecimento de serviços, novos mercados, enfim, uma mudança na dinâmica do trabalho e empregabilidade.

Segundo Pierantoni, Varella (2002, p.58), a ocupação é definida como sendo:

O agrupamento de tarefas, operações e outras manifestações que constituem as obrigações atribuídas a um trabalhador e que resultam na produção de bens e serviços. 
Ao autores citados relatam que a enfermagem é uma categoria que merece destaque por causa de sua composição e representatividade numérica no conjunto dos trabalhadores da área da saúde.

Terceirização em saúde

No que se refere ao mercado de trabalho, cabe enfatizar o recente processo de terceirização que ocorre também no setor saúde, assim como em outros setores de produção. Assim, a modalidade de cooperativa permite a contratação de mão de obra terceirizada, para além da terceirização da prestação de serviços. Todos estes fenômenos atuais estão relacionados à flexibilização.

Segundo Cherchiglia (1999), os resultados das transformações no mundo do trabalho vão configurar a denominada flexibilização do trabalho, e vêm delineando duas vertentes: a variante européia, que se caracteriza essencialmente pela busca de uma gestão institucionalizada e da flexibilidade interna para enfrentar a imprevisibilidade do mercado, por meio de renegociação salarial, redução da jornada de trabalho e "partilha" dos empregos de formas variadas desregulamentação; e a variante americana, que é caracterizada pela multiplicação das formas enfraquecidas de emprego e de trabalho, por meio da negação de conquistas sociais de trabalho, generalização dos contratos temporários e abrandamento da legislação trabalhista e de proteção social, implantação de salário relacionado ao desempenho com diversos sistemas de prêmios, motivando a 
individualização, tendo como resultado a desregulamentação e flexibilização externa do trabalho.

Para Cherchiglia (1999), de um lado, há os trabalhadores assalariados estáveis altamente qualificados e polivalentes, bem remunerados e protegidos. Nesse caso, a flexibilidade seria de caráter funcional, dada pela habilidade do empregador movimentar esse segmento em diversas funções com conteúdos diferenciados; por outro lado, é uma força de trabalho mais instável, com poucos direitos trabalhistas, com contratos de trabalho por tempo determinado ou parcial e um crescente número de desempregados.

Neste caso, a flexibilidade ocorre pela capacidade do empregador alterar o tamanho de sua força de trabalho. Ambas as estratégias combinadas, dentro de um contexto de desregulação, resultam em:

- aumento do pessoal temporário externo fornecido por terceirização;

- desemprego constante;

- diminuição do núcleo dos empregados estáveis e bem pagos e - aumento da precariedade e da exclusão.

O mercado de trabalho brasileiro parece ter seguido a variante americana, com desregulação das relações de trabalho, crescimento do trabalho informal, generalização de contratos por tempo determinado e temporários, subcontratações e terceirizações (Cherchiglia,1999).

O autor citado refere-se que a terceirização é um neologismo cunhado baseado na palavra "terceiro", entendido como intermediário, interveniente, que, na linguagem empresarial, se caracteriza como uma técnica de 
administração por meio da qual se interpõe um terceiro, geralmente, uma empresa, na relação típica de trabalho (empregado versus empregador).

Trata-se do repasse a uma outra empresa de um determinado serviço ou a produção de um certo bem ou atividade da "empresa-origem" para a "empresa-destino" (subcontratada). Estas funções podem incluir etapas do próprio processo produtivo da "empresa-origem" ou apenas atividades / serviços de apoio, tais como serviços de limpeza e manutenção, preparação e distribuição de alimentos para funcionários da empresa, telefonia, vigilância, movimentação de materiais e expedição e comercialização de produtos finais, dentre outros.

A principal finalidade da terceirização seria otimizar a produção, a qualidade, o lucro e a competitividade, mediante um processo de horizontalização de atividades, simplificando-se a estrutura organizacional, a fim de que as empresas possam concentrar seus esforços na melhor metodologia para obtenção do produto ou serviço em razão da diminuição dos encargos trabalhistas e previdenciários. Outra vantagem seria a especialização de empresas prestadoras de serviço (Cherchiglia, 1999).

Dentre as principais técnicas de terceirização, destacam-se:

- a desverticalização: que consiste em passar funções para o fornecedor externo especializado, que, atuando em suas próprias instalações, manufatura partes e componentes especificados pelo contratante;

- a prestação de serviço: ocorre quando um terceiro intervém numa atividade-meio do contratante, executando seu trabalho nas instalações 
deste ou onde for determinado. A prestação de serviços pode ser realizada por empresa ou cooperativa de serviços e trabalho;

Além destas, ainda há a franquia, compra de serviços, nomeação de representantes, concessão, permissão e alocação de mão-de-obra (a aquisição ou o aluguel de horas de trabalho, esta forma poderá ser desenvolvida de duas maneiras: trabalho temporário e trabalho avulso sindicalizado). Vale a pena lembrar que há uma legislação que regulamenta a contratação de mão-de-obra terceirizada no Brasil (Cherchiglia, 1999).

No setor da saúde, a terceirização tem sido influenciada pelas pressões advindas do aumento dos custos do setor saúde, acima das taxas de inflação e da necessidade de eficiência em um ambiente competitivo. A tendência atual de terceirização da contratação de trabalho no setor saúde vai além dos serviços gerais de limpeza, vigilância, alimentação, manutenção etc., já tradicionais, e atinge, também os serviços profissionais e técnicos da saúde (laboratórios, serviços de imagem, pronto-socorro, etc.) (Cherchiglia, 1999).

O autor citado refere-se que no Boletim de Indicadores do Programa de Estudos Avançados em Administração Hospitalar e de Sistemas de Saúde (PROAHSA) em 1997, 49\% da mão-de-obra dos hospitais de grande porte (151 a 300 leitos) eram terceirizados, $28 \%$ dos hospitais com mais de 500 leitos, $10 \%$ dos de médio porte (51-a 150 leitos) e só $3 \%$ da mão de obra dos hospitais de pequeno porte (5 a 50 leitos).

Os setores mais terceirizados a exemplo dos americanos são os de manutenção e conservação (limpeza, segurança, alimentação, manutenção 
de equipamentos e lavanderia) e, entre as áreas técnicas e profissionais, a área administrativa e alguns setores médicos como laboratório, imagem e pronto-atendimento.

Em estudo recente do Ministério da Saúde sobre o mercado brasileiro de trabalho em enfermagem, pode-se constatar que 1,7 e 1,5\% dos hospitais pesquisados contratavam de agências, respectivamente, enfermeiros e auxiliares de enfermagem.

O poder público não poderia transferir a uma instituição privada toda a administração e execução das atividades de saúde prestadas apenas por um hospital público ou um centro de saúde. Poderia haver terceirização dos serviços de saúde se o que estiver sendo transferido pelo poder público, for apenas a execução material de determinadas atividades ligadas ao setor de saúde, como de hemocentros, exames, consultas, serviços laboratoriais, internações hospitalares, de imagem, mas não a sua gestão operacional (Cherchiglia, 1999).

As vendas de serviços profissionais e técnicos, geralmente são realizadas por cooperativas de trabalho que, inicialmente, eram restritas a determinadas especialidades médicas, tendem nos dias atuais, a generalizar-se, organizando serviços de outros profissionais, como psicólogo e odontólogo (Cherchiglia, 1999).

Esse tipo de contrato tem permitido, por um lado maior flexibilidade na gestão de sua força de trabalho e, por outro lado, a precarização do trabalho que tem variado, conforme maior pressão ou poder do sindicato em negociar 
salários, benefícios e direitos trabalhistas e previdenciários (Cherchiglia, 1999).

Assim, torna-se ainda mais necessário avaliar as conseqüências do processo de terceirização e qualidade dos serviços prestados. No setor saúde, a mensuração "objetiva" do valor do seu produto (ou resultados) é de difícil avaliação / mensuração, pois envolve um processo de atribuição de valores a bens que representam significados sociais bastante marcados pela questão da subjetividade.

Para Peduzzi (1998), nas intervenções de enfermagem nada é totalmente definitivo antes da execução, isto é, não é possível nem desejável definir a ação por completo antes da execução, pois há de se tomar em consideração o sujeito a quem se destina a intervenção. Além disso, deve-se considerar a análise da dimensão intersubjetiva do processo, que é de extrema importância, pois se trata de uma prática na qual a intervenção técnica está sempre permeada pela interação, estando as dimensões ética e comunicativa imediatamente associadas à dimensão técnica.

Nos serviços de saúde, o produto vem sendo avaliado de uma tripla forma: pela quantidade de serviço; pela qualidade das ações de saúde, ou seja, da maior ou menor capacidade de recuperação de um agravo à saúde, atribuída a um determinado serviço; e pelo valor e/ou faturamento e resultados operacionais dos serviços prestados (Cherchiglia, 1999). 


\section{METODOLOGIA}

\section{Tipo de estudo}

Esta pesquisa foi desenvolvida nas modalidades qualitativa e quantitativa. A construção do objeto de estudo e a análise da caracterização do trabalho de enfermagem em laboratórios de análises clínicas, tomaram como referencial teórico os estudos do processo de trabalho em saúde e em enfermagem que, originariamente, advêm das Ciências Sociais. Também foi usada a abordagem quantitativa, visto que os dados numéricos obtidos foram armazenados em banco de dados e receberam um tratamento estatístico.

Igualmente, caracteriza-se como um estudo do tipo exploratóriodescritivo, tendo em vista que a aplicação da fase exploratória justifica-se por ser um método que visa a aumentar o conhecimento do pesquisador sobre o fenômeno investigado ou conseguir nova compreensão deste, bem como formular um problema mais preciso de pesquisa ou criar novas hipóteses.

A fase descritiva tem como objetivos principais a apresentação mais precisa das características de uma situação, um grupo ou um indivíduo específico (seja com ou sem hipóteses iniciais a respeito da natureza dessas 
características), além disso, visa a verificação da freqüência com que algum evento ocorre ou está ligado a uma hipótese inicial específica (Selltz, et al., 1974; Triviños, 1987).

\section{Campo de estudo}

O campo de estudo foi constituído por laboratórios de análises clínicas públicos e privados e unidades básicas de saúde, ambos com setor de coleta de material biológico no Município de São Paulo, em 2002.

\section{População e Amostragem}

A idéia inicial foi selecionar uma amostra da população de laboratórios de análises clínicas, pois a listagem inicial conseguida era extensa, porém, no decorrer do desenvolvimento da definição desta amostra, foram encontradas dificuldades relevantes, e a principal foi a indisponibilidade de informação atualizada, que interferiu diretamente na seleção da amostra.

O primeiro passo para a obtenção da população foi a realização de uma solicitação à Fundação Sistema Estadual de Análise de Dados SEADE (SEADE, 2002) e à Sociedade Brasileira de Análises Clínicas SBAC (SBAC, 2002) da relação dos laboratórios de análises clínicas do Município de São Paulo existentes em 2002. Ambas forneceram listagens com 138 e 584 laboratórios e unidades básicas de saúde. 
Diante da relação de 722 laboratórios de análises clínicas, foi feita uma primeira depuração, analisando-se os indicativos constantes nas razões sociais e/ou nomes fantasias dos serviços.

A partir deste princípio foram excluídos os laboratórios que não eram de análises clínicas, como os bancos de sangue, serviços de imagem, laboratórios de veterinária, genética, de alimentos, farmacêuticos, serviços de medicina ortomolecular, clínicas médicas e cirúrgicas, empresas de produtos laboratoriais ou hospitalares, empresas que constavam na listagem, mas que não eram da área da saúde, bem como os nomes repetidos nas duas relações. Resultaram desse processo 595 laboratórios e, frente a este número, optou-se por realizar um plano de amostragem desta população.

A fim obter-se um melhor rendimento e maior facilidade no manejo da relação desses laboratórios, a listagem foi ordenada em ordem alfabética decrescente. Esse tipo de organização da relação só pôde ser realizado porque o nome dos laboratórios não representa uma variável de estudo (Cochran, 1965).

Para a definição da amostra*, optou-se pelo método de amostragem sistemática não-probabilística, pela facilidade com que esse método permite a seleção de uma amostra dentro de um grande universo, por ser eficiente quando a população é ordenada de forma aleatória, evitando viés na composição da amostra, além de apresentar boa precisão (Cochran, 1965).

\footnotetext{
* O plano amostral foi definido pela Sra. Nishimoto IN. Estatística do Centro de Estudos do Hospital do Câncer - Fundação Antonio Prudente.
} 
A amostra sistemática pode ser classificada em probabilística ou nãoprobabilística, dependendo dos critérios de seleção do primeiro elemento, pois este determinará a inclusão ou exclusão dos demais elementos da amostra. Se o primeiro caso for selecionado de forma aleatória, a amostra será probabilística, pois, até então, todos os outros componentes da população têm chances iguais de serem incluídos. No entanto, se este seguir algum critério do intervalo, as chances de seleção dos outros elementos deixarão de ser iguais, e a amostra passará a ser classificada como não-probabilística (Chein, 1974).

Na metodologia de amostragem sistemática, seguem-se os seguintes passos: define-se e organiza-se a listagem da população inicial a ser estudada; numeram-se todos os componentes da relação, depois selecionase, aleatoriamente, um número na tabela de dígitos casuais. Nesta pesquisa, adotou-se a tabela de números aleatórios (Haddad, 2004) (anexo II) - e este número determinará o intervalo entre cada nome da relação que será selecionado, em nosso caso, o número três foi o sorteado (Selltz, et al., 1974; Cochran, 1965).

O primeiro elemento escolhido seguiu o número sorteado, assim, o terceiro laboratório da listagem iniciou a composição da amostra, seguido pelos demais terceiros serviços subseqüentes, estabelecendo um intervalo de três em três, evidenciando, portanto, o caráter não-probabilístico dessa amostra. Do processo, resultou a seleção de 198 laboratórios dos 595, inicialmente, obtidos. 
Vale a pena ressaltar que a listagem geral estava incompleta quanto às informações, ou seja, estavam desatualizadas, pois, na maioria das vezes, faltavam o nome do responsável técnico, os dados de endereço, tais como: o código de endereçamento postal (CEP) e o bairro, além de não constar o número de telefone das instituições ou estar incorreto. Essa dificuldade levou-nos a recorrer a outra fonte de informações a fim de completar os dados necessários dos 198 laboratórios selecionados na primeira amostra.

A fonte escolhida foi a consulta on-line ao guia de assinantes no endereço eletrônico da Telefônica www.telefonica.com.br , em que se insere o nome da instituição e/ou seu endereço e o número do telefone cadastrado é fornecido, se constar no banco de dados da Telefônica e se houver autorização do cliente para sua divulgação. Seguindo esse método, foram localizados 39 telefones de um total de 198 laboratórios, previamente, selecionados.

Pela consulta do site, observou-se que os nomes das instituições nem sempre eram os mesmos fornecidos por elas ao cadastro da Telefônica, o que impossibilitou a obtenção dos números dos telefones de uma parte das mesmas. Além disso, outros serviços não apareceram no site nem foram localizados pelo endereço indicado na relação original, impedindo a obtenção da informação. Nestes casos, foi feito um contato direto com a Telefônica a fim de que, com o auxílio do atendente, o número do telefone pudesse ser obtido, mas, mesmo assim isso não foi possível para a maioria delas. 
Apoiado nos dados obtidos, especialmente, nos números atualizados dos telefones, foi feito um primeiro contato telefônico com os laboratórios selecionados na amostra a fim de confirmar e/ou completar os dados de endereço, o nome da instituição e do responsável técnico pelo recebimento da correspondência, visto que se observou ainda haver divergências relacionadas ao endereço real da instituição e seu nome na relação obtida.

Outro objetivo deste contato telefônico inicial foi checar o critério de inclusão no estudo: ser laboratório de análises clínicas ou unidade básica de saúde que possua um setor de coleta de amostra biológica. Na listagem inicial, constavam ainda alguns nomes de empresas prestadoras de serviço às instituições de saúde, em geral, tais como: fornecedores de artigos hospitalares e laboratoriais, bem como outros serviços que não eram laboratórios de análises clínicas, sendo, portanto, também excluídos da amostra.

Neste contato telefônico, do total de 198 laboratórios, foram selecionados $68(34,3 \%)$ e excluídos $130(65,7 \%)$. Na primeira seleção, a perda amostral foi superior a $30 \%$, por isso, optou-se por repor essa perda. Os motivos das perdas amostrais foram apresentados nos dados da Figura 1.

Uma nova amostra foi composta pelos laboratórios posteriores aos já selecionados, respeitando-se o mesmo intervalo anteriormente determinado, do qual resultou uma segunda seleção com 197 laboratórios.

Todo o processo já descrito anteriormente foi repetido e foram obtidos mais 24 novos telefones. Nesta segunda seleção, compuseram a amostra 62 
(31,5\%) laboratórios e 135 (68,5\%) foram excluídos (Figura 1). A perda novamente superou os $30 \%$ e para tentar supri-la foi feita uma terceira listagem com os 200 laboratórios restantes na relação geral inicial.

Mais uma vez todo o processo no site foi repetido e foram obtidos mais 17 novos telefones. Resultaram desta terceira seleção, 50 (25\%) laboratórios selecionados e 150 (75\%) excluídos, após o contato telefônico (Figura 1).

Figura 1- Relação dos motivos das perdas amostrais, segundo seleção amostral. Município de São Paulo, 2003

\begin{tabular}{|c|c|c|c|c|}
\hline \multirow[t]{2}{*}{ Motivos das perdas amostrais } & \multicolumn{4}{|c|}{ Seleção Amostral } \\
\hline & $1^{\mathrm{a}}$ & $2^{a}$ & $3^{a}$ & Total \\
\hline Laboratórios repetidos & 24 & 24 & 44 & 92 \\
\hline Pertencente ao teste piloto & 1 & 1 & 0 & 2 \\
\hline $\begin{array}{l}\text { Telefones inexistentes na listagem geral e } \\
\text { não localizados no site }\end{array}$ & 63 & 82 & 77 & 222 \\
\hline $\begin{array}{l}\text { Telefones incorretos na listagem geral e } \\
\text { os que não existiam no site }\end{array}$ & 3 & 5 & 12 & 20 \\
\hline Telefones incorretos no cadastro do site & 17 & 4 & 3 & 24 \\
\hline $\begin{array}{l}\text { Serviços que não eram laboratórios de } \\
\text { análises clínicas }\end{array}$ & 8 & 6 & 2 & 16 \\
\hline Outros tipos de laboratórios & 4 & 1 & 0 & 5 \\
\hline $\begin{array}{l}\text { Não possuíam laboratório de análises } \\
\text { Clínicas }\end{array}$ & 2 & 7 & 5 & 14 \\
\hline $\begin{array}{l}\text { Não realizavam coleta de exames e/ou } \\
\text { não dispunham desse setor }\end{array}$ & 7 & 4 & 2 & 13 \\
\hline Laboratório desativado & 1 & 0 & 3 & 4 \\
\hline Fora do campo de estudo & 0 & 1 & 2 & 3 \\
\hline Total de perdas & 130 & 135 & 150 & 415 \\
\hline
\end{tabular}


Durante a fase de primeiro contato telefônico com as instituições, torna-se interessante destacar com mais detalhes as informações obtidas, pois evidenciaram a grande dificuldade na obtenção dos dados atualizados relacionados aos laboratórios de análises clínicas. Os achados foram demonstrados, segundo a seleção realizada.

Na primeira seleção:

- dos três telefones incorretos na listagem e inexistentes no site: um era residencial, um só dava sinal de ocupado e um não atendia ao chamado;

- entre os oito outros tipos de laboratórios: um laboratório de pedras preciosas, dois de próteses e um de anatomia patológica;

- das oito instituições que não eram laboratório de análises clínicas: uma fábrica, uma empresa, uma clínica veterinária, três consultórios médicos, uma drogaria e uma loja de fralda;

- dos dezessete telefones incorretos no site: cinco eram residenciais, dois telefones não existiam, quatro estavam fora de serviço, um mudou o número do telefone; quatro não atenderam ao chamado e um era caixa postal.

Na segunda seleção:

- dos cinco telefones incorretos na listagem e inexistentes no site: um era clínica de hemodiálise, dois não eram laboratórios e dois telefones haviam mudado; 
- dos seis serviços que não eram laboratórios de análises clínicas: uma administração regional; duas clínicas de hemodiálise; dois consultórios médicos, uma clínica psiquiátrica;

- entre o outro tipo de laboratório: um laboratório de anatomia patológica;

- dos quatro telefones incorretos no site: um era residencial; um telefone mudou; um não atendia e um era caixa postal;

Na terceira seleção:

- dos doze telefones incorretos na listagem e inexistentes no site: todos estavam incorretos;

- das duas instituições que não eram laboratório de análises clínicas: uma era consultório médico e uma empresa;

- dos quatro telefones incorretos no site: um estava fora de serviço; um era fax e um, caixa postal.

Nesta terceira seleção, o alto número de laboratórios repetidos pode ser explicado porque a maioria deles já havia aparecido nas listagens anteriores.

Assim, dos 595 nomes da relação geral inicial, $180 \quad(30,3 \%)$ laboratórios compuseram efetivamente a amostra, 415 (69,7\%) instituições não puderam ser incluídas, pois $92(22,2 \%)$ eram repetidas, duas $(0,5 \%)$ fizeram parte do teste-piloto e os demais $321(77,3 \%)$ serviços foram excluídos pelos motivos citados acima.

Diante da dificuldade de definição da população descrita anteriormente, foi feito um contato com a Vigilância Sanitária de São Paulo CVS (CVS, 2002) que forneceu uma outra listagem composta por 156 
nomes das instituições de SADT no Município de São Paulo, dos quais 44 eram laboratórios de análises clínicas.

Após a depuração desta nova lista, comparando-a com os dados das outras listagens, houve uma contribuição efetiva de mais 16 novos laboratórios que não constavam na listagem elaborada com base nos procedimentos descritos anteriormente.

Considerando-se a expressiva perda amostral, optou-se por desenvolver a pesquisa de campo com a totalidade dos laboratórios identificados que atenderam aos critérios de inclusão. Assim sendo, inicialmente, 196 laboratórios compuseram a população de estudo.

\section{Procedimento de coleta de dados}

Nesta pesquisa, que representa uma primeira aproximação temática sobre o trabalho da enfermagem em laboratórios de análises clínicas, foi efetuado um recorte dos aspectos do processo de trabalho estudados, ou seja, os agentes de trabalho inseridos nesse processo, as atividades desenvolvidas pelos trabalhadores de enfermagem, trabalhadores sem qualificação técnica e regular e os com nível superior que atuam na coleta de exames, bem como a divisão de trabalho entre os agentes da coleta e a inserção da enfermagem na instituição.

Assim sendo, foi elaborado um questionário (anexo III) para a coleta dos dados, contendo questões fechadas e uma aberta, e dividido em três aspectos: caracterização da instituição, dos recursos humanos atuantes na 
coleta e das atividades desenvolvidas por esses agentes, a fim de atingir os objetivos propostos no estudo.

Este instrumento foi escolhido, sobretudo, pela facilidade de aplicação simultânea a todos os elementos da população, fornecendo as respostas com maior rapidez, por alcançar grandes distâncias, ser enviado pelo correio e ser menos dispendioso.

Além destas vantagens, o questionário permite a escolha do melhor momento para ser respondido; não requer preparo especial para a coleta de dados; possibilita o anonimato do informante; conduz a respostas melhores, pois as instruções são escritas e padronizadas. Padronização esta que permite a comparação entre as respostas, as distinções observadas são decorrentes das diferenças dos informantes e não das perguntas (Witt, 1973; Chein, 1974; Cassiani, 1987).

Em contrapartida, este tipo de instrumento de coleta de dados apresenta desvantagens como: possibilidade de má interpretação das perguntas; não atingir a populações que não sabem ler e escrever; o informante pode omitir ou desconsiderar algum item do questionário sem dar explicações; a quantidade e a qualidade das informações obtidas são limitadas pela disponibilidade e interesse do informante que pode ler todas as questões antes de começar a respondê-las e ter as suas respostas influenciadas pelas perguntas do instrumento, podendo ter respostas inválidas.

O questionário apresenta um índice de baixo retorno e impossibilidade de esclarecimento das dúvidas do informante. Além disso, o 
questionário estruturado limita a riqueza das respostas, o conhecimento do referencial teórico e leva à indução da resposta pela formulação da questão (Witt, 1973; Kornhauser, Sheatsley 1974; Cassiani, 1987).

Diante desses pontos favoráveis e desfavoráveis, um questionário deve ser elaborado, observando algumas características, como a inclusão de perguntas relacionadas à questão da pesquisa proposta, considerando a revisão da literatura e envolvendo a experiência do pesquisador. As questões devem ser claras, concretas, precisas e em uma quantidade limitada a no máximo 30, além da adequação da linguagem à populaçãoalvo.

As perguntas não devem possibilitar mais de uma interpretação, conter uma única idéia de cada vez e não sugerirem respostas. As questões fechadas com alternativas exaustivas favorecem a tabulação dos dados coletados.

Deve-se evitar perguntas que causem embaraços, respostas defensivas, estereotipadas ou socialmente indesejáveis, e questões diretas ao informante como, por exemplo, "o que você acha", pois podem provocar respostas de fuga.

O instrumento deve ser iniciado com questões mais simples e, sempre que houver possibilidade, conter perguntas dispersadas, a fim de evitar "contágio" entre elas (uma responde a outra), bem como uma introdução, dados sobre o informante, questões pertinentes ao tema do 
estudo e perguntas controladoras, que são repetidas sob outro aspecto, mas que abordam o mesmo assunto*

Depois da aprovação do projeto pela Comissão de Ética em Pesquisa da Escola de Enfermagem da Universidade de São Paulo (Conselho Nacional de Saúde, 1996), referida a seguir, procedeu-se ao teste do instrumento de coleta de dados.

Para o teste-piloto, foram escolhidos dois laboratórios clínicos, um foi selecionado a partir da consulta ao site da telefônica, observando-se que o mesmo não constasse na relação resultante da fusão das listagens fornecidas pelas instituições Fundação SEADE e SBAC e que atendessem a uma clientela externa em regime ambulatorial. O segundo laboratório foi incluído no teste por atuar dentro de uma instituição hospitalar, tendo assim uma clientela interna em regime de internação, além de ser terceirizado e pertencer a uma rede de filiais.

Para o agendamento de uma entrevista, foi feito um contato telefônico em que foram entregues aos informantes o instrumento da coleta de dados (anexo III), a carta de autorização da instituição (anexo IV), o Termo de Consentimento Livre e Esclarecido (anexo V) e o Parecer de Aprovação da Comissão de Ética em Pesquisa da Escola de Enfermagem da Universidade de São Paulo (anexo VI).

Um deles respondeu ao questionário na presença do pesquisador e o outro preferiu fazê-lo num momento posterior, porém ambos esclareceram

\footnotetext{
* Graziano KU. Instrumentos de coleta de dados. [material didático]
} 
as dúvidas que surgiram, contribuindo, assim, para a melhoria do instrumento.

Observou-se que os informantes não dispunham de dados precisos relativos ao ano da inauguração da instituição e número de pacientes atendidos mensalmente, o que implicaria que fosse interrompido o preenchimento do questionário para ir buscar estas informações. Assim sendo, foi alterado o enunciado da questão referente a esses pontos.

$\mathrm{Na}$ questão, que aborda as atividades executadas na coleta, como não havia uma coluna reservada a outros profissionais de nível superior, um informante colocou-se como "outro tipo de trabalhadores da coleta de exames sem qualificação técnica formal e regular".

O informante pertencente à rede hospitalar manifestou apenas uma dúvida relativa à formação exigida para o trabalho na coleta, ou seja, tratavase dos critérios do conselho regional ou do próprio laboratório.

O laboratório em regime ambulatorial estava cadastrado on-line com um nome, porém, ao preencher os anexos IV e V, esclareceu que o nome constante na Telefônica referia-se a uma filial que havia fechado e que agora era identificada apenas pelo nome da matriz, tendo, portanto, seu nome modificado. Diante deste fato, optou-se por não enviar aos laboratórios os anexos IV e $\mathrm{V}$ preenchidos com o nome da instituição, mas deixar que o próprio informante o fizesse, a fim de evitar o nome incorreto do serviço, o que poderia inibir o preenchimento dos impressos.

Convém salientar que, ambos, o laboratório localizado dentro de um hospital e o próprio hospital constavam na relação final dos laboratórios, 
bem como o nome da central do laboratório em regime ambulatorial, e por isso foram excluídos da população de estudo.

Após a finalização do teste, as alterações necessárias no instrumento foram feitas, conforme assinalado acima.

Assim, o questionário foi enviado pelo correio aos responsáveis dos 196 laboratórios selecionados para o estudo, a Carta de Autorização da Instituição (anexo IV), com o Termo de Consentimento Livre e Esclarecido (anexo V), estes dois últimos em duas vias, o Parecer de Aprovação da Comissão de Ética em Pesquisa da Escola de Enfermagem da Universidade de São Paulo (anexo VI), a Carta de Apresentação (anexo VII) explicando os objetivos do projeto e solicitando a participação dos mesmos na pesquisa e um envelope já selado para facilitar o retorno do questionário.

Sete semanas após a data do envio dos questionários, apenas 16 $(8,1 \%)$ retornaram respondidos. Iniciou-se, então, uma busca ativa por telefone, na qual o contato foi feito diretamente com o responsável da instituição e/ou da coleta. Esta fase durou cerca de dez semanas.

Dos cento e noventa e seis laboratórios selecionados, não se obteve contato com apenas sete. As razões que levaram a impossibilidade de contato nessa fase variaram entre: o telefone não atendia; as pessoas-chave estavam freqüentemente ocupadas em reuniões ou em outras unidades; o horário do contato telefônico não coincidia com o momento em que os responsáveis estavam na instituição. Foram feitas, cerca de seis ligações telefônicas sem sucesso para cada um destes sete laboratórios. 
A busca ativa foi realizada efetivamente em 189 laboratórios e 96 instituições solicitaram o reenvio do instrumento de coleta de dados. Dentre estes, os responsáveis por 32 laboratórios informaram que não receberam o questionário no primeiro envio, em outro serviço o questionário foi extraviado internamente e, em outro, foi descartado pelo próprio responsável por não ter despertado interesse inicial.

Além disso, cinco instituições alegaram que já haviam respondido e colocado o questionário no correio, porém os mesmos não chegaram a seu destino. Houve mudança de diretoria ou do responsável em 13 laboratórios após o mês de envio do primeiro questionário, este não foi repassado aos atuais e dois serviços estavam com endereço incorreto, impossibilitando sua localização pelo correio e, conseqüentemente, houve devolução do material enviado.

Seis laboratórios pertencentes a hospitais da rede pública que solicitaram que o projeto tramitasse em suas próprias comissões de ética em pesquisa. O material foi entregue e apenas dois retornaram dentro do período da coleta.

Em cinqüenta e nove laboratórios, o reenvio não foi necessário, pois 40 confirmaram que o receberam e 19 responsáveis não quiseram participar da pesquisa, alegando os seguintes motivos: três laboratórios estavam desativados; três serviços em processo de encerramento; um realizando mudança de endereço; um em fase de transição interna para o sistema de cooperativa; em três, a autorização para participar não foi concedida; cinco 
responsáveis não se interessaram; dois estavam em dúvida se responderiam e um alegou ser de pequeno porte.

Nesta fase de busca ativa, identificou-se que, dos 196 serviços selecionados, $22(11,2 \%)$ eram repetidos, três $(1,5 \%)$ não tinham setores de coleta de exames laboratoriais, e três (1,5\%) não eram laboratório de análises clínicas, revelando que, apesar do primeiro contato ter sido feito a fim de checar também o critério de inclusão, esse contato não foi efetivo nestas instituições.

Assim, houve necessidade de excluir esses 28 (14,3\%) serviços da população já identificada e fazer uma nova composição do universo da população do estudo que resultou, efetivamente, em 168 laboratórios que atenderam aos critérios de inclusão.

Convém salientar que, durante o processo de busca ativa, três $(1,5 \%)$ responsáveis por laboratórios referiram que não iriam participar da pesquisa por acharem que havia um caráter fiscalizador ou especulatório, visto que estavam em desacordo com as normas do Conselho Regional de Enfermagem (provavelmente, estavam referindo-se à Resolução COFEN$\left.146^{*}\right)$. Após a explicação dos objetivos da pesquisa e esclarecimento de que não havia o caráter fiscalizador, esses serviços concordaram participar da pesquisa.

Outros dois $(1 \%)$ responsáveis fizeram referência à demissão da única auxiliar de enfermagem contratada, por não poderem contar com uma

\footnotetext{
* Resolução COFEN-146, de 12 de junho de 1992. Dispõe sobre a obrigatoriedade de haver enfermeiro em todas as unidades de serviço em que são desenvolvidas ações de enfermagem
} 
enfermeira em seu quadro de serviço dada a baixa demanda do laboratório, bem como pelo alto custo que o enfermeiro representaria à instituição.

Já nos primeiros contatos com as instituições, chama a atenção que, ainda nas fases de seleção dos laboratórios e, em torno da busca ativa, constatou-se que da amostra de 196 laboratórios selecionados inicialmente, $27(13,8 \%)$ instituições terceirizaram o serviço de laboratório de análises clínicas, em especial, os serviços hospitalares, prontos-socorros, fundações, institutos, centros médicos, policlínicas e ambulatórios gerais.

A fase de coleta durou cinco meses e foi realizada no período de abril a setembro de 2003. Da população final de estudo composta por 168 laboratórios de análises clínicas, no início, haviam retornado apenas 16 instrumentos, e após a busca ativa, mais 29 instituições responderam o questionário, totalizando um retorno de $45(26,8 \%)$ questionários nesta pesquisa. Assim, obteve-se uma amostragem que se caracteriza como uma amostra por conveniência (Triola, 1999), pois foram utilizados os questionários disponíveis, ou seja, que retornaram preenchidos pelas instituições que se dispuseram a fazê-lo.

O baixo retorno dos questionários foi uma preocupação inicial, despertando a necessidade de consultar especialistas no assunto e verificar na literatura qual era o índice de retorno de questionários. A título de ilustração, a consulta foi feita pelos unitermos "questionário" e "enfermagem" na base de dados DEDALUS, no período de 1999 a 2003. Assim, nesta busca foram identificados oito trabalhos em que a informação sobre a porcentagem do retorno dos questionários era citada no resumo. 
Nestes estudos, observou-se uma ampla variação de retorno dos questionários. Quando os mesmos foram enviados às populações abertas, abrangentes e sem vínculo com o pesquisador, o retorno foi baixo, variando entre $3,6 \%$ a $67,5 \%$ (Graziano, 1999; Kitahara, 1999; Gryschek, 2000, Caldonha, 2002; Mion Júnior, 2002).

Kobayashi (2002) cita um retorno de $68,4 \%$, após a busca ativa. Já nas pesquisas em que a população-alvo conhecia ou tinha algum vínculo ou proximidade com o pesquisador, o retorno dos questionários foi maior, variando entre $64,6 \%$ a $83,3 \%$ (Lino, 1999; Oguisso, 2001; Costa, 2002). Kornhauser, Sheatsley (1974) citam uma variação de retorno de 10 a 50\%.

Diante dessas estatísticas, observou-se que o retorno de $26,8 \%$ estava numa faixa aceitável. Uma outra hipótese para o baixo retorno dos questionários pode estar relacionada ao tipo de população do estudo, pois nesta população, em especial, os informantes são diretores e/ou responsáveis pelo setor de coleta e, provavelmente, são sobrecarregados com as atividades gerenciais do trabalho, restando pouco tempo para outras atividades de menor impacto em seu dia-a-dia.

Esta interpretação está pautada na experiência da busca ativa nos laboratórios, pois, na maioria das vezes, foi feita mais de uma tentativa de contato telefônico pela impossibilidade do responsável atender ao telefonema no exato momento em que ele acontecia. Assim, a vantagem que o questionário apresenta do informante poder escolher o melhor momento para respondê-lo, aplicado à presente pesquisa não caracterizou uma vantagem efetiva. 


\section{Aspectos éticos da pesquisa}

O projeto de pesquisa foi aprovado pelo Comitê de Ética em Pesquisa da Escola de Enfermagem da Universidade de São Paulo atendendo às exigências da Resolução nº 196 de 10 de outubro de 1996 do Conselho Nacional de Saúde (Conselho Nacional de Saúde, 1996).

Compuseram os aspectos éticos da pesquisa os documentos:

a) Solicitação de autorização da direção dos serviços por meio da Carta de Autorização da Instituição (anexo IV);

b) Solicitação do consentimento dos informantes do questionário por meio do Termo de Consentimento Livre e Esclarecido (anexo V);

c) Parecer de Aprovação da Comissão de Ética da Escola de Enfermagem da Universidade de São Paulo (anexo VI);

d) Carta de apresentação da pesquisa e pesquisadora (anexo VII), bem como os objetivos do estudo, o caráter de livre escolha de participação e instruções para o preenchimento e devolução do questionário e documentos anexos. 


\section{Procedimento de análise dos dados}

As informações coletadas foram armazenadas em um banco de dados montado no Microsoft Excel, a fim de facilitar o tratamento estatístico feito pelo programa Intercooled Estata $7.0^{*}$ caracterizando a análise quantitativa dos dados obtidos.

A análise também esteve voltada à caracterização do laboratório e dos recursos humanos atuantes nos setores de coleta de exames dos serviços, bem como às atividades desenvolvidas pelos agentes desse setor, destacando-se a enfermagem. Estes aspectos foram analisados com base no referencial teórico adotado, particularmente, quanto às categorias analíticas processo de trabalho, divisão de trabalho e recursos humanos em saúde. Sob este aspecto, os resultados foram analisados de forma qualitativa.

\footnotetext{
* Intercooled Estata 7.0 - programa estatístico de tratamento de dados utilizado nesta pesquisa
} 


\section{RESULTADOS}

Os resultados foram apresentados seguindo os três tópicos investigados: a caracterização dos laboratórios, dos recursos humanos e das atividades desenvolvidas pelos trabalhadores do setor de coleta de exames.

Convém relembrar que a população de estudo foi composta por 168 laboratórios e unidades básicas de saúde que possuíam o setor de coleta de exames. Deste total, responderam o questionário apenas $45(26,8 \%)$ serviços, que compuseram a amostra de estudo desta pesquisa, configurada na modalidade de amostra por conveniência. 


\section{A) - CARACTERIZAÇÃO DOS LABORATÓRIOS ESTUDADOS}

Tabela 1 - Distribuição dos laboratórios estudados, segundo categoria profissional dos informantes. Município de São Paulo, 2003

\begin{tabular}{lcc}
\hline Categoria profissional dos & \multicolumn{2}{c}{ Laboratórios } \\
informantes & $\mathbf{N}^{\circ}$ & $\%$ \\
\hline Auxiliar de Enfermagem & 1 & 2,2 \\
Biólogo & 4 & 8,9 \\
Biomédico & 14 & 31,1 \\
Enfermeiro & 8 & 17,8 \\
Enfermeiro e Médico & 2 & 4,4 \\
Farmacêutico-Bioquímico & 3 & 6,7 \\
Médico & 4 & 8,9 \\
Médico e Biomédico & 1 & 2,2 \\
Técnico de Laboratório & 1 & 2,2 \\
Sem informação & 7 & 15,6 \\
\hline Total & $\mathbf{4 5}$ & $\mathbf{1 0 0}$ \\
\hline
\end{tabular}

Quanto à categoria do profissional do informante, que respondeu o questionário, observa-se maior freqüência no biomédico $14(31,1 \%)$, pelo enfermeiro $8(17,8 \%)$ considerando-os isoladamente. Estes responderam o questionário enviado para a coleta de dados com outra categoria profissional, o que resulta na freqüência de 15 (33,3\%) aos biomédicos e 10 $(22,2 \%)$ aos os enfermeiros. 
Tabela 2 - Distribuição dos laboratórios estudados, segundo tipo de unidade. Município de São Paulo, 2003

\begin{tabular}{lcc}
\hline Tipo de unidade & \multicolumn{2}{c}{ Laboratórios } \\
& $\mathbf{N}^{\mathbf{0}}$ & $\mathbf{\%}$ \\
\hline Independente & 36 & 80 \\
Filial & 8 & 17,8 \\
Sem informação & 1 & 2,2 \\
\hline Total & $\mathbf{4 5}$ & $\mathbf{1 0 0}$ \\
\hline
\end{tabular}

Quanto ao tipo de unidade laboratorial, observa-se que $36(80 \%)$ da amostra estudada é do tipo independente, ou seja, não pertence a uma rede de filiais, enquanto $8(17,8 \%)$ fazem parte de uma rede.

Tabela 3 - Distribuição dos laboratórios estudados, segundo a natureza jurídica. Município de São Paulo, 2003

\begin{tabular}{lcc}
\hline Natureza jurídica & \multicolumn{2}{c}{ Laboratórios } \\
& No & \% \\
\hline Público & 15 & 33,3 \\
Privado & 30 & 66,7 \\
Fundação & - & - \\
\hline Total & $\mathbf{4 5}$ & $\mathbf{1 0 0}$ \\
\hline
\end{tabular}

Dos laboratórios que participaram do estudo, $30(66,7 \%)$ são instituições privadas e 15 (33,3\%) públicas; dois laboratórios da amostra indicaram duas naturezas jurídicas: fundação e pública; no entanto, foram consideradas como públicas por não terem apresentado diferenças quando analisadas como fundação ou como instituições públicas. 
Tabela 4 - Distribuição dos laboratórios estudados, segundo ano de início de funcionamento. Município de São Paulo, 2003

\begin{tabular}{lcc}
\hline Ano de início de & \multicolumn{2}{c}{ Laboratórios } \\
funcionamento & $\mathbf{N}^{\mathbf{2}}$ & $\%$ \\
\hline até 1969 & 5 & 11,1 \\
1970 a 1979 & 8 & 17,8 \\
1980 a 1989 & 10 & 22,2 \\
1990 a 1999 & 12 & 26,7 \\
2000 a 2002 & 1 & 2,2 \\
Sem informação & 9 & 20 \\
\hline Total & $\mathbf{4 5}$ & $\mathbf{1 0 0}$ \\
\hline
\end{tabular}

Os dados da Tabela 4 mostram que, dentre os laboratórios que responderam a esta questão, o maior número iniciou o funcionamento, nas décadas de 1980 e 1990, que somadas correspondem a 22 (48,9\%) instituições datadas dessa época.

Tabela 5 - Distribuição dos laboratórios estudados, segundo regime de atendimento. Município de São Paulo, 2003

\begin{tabular}{lcc}
\hline Regime de atendimento & \multicolumn{2}{c}{ Laboratórios } \\
& $\mathbf{N}^{\mathbf{0}}$ & $\%$ \\
\hline Somente Não Internação & 18 & 40 \\
Somente Internação & - & - \\
Ambos & 27 & 60 \\
\hline Total & $\mathbf{4 5}$ & $\mathbf{1 0 0}$ \\
\hline
\end{tabular}

Nota-se que $27(60 \%)$ dos laboratórios estudados têm ambos os regimes de atendimento: não-internação e internação, enquanto os demais 
$18(40 \%)$ só atendem sob o regime de não-internação. Nesta amostra, não há atendimento exclusivo em regime de internação.

Tabela 6 - Distribuição dos laboratórios estudados, segundo número aproximado de atendimentos mensais. Município de São Paulo, 2003

\begin{tabular}{|c|c|c|}
\hline \multirow{2}{*}{$\begin{array}{l}\text { Número aproximado de } \\
\text { atendimentos mensais }\end{array}$} & \multicolumn{2}{|c|}{ Laboratórios } \\
\hline & $\mathbf{N}^{\circ}$ & $\%$ \\
\hline até 500 & 8 & 17,8 \\
\hline 501 a 2.000 & 6 & 13,3 \\
\hline 2.001 a 4.000 & 7 & 15,6 \\
\hline 4.001 a 6.000 & 5 & 11,1 \\
\hline 6.001 a 8.000 & 2 & 4,4 \\
\hline 8.001 a 10.000 & 2 & 4,4 \\
\hline Mais 10.000 & 4 & 8,9 \\
\hline Sem informação & 11 & 24,4 \\
\hline TOTAL & 45 & 100 \\
\hline
\end{tabular}

A Tabela 6 evidencia que $8(17,8 \%)$ laboratórios estudados realizam até 500 atendimentos mensais. Dentre aqueles que fazem um número maior de atendimentos, observa-se uma concentração nas faixas compreendidas, entre 501 e 6.000, que somadas representam 18 (40\%) da amostra.

Apenas $4(8,9 \%)$ laboratórios executam mais de 10.000 atendimentos/mensais. Dentre estes, chama atenção um serviço com ambos os regimes de internação e não internação, com 51.622 atendimentos/mensais. 
Tabela 7 - Distribuição dos laboratórios estudados que possuem regime de não internação, segundo período de atendimento do setor de coleta de exames. Município de São Paulo, 2003

\begin{tabular}{llcc}
\hline Regime de & Período de atendimento & \multicolumn{2}{c}{ Laboratórios } \\
Atendimento & & No $^{\circ}$ & \% \\
\hline \multicolumn{1}{c}{ Não Internação } & Manhã & 17 & 37,8 \\
& Manhã +Tarde & 24 & 53,3 \\
& Manhã +Tarde +Noite & 3 & 6,7 \\
& Sem informação & 1 & 2,2 \\
\cline { 2 - 4 } & TOTAL & $\mathbf{4 5}$ & $\mathbf{1 0 0}$ \\
\hline
\end{tabular}

Tabela 8 - Distribuição dos laboratórios estudados que possuem regime de internação, segundo período de atendimento do setor de coleta de exames. Município de São Paulo, 2003

\begin{tabular}{llcc}
\hline $\begin{array}{l}\text { Regime de } \\
\text { Atendimento }\end{array}$ & Período de atendimento & \multicolumn{2}{c}{ Laboratórios } \\
& & $\mathbf{N}^{\mathbf{0}}$ & $\mathbf{\%}$ \\
\hline \multirow{3}{*}{ Internação } & Manhã & 4 & 14,8 \\
& Manhã +Tarde & 4 & 14,8 \\
& Manhã +Tarde +Noite & 19 & 70,4 \\
\cline { 2 - 4 } & TOTAL & $\mathbf{2 7}^{*}$ & $\mathbf{1 0 0}$ \\
\hline
\end{tabular}

${ }^{*}$ O valor total de 27 (60\%) deve-se ao fato de que 18 (40\%) laboratórios não atendem em regime de internação, conforme mostra a Tabela 5.

Os dados das Tabelas 7 e 8 mostram que o período de atendimento aos pacientes/clientes em regime de não-internação, ou seja, em serviços ambulatoriais é feito majoritariamente durante manhã e tarde $24(53,3 \%)$, e os serviços com atendimento em regime de internação, 19 (70,4\%) realizam a coleta nos três períodos.

Observa-se, também que $4(14,8 \%)$ dos laboratórios em regime de internação fazem as coletas de exames somente no período matutino. 
Tabela 9 - Distribuição dos laboratórios estudados, segundo tipo de cliente. Município de São Paulo, 2003

\begin{tabular}{lcc}
\hline Tipo de cliente & \multicolumn{2}{c}{ Laboratórios } \\
& $\mathbf{N}^{\circ}$ & $\mathbf{\%}$ \\
\hline Interna & 1 & 2,2 \\
Externa & 12 & 26,7 \\
Ambas & 27 & 60 \\
Sem informação & 5 & 11,1 \\
\hline TOTAL & $\mathbf{4 5}$ & $\mathbf{1 0 0}$ \\
\hline
\end{tabular}

Quanto ao tipo de cliente, 27 (60\%) dos laboratórios estudados executam coleta de exames tanto em cliente externo como em interno, enquanto $1(2,2 \%)$ atende só cliente interno e $12(26,7 \%)$, só externo.

Tabela 10 - Distribuição dos laboratórios estudados, segundo tipo de análises clínicas. Município de São Paulo, 2003

\begin{tabular}{lcc}
\hline Tipo de análises clínicas & \multicolumn{2}{c}{ Laboratórios } \\
& $\mathbf{N}^{\mathbf{0}}$ & $\%$ \\
\hline Bioquímica+Hematologia & 3 & 6,7 \\
Bioquímica+Hematologia+Biologia Molecular & 1 & 2,2 \\
Bioquímica+Hematologia+Outros & 2 & 4,4 \\
Bioquímica+Hematologia+Imunologia+Microbiologia & 13 & 28,9 \\
Bioquímica+Hematologia+Microbiologia+Outros & 1 & 2,2 \\
$\begin{array}{l}\text { Bioquímica+Hematologia+Imunologia+Biologia Molecular } \\
+ \text { Outros }\end{array}$ & 1 & 2,2 \\
$\begin{array}{l}\text { Bioquímica+Hematologia+Imunologia+Microbiologia+Outros } \\
\text { Bioquímica+Hematologia+ Imunologia + Biologia Molecular }\end{array}$ & 16 & 35,6 \\
+ Microbiologia+Outros & 7 & 15,6 \\
Hematologia+Biologia Molecular+Microbiologia & 1 & 2,2 \\
\hline TOTAL & $\mathbf{4 5}$ & $\mathbf{1 0 0}$ \\
\hline
\end{tabular}


Nos dados da Tabela 10, notam-se que 45 (100\%) dos laboratórios estudados realizam exames de hematologia e $44(97,8 \%)$ de bioquímica. A maioria das instituições faz, também, exames de microbiologia, 38 (84,5\%), imunologia, 37 (82,3\%), e outros tipos de análises laboratoriais, 27 (60\%). Dentre estes, a biologia molecular é o exame realizado com menor freqüência: $10(22,2 \%)$.

Tabela 11 - Distribuição dos laboratórios estudados, segundo outros tipos de análises clínicas. Município de São Paulo, 2003

\begin{tabular}{lcc}
\hline Outros tipos de análises clínicas & \multicolumn{2}{c}{ Laboratórios } \\
& $\mathbf{N}^{\circ}$ & $\%$ \\
\hline Não têm outras análises & 18 & 40 \\
Urinálise & 2 & 4,4 \\
Urinálise+Hormônios+Citometria de Fluxo & 1 & 2,2 \\
Urinálise+Parasitologia & 4 & 8,9 \\
Urinálise+Parasitologia+Hormônios & 4 & 8,9 \\
Urinálise+Parasitologia+Hormônios+Anatomia Patológica & 1 & 2,2 \\
Parasitologia & 2 & 4,4 \\
Parasitologia+Hormônios+Líquor & 1 & 2,2 \\
Parasitologia+Citogenética+Toxicologia+Hemostasia+ & 1 & 2,2 \\
Anatomia Patológica & & \\
Hormônios & 2 & 4,4 \\
Citologia & 1 & 2,2 \\
Citologia+Líquor & 1 & 2,2 \\
Citologia+Genética & 1 & 2,2 \\
Sem informação & 6 & 13,3 \\
\hline TOTAL & 45 & $\mathbf{1 0 0}$ \\
\hline
\end{tabular}

Dentre os $27(60 \%)$ laboratórios que informaram realizar outros tipos de análises clínicas, os que aparecem com maior freqüência são 
parasitologia $13(28,9 \%)$ e urinálise $12(26,7 \%)$, e, com menor referência, as análises clínicas de toxicologia, hemostasia, genética, citogenética e citometria de fluxo, cada uma destas realizada em apenas 1 (2,2\%) laboratório.

Tabela 12 - Distribuição dos laboratórios estudados, segundo realização de treinamento de pessoal de coleta de exames. Município de São Paulo, 2003

\begin{tabular}{lcc}
\hline Treinamento de pessoal & \multicolumn{3}{c}{ Laboratórios } \\
& $\mathbf{N}^{\mathbf{0}}$ & $\mathbf{\%}$ \\
\hline Sim & 37 & 82,2 \\
Não & 7 & 15,6 \\
Sem informação & 1 & 2,2 \\
\hline TOTAL & $\mathbf{4 5}$ & $\mathbf{1 0 0}$ \\
\hline
\end{tabular}

Na Tabela 12 chama atenção o fato de 7 (15,6\%) laboratórios não executarem treinamento de pessoal de coleta de exames. Os demais 37 $(82,2 \%)$ serviços estudados fazem treinamento. 
Tabela 13 - Distribuição dos laboratórios estudados, segundo a carga horária de treinamento de pessoal de coleta de exames. Município de São Paulo, 2003

\begin{tabular}{lcr}
\hline Carga horária de treinamento & \multicolumn{2}{c}{ Laboratórios } \\
& $\mathbf{N}^{\mathbf{0}}$ & $\%$ \\
\hline Não há & 7 & 15,6 \\
até $10 \mathrm{~h}$ & 5 & 11,1 \\
$11-20 \mathrm{~h}$ & 4 & 8,9 \\
$21-30 \mathrm{~h}$ & 2 & 4,4 \\
$31-40 \mathrm{~h}$ & 2 & 4,4 \\
$41-50 \mathrm{~h}$ & 1 & 2,2 \\
$51-100$ h & 2 & 4,4 \\
$101-150$ h & 2 & 4,4 \\
$2,5-3$ meses & 2 & 4,4 \\
$11-6$ h ao Ano & 2 & 4,4 \\
$2-7$ h ao Mês & 5 & 11,1 \\
Variável & 4 & 8,9 \\
Sem informação & 7 & 15,6 \\
\hline TOTAL & $\mathbf{4 5}$ & $\mathbf{1 0 0}$ \\
\hline
\end{tabular}

Os dados obtidos revelam que cerca de 20 (44,4\%) laboratórios realizam um treinamento único e pontual, não demonstrando a existência de capacitação continuada para a coleta de exames. A carga horária deste treinamento pontual mostra uma expressiva variação que pode ser de menos de 10 a 150 horas.

Apenas $7(15,6 \%)$ instituições informaram realizar treinamento de pessoal de coleta de exames, mantendo uma carga horária periódica mensal ou anual.

Chama atenção, também, o fato de que 4 (8,9\%) laboratórios não tenham uma carga horária de treinamento definida. 
Tabela 14 - Distribuição dos laboratórios estudados, segundo profissional responsável pelo treinamento de pessoal de coleta de exames. Município de São Paulo, 2003

\begin{tabular}{lcc}
\hline Profissional responsável pelo treinamento & \multicolumn{2}{c}{ Laboratórios } \\
& $\mathbf{N}^{\mathbf{0}}$ & $\%$ \\
\hline Não há & 7 & 15,6 \\
Fornecedor de material de laboratório & 1 & 2,2 \\
Biólogo & 2 & 4,4 \\
Biomédico & 6 & 13,3 \\
Enfermeiro & 9 & 20 \\
Enfermeiro + Auxiliar de Enfermagem & 1 & 2,2 \\
Enfermeiro + Fornecedor de seringa & 1 & 2,2 \\
Farmacêutico-Bioquímico & 2 & 4,4 \\
Médico & 2 & 4,4 \\
Técnico de Laboratório & 1 & 2,2 \\
Sem informação & 13 & 28,9 \\
\hline TOTAL & $\mathbf{4 5}$ & $\mathbf{1 0 0}$ \\
\hline
\end{tabular}

Dentre os profissionais responsáveis pelo treinamento de pessoal de coleta de exames, o enfermeiro aparece com maior freqüência $11(24,4 \%)$, seguido pelo biomédico 6 (13,3\%). Convém salientar que em 1 (2,2\%) laboratório o treinamento está sob a responsabilidade apenas de uma empresa fornecedora de materiais de laboratório, sem a participação de outro profissional da instituição.

O profissional técnico de laboratório aparece, também, como o responsável pelo treinamento em 1 (2,2\%) serviço. 
Tabela 15 - Distribuição dos laboratórios estudados, segundo realização de coleta de exames domiciliares. Município de São Paulo, 2003

\begin{tabular}{lcc}
\hline Coleta de exames & \multicolumn{2}{c}{ Laboratórios } \\
domiciliares & $\mathbf{N}^{\mathbf{0}}$ & $\%$ \\
\hline Não & 23 & 51,1 \\
Sim & 22 & 48,9 \\
\hline TOTAL & $\mathbf{4 5}$ & $\mathbf{1 0 0}$ \\
\hline
\end{tabular}

Dos 45 laboratórios estudados, a maioria $23(51,1 \%)$ não executa coleta domiciliar e $22(48,9 \%)$ realiza.

Tabela 16 - Distribuição dos laboratórios estudados, segundo profissional responsável pela coleta de exames domiciliares. Município de São Paulo, 2003

\begin{tabular}{lcc}
\hline Profissional responsável pela coleta de & \multicolumn{2}{c}{ Laboratórios } \\
exames domiciliares & No & $\%$ \\
\hline Não há & 23 & 51,1 \\
Auxiliar de Enfermagem & 2 & 4,4 \\
Biólogo & 1 & 2,2 \\
Biomédico & 5 & 11,1 \\
Enfermeiro & 4 & 8,9 \\
Farmacêutico-Bioquímico & 2 & 4,4 \\
Médico & 1 & 2,2 \\
Técnico de Laboratório & 1 & 2,2 \\
Terceiros & 2 & 4,4 \\
Sem informação & 4 & 8,9 \\
\hline TOTAL & $\mathbf{4 5}$ & $\mathbf{1 0 0}$ \\
\hline
\end{tabular}

O profissional que mais apareceu como responsável pela coordenação da coleta domiciliar é o biomédico $5(11,1 \%)$, seguido pelo 
enfermeiro 4 (8,9\%). Em 2 (4,4\%) laboratórios, esta atividade é realizada por serviços terceirizados. O auxiliar de enfermagem aparece como responsável em $2(4,4 \%)$ instituições e o técnico de laboratório tem essa responsabilidade em $1(2,2 \%)$ dos serviços estudados.

\section{B) - CARACTERIZAÇÃO DOS RECURSOS HUMANOS}

Tabela 17 - Distribuição dos laboratórios estudados, segundo categoria profissional existente no setor de coleta de exames. Município de São Paulo, 2003

\begin{tabular}{|c|c|c|c|c|c|c|}
\hline \multirow[t]{2}{*}{ Categoria profissional existente } & \multicolumn{6}{|c|}{ Laboratórios } \\
\hline & Sim & $\%$ & Não & $\%$ & TOTAL & $\%$ \\
\hline Auxiliar de Enfermagem & 35 & 77,8 & 10 & 22,2 & 45 & 100 \\
\hline Auxiliar de Patologia Clínica & 5 & 11,1 & 40 & 88,9 & 45 & 100 \\
\hline Auxiliar de Laboratório & 19 & 42,2 & 26 & 57,8 & 45 & 100 \\
\hline Biólogo & 14 & 31,1 & 31 & 68,9 & 45 & 100 \\
\hline Biomédico & 23 & 51,1 & 22 & 48,9 & 45 & 100 \\
\hline Enfermeiro & 15 & 33,3 & 30 & 66,7 & 45 & 100 \\
\hline Médico & 12 & 26,7 & 33 & 73,3 & 45 & 100 \\
\hline Farmacêutico- Bioquímico & 12 & 26,7 & 33 & 73,3 & 45 & 100 \\
\hline Técnico de Patologia Clínica & 8 & 17,8 & 37 & 82,2 & 45 & 100 \\
\hline Técnico de Enfermagem & 6 & 13,3 & 39 & 86,7 & 45 & 100 \\
\hline Técnico de Laboratório & 16 & 35,6 & 29 & 64,4 & 45 & 100 \\
\hline $\begin{array}{l}\text { Outros Trabalhadores Sem } \\
\text { Qualificação Técnica Formal }\end{array}$ & 3 & 6,7 & 42 & 93,3 & 45 & 100 \\
\hline
\end{tabular}

Quanto aos profissionais atuantes na coleta de exames, a Tabela 17 mostra que é o auxiliar de enfermagem, referido em $35(77,8 \%)$ serviços, 
que mais aparece com qualificação profissional de nível médio, seguido pelo auxiliar de laboratório citado em 19 (42,2\%) instituições.

Quanto aos profissionais de nível técnico, aparece com maior freqüência o técnico de laboratório, 16 (35,6\%), seguidos pelo técnico de patologia clínica, 8 (17,8\%). O técnico de enfermagem é referido apenas por $6(13,3 \%)$ laboratórios.

O profissional de nível superior mais freqüente é o biomédico que aparece em 23 (51,1\%) laboratórios, seguido pelo enfermeiro em 15 (33,3\%) e pelo biólogo em $14(31,1)$ instituições.

Convém salientar que $3(6,7 \%)$ laboratórios têm em seu quadro de coleta de exames outros trabalhadores sem qualificação técnica formal e regular ao exercício desse trabalho. 


\section{C) - CARACTERIZAÇÃO DAS ATIVIDADES DESENVOLVIDAS}

No que se refere às atividades desenvolvidas no setor de coleta de exames em laboratórios de análises clínicas, os resultados são apresentados, distinguindo as atividades de assistência e gerenciamento.

Apesar da atividade de treinamento em serviço ser, usualmente, considerada de natureza gerencial; neste estudo, será apresentada separadamente, visto ter sido identificado que não ocorre em 7 (15,6\%) laboratórios.

Assim sendo, foram consideradas atividades assistenciais: recepção de amostras já coletas; coleta de exames em geral (sangue, urina, fezes, culturas, micológicos, etc.); coleta de exames de maior complexidade (provas funcionais, teste do pezinho, etc.); auxílio em procedimentos médicos (mielograma, líquor, etc.); gasometria arterial; manipulação de cateteres centrais; orientações sobre os exames; encaminhamento das amostras coletadas ao setor técnico; coleta domiciliar. Como atividades gerenciais, foram considerados: teste de materiais utilizados na coleta de exames; supervisão; coordenação; planejamento das ações de enfermagem; participação na seleção de recursos humanos de enfermagem; previsão e provisão de pessoal; elaboração de escalas. 
Tabela 18- Distribuição dos laboratórios estudados, segundo realização de atividades do enfermeiro no setor de coleta de exames. Município de São Paulo, 2003

\begin{tabular}{|c|c|c|c|c|c|c|}
\hline \multirow{2}{*}{ Atividades do enfermeiro } & \multicolumn{6}{|c|}{ Laboratórios } \\
\hline & Sim & $\%$ & Não & $\%$ & Total & $\%$ \\
\hline Recepção de amostras já coletas & 5 & 11,1 & 40 & 88,9 & 45 & 100 \\
\hline $\begin{array}{l}\text { Coleta de exames, em geral } \\
\text { (sangue, urina, fezes, culturas, } \\
\text { micológicos, etc.) }\end{array}$ & 10 & 22,2 & 35 & 77,8 & 45 & 100 \\
\hline $\begin{array}{l}\text { Coleta de exames de maior } \\
\text { complexidade (provas funcionais, } \\
\text { teste do pezinho, etc.) }\end{array}$ & 7 & 15,6 & 38 & 84,4 & 45 & 100 \\
\hline $\begin{array}{l}\text { Auxílio em procedimentos médicos } \\
\text { (mielograma, líquor, etc.) }\end{array}$ & 9 & 20 & 36 & 80 & 45 & 100 \\
\hline Gasometria arterial & 11 & 24,4 & 34 & 75,6 & 45 & 100 \\
\hline Manipulação de cateteres centrais & 9 & 20 & 36 & 80 & 45 & 100 \\
\hline Orientações sobre os exames & 12 & 26,7 & 33 & 73,3 & 45 & 100 \\
\hline $\begin{array}{l}\text { Encaminhamento das amostras } \\
\text { coletadas ao setor técnico }\end{array}$ & 2 & 4,4 & 43 & 95,6 & 45 & 100 \\
\hline Coleta domiciliar & 2 & 4,4 & 43 & 95,6 & 45 & 100 \\
\hline $\begin{array}{l}\text { Teste de materiais utilizados na } \\
\text { coleta de exames }\end{array}$ & 9 & 20 & 36 & 80 & 45 & 100 \\
\hline Supervisão & 15 & 33,3 & 30 & 66,7 & 45 & 100 \\
\hline Coordenação & 14 & 31,1 & 31 & 68,9 & 45 & 100 \\
\hline $\begin{array}{l}\text { Planejamento ações de } \\
\text { enfermagem }\end{array}$ & 17 & 37,8 & 28 & 62,2 & 45 & 100 \\
\hline $\begin{array}{l}\text { Participação na seleção recursos } \\
\text { humanos em enfermagem }\end{array}$ & 14 & 31,1 & 31 & 68,9 & 45 & 100 \\
\hline Previsão e provisão de pessoal & 12 & 26,7 & 33 & 73,3 & 45 & 100 \\
\hline Elaboração de escalas & 16 & 35,6 & 29 & 64,4 & 45 & 100 \\
\hline Treinamento em serviço & 16 & 35,6 & 29 & 64,4 & 45 & 100 \\
\hline
\end{tabular}


A Tabela 18 mostra que a atuação do enfermeiro está mais concentrada nas atividades de gerenciamento. Considerados os 45 laboratórios estudados, a percentagem das atividades gerenciais do enfermeiro varia de $9(20 \%)$ a $17(37,8 \%)$ serviços. Por outro lado, as atividades assistenciais variam de $2(4,4 \%)$ a $12(26,7 \%)$ laboratórios e o treinamento em serviço é executado por este profissional em 16 ( 35,6\%) instituições.

Dentre as atividades assistenciais do enfermeiro, predominam: orientações sobre os exames, realizadas em 12 (26,7\%) serviços; gasometria arterial, em $11(24,4 \%)$ laboratórios e coleta de exames em geral, em $10(22,2 \%)$ instituições.

Dentre as atividades gerenciais, predominam: planejamento das ações de enfermagem, realizado em 17 (37,8\%) serviços; elaboração das escalas, em 16 (35,6\%) laboratórios e supervisão, em 15 (33,3\%) instituições. 
Tabela 19- Distribuição dos laboratórios estudados, segundo realização de atividades do técnico de enfermagem no setor de coleta de exames. Município de São Paulo, 2003

\begin{tabular}{|c|c|c|c|c|c|c|}
\hline \multirow{2}{*}{$\begin{array}{c}\text { Atividades do técnico de } \\
\text { enfermagem }\end{array}$} & \multicolumn{6}{|c|}{ Laboratórios } \\
\hline & Sim & $\%$ & Não & $\%$ & Total & $\%$ \\
\hline Recepção de amostras já coletas & 4 & 8,9 & 41 & 91,1 & 45 & 100 \\
\hline $\begin{array}{l}\text { Coleta de exames, em geral } \\
\text { (sangue, urina, fezes, culturas, } \\
\text { micológicos, etc.) }\end{array}$ & 9 & 20 & 36 & 80 & 45 & 100 \\
\hline $\begin{array}{l}\text { Coleta de exames de maior } \\
\text { complexidade (provas funcionais, } \\
\text { teste do pezinho, etc.) }\end{array}$ & 2 & 4,4 & 43 & 95,6 & 45 & 100 \\
\hline $\begin{array}{l}\text { Auxílio em procedimentos médicos } \\
\text { (mielograma, líquor, etc.) }\end{array}$ & 4 & 8,9 & 41 & 91,1 & 45 & 100 \\
\hline Gasometria arterial & 1 & 2,2 & 44 & 97,8 & 45 & 100 \\
\hline Manipulação de cateteres centrais & 1 & 2,2 & 44 & 97,8 & 45 & 100 \\
\hline Orientações sobre os exames & 3 & 6,7 & 42 & 93,3 & 45 & 100 \\
\hline $\begin{array}{l}\text { Encaminhamento das amostras } \\
\text { coletadas ao setor técnico }\end{array}$ & 4 & 8,9 & 41 & 91,1 & 45 & 100 \\
\hline Coleta domiciliar & 2 & 4,4 & 43 & 95,6 & 45 & 100 \\
\hline $\begin{array}{l}\text { Teste de materiais utilizados na } \\
\text { coleta de exames }\end{array}$ & 2 & 4,4 & 43 & 95,6 & 45 & 100 \\
\hline Supervisão & 2 & 4,4 & 43 & 95,6 & 45 & 100 \\
\hline Coordenação & 1 & 2,2 & 44 & 97,8 & 45 & 100 \\
\hline $\begin{array}{l}\text { Planejamento ações de } \\
\text { enfermagem }\end{array}$ & - & - & 45 & 100 & 45 & 100 \\
\hline $\begin{array}{l}\text { Participação na seleção recursos } \\
\text { humanos em enfermagem }\end{array}$ & - & - & 45 & 100 & 45 & 100 \\
\hline Previsão e provisão de pessoal & - & - & 45 & 100 & 45 & 100 \\
\hline Elaboração de escalas & - & - & 45 & 100 & 45 & 100 \\
\hline Treinamento em serviço & 2 & 4,4 & 43 & 95,6 & 45 & 100 \\
\hline
\end{tabular}


O técnico de enfermagem executa sobretudo atividades assistenciais, pois, considerados os 45 laboratórios estudados, observa-se que estas ações variam de $1(2,2 \%)$ a $9(20 \%)$ serviços. Por outro lado, as atividades gerencias variam de $1(2,2 \%)$ a $2(4,4 \%)$ laboratórios e o treinamento é realizado por este profissional em $2(4,4 \%)$ instituições.

Dentre as atividades assistenciais do técnico de enfermagem, predominam: coleta de exames em geral, realizada em $9(20 \%)$ serviços, seguida da recepção de amostras já coletadas, auxilio em procedimentos médicos e encaminhamento das amostras coletadas, realizadas em 4 (8,9\%) laboratórios.

Convém salientar que a atividade de gasometria arterial é privativa do enfermeiro e é executada pelo técnico de enfermagem em 1 (2,2\%) laboratório da amostra estudada.

Dentre as atividades gerencias, predominam: teste de materiais e supervisão, realizadas em $2(4,4 \%)$ instituições. 
Tabela 20 - Distribuição dos laboratórios estudados, segundo realização de atividades do auxiliar de enfermagem no setor de coleta de exames. Município de São Paulo, 2003

\begin{tabular}{|c|c|c|c|c|c|c|}
\hline \multirow{2}{*}{$\begin{array}{c}\text { Atividades do auxiliar de } \\
\text { enfermagem }\end{array}$} & \multicolumn{6}{|c|}{ Laboratórios } \\
\hline & Sim & $\%$ & Não & $\%$ & Total & $\%$ \\
\hline Recepção de amostras já coletas & 22 & 48,9 & 23 & 51,1 & 45 & 100 \\
\hline $\begin{array}{l}\text { Coleta de exames, em geral } \\
\text { (sangue, urina, fezes, culturas, } \\
\text { micológicos, etc.) }\end{array}$ & 35 & 77,8 & 10 & 22,2 & 45 & 100 \\
\hline $\begin{array}{l}\text { Coleta de exames de maior } \\
\text { complexidade (provas funcionais, } \\
\text { teste do pezinho, etc.) }\end{array}$ & 13 & 28,9 & 32 & 71,1 & 45 & 100 \\
\hline $\begin{array}{l}\text { Auxílio em procedimentos médicos } \\
\text { (mielograma, líquor, etc.) }\end{array}$ & 11 & 24,4 & 34 & 75,6 & 45 & 100 \\
\hline Gasometria arterial & 3 & 6,7 & 42 & 93,3 & 45 & 100 \\
\hline Manipulação de cateteres centrais & 4 & 8,9 & 41 & 91,1 & 45 & 100 \\
\hline Orientações sobre os exames & 22 & 48,9 & 23 & 51,1 & 45 & 100 \\
\hline $\begin{array}{l}\text { Encaminhamento das amostras } \\
\text { coletadas ao setor técnico }\end{array}$ & 24 & 53,3 & 21 & 46,7 & 45 & 100 \\
\hline Coleta domiciliar & 10 & 22,2 & 35 & 77,8 & 45 & 100 \\
\hline $\begin{array}{l}\text { Teste de materiais utilizados na } \\
\text { coleta de exames }\end{array}$ & 9 & 20 & 36 & 80 & 45 & 100 \\
\hline Supervisão & 1 & 2,2 & 44 & 97,8 & 45 & 100 \\
\hline Coordenação & 1 & 2,2 & 44 & 97,8 & 45 & 100 \\
\hline $\begin{array}{l}\text { Planejamento ações de } \\
\text { enfermagem }\end{array}$ & 1 & 2,2 & 44 & 97,8 & 45 & 100 \\
\hline $\begin{array}{l}\text { Participação na seleção recursos } \\
\text { humanos em enfermagem }\end{array}$ & 1 & 2,2 & 44 & 97,8 & 45 & 100 \\
\hline Previsão e provisão de pessoal & - & - & 45 & 100 & 45 & 100 \\
\hline Elaboração de escalas & 1 & 2,2 & 44 & 97,8 & 45 & 100 \\
\hline Treinamento em serviço & 3 & 6,7 & 42 & 93,3 & 45 & 100 \\
\hline
\end{tabular}


O auxiliar de enfermagem executa sobretudo atividades assistenciais, pois, considerados os 45 laboratórios estudados, observa-se que estas ações variam de $3(6,7 \%)$ a $35(77,8 \%)$ laboratórios. Por outro lado, as atividades gerencias variam de $1(2,2 \%)$ a $9(20 \%)$ serviços e o treinamento é realizado por este agente em $3(6,7)$ instituições.

Dentre as atividades assistenciais realizadas pelo auxiliar de enfermagem, predominam: coleta de exames em geral, realizada em 35 $(77,8 \%)$ serviços, seguida de encaminhamento das amostras coletadas, em $24(53,3 \%)$ laboratórios, orientações sobre os exames e recepção das amostras coletadas, em 22 (48,9\%) instituições.

Assim como o técnico de enfermagem, o auxiliar de enfermagem executa a técnica de punção de gasometria arterial em 3 (6,7\%) instituições.

Dentre as atividades de gerenciamento aparece com maior freqüência o teste de materiais, realizado em 9 (20\%) serviços. 
Tabela 21 - Distribuição dos laboratórios estudados, segundo realização de atividades de outros trabalhadores sem qualificação técnica formal e regular no setor de coleta de exames. Município de São Paulo, 2003

\section{Atividades de outros trabalhadores sem qualificação técnica formal e regular}

Recepção de amostras já coletas

Coleta de exames, em geral (sangue, urina, fezes, culturas, micológicos, etc.)

Coleta de exames de maior complexidade (provas funcionais, teste do pezinho, etc.)

Auxílio em procedimentos médicos (mielograma, líquor, etc.)

Gasometria arterial

Manipulação de cateteres centrais

Orientações sobre os exames

Encaminhamento das amostras coletadas ao setor técnico

Coleta domiciliar

Teste de materiais utilizados na coleta de exames

Supervisão

Coordenação

Planejamento ações de enfermagem

Participação na seleção recursos humanos em enfermagem

Previsão e provisão de pessoal

Elaboração de escalas

Treinamento em serviço

\begin{tabular}{rrrrrrr}
\multicolumn{8}{c}{ Laboratórios } \\
\hline Sim & $\%$ & Não & $\%$ & Total & $\%$ \\
& & & & & \\
13 & 28,9 & 32 & 71,1 & $\mathbf{4 5}$ & $\mathbf{1 0 0}$ \\
1 & 2,2 & 44 & 97,8 & $\mathbf{4 5}$ & $\mathbf{1 0 0}$
\end{tabular}

45100

45100

$-\quad 45100$

$45 \quad 100$

45100

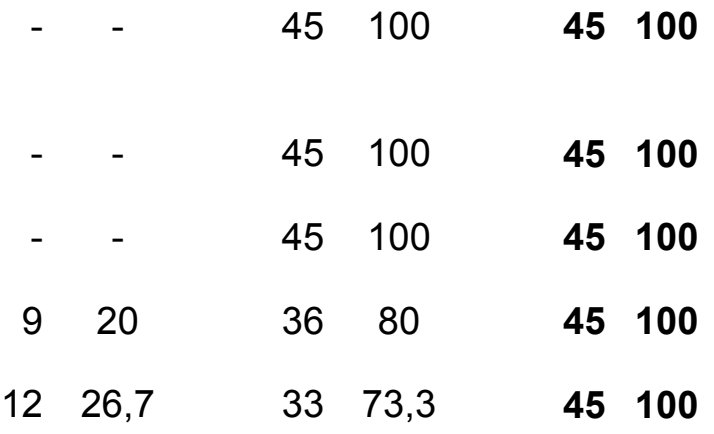

12,2

4497,8

$45 \quad 100$

$45 \quad 100$

$45 \quad 100$

$\begin{array}{rrrrrrr}- & - & 45 & 100 & \mathbf{4 5} & \mathbf{1 0 0} \\ 1 & 2,2 & 44 & 97,8 & \mathbf{4 5} & \mathbf{1 0 0} \\ - & - & 45 & 100 & \mathbf{4 5} & \mathbf{1 0 0} \\ & & & & & & \\ - & - & 45 & 100 & \mathbf{4 5} & \mathbf{1 0 0} \\ & & - & 45 & 100 & \mathbf{4 5} & \mathbf{1 0 0} \\ - & - & 45 & 100 & \mathbf{4 5} & \mathbf{1 0 0} \\ - & - & & & & & \\ - & - & 45 & 100 & \mathbf{4 5} & \mathbf{1 0 0}\end{array}$


Os trabalhadores sem qualificação técnica formal e regular desenvolvem predominantemente atividades relacionadas com a recepção de amostras já coletadas, realizada em 13 (28,9\%) laboratórios; encaminhamento das amostras coletadas, em 12 (26,7\%) serviços e orientações sobre os exames, e, 9 (20\%) instituições.

Quanto às atividades de gerenciamento, observa-se que os trabalhadores sem qualificação técnica formal e regular realizam a atividade de coordenação em 1 (2,2\%) laboratório, e não executam atividades de treinamento em nenhuma instituição estudada.

Convém ressaltar que o trabalhador sem qualificação técnica formal e regular é citado em apenas $3(6,7 \%)$ instituições estudadas (Tabela 17), porém, nos dados relacionados às atividades desenvolvidas pelos profissionais no setor de coleta de exames laboratoriais, este agente aparece em 13 (35,1\%) laboratórios. 
Tabela 22 - Distribuição dos laboratórios estudados, segundo realização de atividades de outros trabalhadores com nível superior no setor de coleta de exames. Município de São Paulo, 2003

\begin{tabular}{|c|c|c|c|c|c|c|}
\hline \multirow{2}{*}{$\begin{array}{l}\text { Atividades de outros } \\
\text { trabalhadores com nível superior }\end{array}$} & \multicolumn{6}{|c|}{ Laboratórios } \\
\hline & Sim & $\%$ & Não & $\%$ & Total & $\%$ \\
\hline Recepção de amostras já coletas & 14 & 31,1 & 31 & 68,9 & 45 & 100 \\
\hline $\begin{array}{l}\text { Coleta de exames, em geral } \\
\text { (sangue, urina, fezes, culturas, } \\
\text { micológicos, etc.) }\end{array}$ & 17 & 37,8 & 28 & 62,2 & 45 & 100 \\
\hline $\begin{array}{l}\text { Coleta de exames de maior } \\
\text { complexidade (provas funcionais, } \\
\text { teste do pezinho, etc.) }\end{array}$ & 10 & 22,2 & 35 & 77,8 & 45 & 100 \\
\hline $\begin{array}{l}\text { Auxílio em procedimentos médicos } \\
\text { (mielograma, líquor, etc.) }\end{array}$ & 5 & 11,1 & 40 & 88,9 & 45 & 100 \\
\hline Gasometria arterial & 9 & 20 & 36 & 80 & 45 & 100 \\
\hline Manipulação de cateteres centrais & 4 & 8,9 & 41 & 91,1 & 45 & 100 \\
\hline Orientações sobre os exames & 25 & 55,6 & 20 & 44,4 & 45 & 100 \\
\hline $\begin{array}{l}\text { Encaminhamento das amostras } \\
\text { coletadas ao setor técnico }\end{array}$ & 11 & 24,4 & 34 & 75,6 & 45 & 100 \\
\hline Coleta domiciliar & 5 & 11,1 & 40 & 88,9 & 45 & 100 \\
\hline $\begin{array}{l}\text { Teste de materiais utilizados na } \\
\text { coleta de exames }\end{array}$ & 17 & 37,8 & 28 & 62,2 & 45 & 100 \\
\hline Supervisão & 25 & 55,6 & 20 & 44,4 & 45 & 100 \\
\hline Coordenação & 28 & 62,2 & 17 & 37,8 & 45 & 100 \\
\hline $\begin{array}{l}\text { Planejamento ações de } \\
\text { enfermagem }\end{array}$ & 11 & 24,4 & 34 & 75,6 & 45 & 100 \\
\hline $\begin{array}{l}\text { Participação na seleção recursos } \\
\text { humanos em enfermagem }\end{array}$ & 15 & 33,3 & 30 & 66,7 & 45 & 100 \\
\hline Previsão e provisão de pessoal & 18 & 40 & 27 & 60 & 45 & 100 \\
\hline Elaboração de escalas & 17 & 37,8 & 28 & 62,2 & 45 & 100 \\
\hline Treinamento em serviço & 18 & 40 & 27 & 60 & 45 & 100 \\
\hline
\end{tabular}


Excluindo o enfermeiro, cujas atividades foram apresentadas anteriormente, os outros trabalhadores de nível superior desenvolvem tanto atividades assistenciais, como atividades gerenciais. Esses profissionais também executam ações de treinamento em 18 (40\%) instituições.

Considerada a totalidade dos laboratórios estudados, as atividades assistenciais dos trabalhadores de nível superior, variam de $4(8,9 \%)$ a 25 $(55,6 \%)$ serviços. As atividades gerenciais variam de $11(24,4 \%)$ a 28 $(62,2 \%)$ instituições e o treinamento é realizado por estes profissionais em $18(40 \%)$ laboratórios.

Dentre as atividades assistenciais, predominam: orientações sobre os exames, realizadas em 25 (55,6\%) serviços, seguidas de coleta de exames em geral, em 17 (37,8\%) laboratórios e recepção de amostras coletadas, em $14(31,1 \%)$ instituições.

Dentre as atividades gerenciais, predominam: coordenação, realizada em 28 (62,2\%) laboratórios; seguida por supervisão, em 25 (55,6\%) serviços e previsão e provisão de pessoal, em 18 (40\%) instituições. 
Tabela 23 - Distribuição dos laboratórios estudados, segundo existência de divisão de atividades assistenciais e gerenciais entre os trabalhadores de enfermagem no setor de coleta de exames. Município de São Paulo, 2003

\begin{tabular}{lcc}
\hline Existência de divisão de atividades & \multicolumn{2}{c}{ Laboratórios } \\
assistenciais e gerenciais entre os & No & $\%$ \\
trabalhadores de enfermagem & 19 & 42,2 \\
\hline Não & 16 & 35,6 \\
Sim & 8 & 17,8 \\
Não há pessoal de enfermagem & 2 & 4,4 \\
Sem informação & $\mathbf{4 5}$ & $\mathbf{1 0 0}$ \\
\hline TOTAL
\end{tabular}

A Tabela 23 mostra que não há divisão das atividades assistenciais e gerenciais entre os trabalhadores de enfermagem em 19 (42,2\%) laboratórios estudados, porém esta distinção existe em 16 (35,6\%) destes. 
Tabela 24 - Distribuição dos laboratórios estudados com profissionais de enfermagem, segundo divisão de atividades assistenciais e gerenciais entre estes no setor de coleta de exames. Município de São Paulo, 2003

\begin{tabular}{|c|c|c|c|c|c|c|c|c|c|c|}
\hline \multirow[t]{4}{*}{$\begin{array}{l}\text { Categoria } \\
\text { profissional }\end{array}$} & \multicolumn{10}{|c|}{$\begin{array}{c}\text { Divisão de atividades assistenciais e gerenciais entre os } \\
\text { profissionais de enfermagem }\end{array}$} \\
\hline & \multicolumn{2}{|c|}{ Não } & \multicolumn{6}{|c|}{ Sim } & \multicolumn{2}{|c|}{ TOTAL } \\
\hline & \multirow[b]{2}{*}{$\mathbf{N}^{\circ}$} & \multirow[b]{2}{*}{$\%$} & \multicolumn{2}{|c|}{ Assistencial } & \multicolumn{2}{|c|}{ Gerencial } & \multicolumn{2}{|c|}{ Ambas } & \multirow[b]{2}{*}{$\mathbf{N}^{\circ}$} & \multirow[b]{2}{*}{$\%$} \\
\hline & & & & $\%$ & $\mathbf{N}^{\circ}$ & $\%$ & $\mathbf{N}^{\circ}$ & $\%$ & & \\
\hline Enfermeiro & 3 & 20 & - & - & 4 & 26,7 & 8 & 53,3 & 15 & 100 \\
\hline $\begin{array}{l}\text { Técnico de } \\
\text { Enfermagem }\end{array}$ & - & - & 3 & 50 & 1 & 16,7 & 2 & 33,3 & 6 & 100 \\
\hline $\begin{array}{l}\text { Auxiliar de } \\
\text { Enfermagem }\end{array}$ & 19 & 54,3 & 14 & 40 & - & - & 2 & 5,7 & 35 & 100 \\
\hline
\end{tabular}

Os dados da Tabela 24 mostram, dentre as instituições estudadas que possuem profissionais de enfermagem no quadro de pessoal, $3(20 \%)$ informaram não divisão das atividades assistenciais e gerenciais entre os enfermeiros e 19 (54,3\%) referiram não haver esta distinção entre os auxiliares de enfermagem.

Dentre as instituições estudadas que informaram haver esta divisão de atividades, as ações exclusivamente assistenciais são praticadas pelo auxiliar de enfermagem em 14 (40\%) instituições, pelo técnico de enfermagem em 3 (50\%) serviços, enquanto o enfermeiro não tem ações unicamente assistenciais. Os enfermeiros só realizam atividades gerenciais em 4 (26,7\%) instituições, o técnico em 1 (16,7\%) serviço e o auxiliar não as realiza nos laboratórios pesquisados. Por outro lado, nota-se que o enfermeiro faz ambas atividades de assistência e de gerenciamento em 8 
$(53,3 \%)$ das instituições, o técnico de enfermagem em $2(33,3 \%)$ e o auxiliar de enfermagem, em 2 (5,7\%).

Tabela 25 - Distribuição dos laboratórios estudados, segundo inserção da equipe de enfermagem na estrutura organizacional. Município de São Paulo, 2003

\begin{tabular}{lcc}
\hline Inserção da equipe de enfermagem na & \multicolumn{2}{c}{ Laboratórios } \\
estrutura organizacional & No & $\%$ \\
\hline & & \\
Subordinação à área da enfermagem & 8 & 17,8 \\
Subordinação à direção do serviço & 11 & 24,4 \\
Subordinação à chefia do laboratório & 13 & 28,9 \\
Sem informação & 13 & 28,9 \\
\hline TOTAL & $\mathbf{4 5}$ & $\mathbf{1 0 0}$ \\
\hline
\end{tabular}

Relacionada à inserção na estrutura organizacional, a Tabela 25 mostra que a enfermagem está subordinada à chefia do próprio laboratório em $13(28,9 \%)$ das instituições estudadas, seguida pela subordinação à direção do serviço em $11(24,4 \%)$ e à área de enfermagem em $8(17,8 \%)$ dos serviços. 
Tabela 26 - Distribuição dos laboratórios estudados com resposta, segundo a qualificação profissional necessária para atuar no setor de coleta de exames. Município de São Paulo, 2003

\begin{tabular}{lcccccc}
\hline Qualificação profissional & \multicolumn{7}{c}{ Laboratórios } \\
\cline { 2 - 7 } necessária para atuar & Sim & $\%$ & Não & $\%$ & Total & \\
\hline Auxiliar de coleta & 2 & 5,3 & 36 & 94,7 & 38 & 100 \\
Auxiliar de enfermagem & 31 & 81,6 & 7 & 18,4 & 38 & 100 \\
Auxiliar de laboratório & 3 & 7,9 & 35 & 92,1 & 38 & 100 \\
Auxiliar de patologia clínica & 2 & 5,3 & 36 & 94,7 & 38 & 100 \\
Biólogo & 2 & 5,3 & 36 & 94,7 & 38 & 100 \\
Biomédico & 5 & 13,2 & 33 & 86,8 & 38 & 100 \\
Enfermeiro & 8 & 21,1 & 30 & 78,9 & 38 & 100 \\
Farmacêutico-bioquímico & 3 & 7,9 & 35 & 92,1 & 38 & 100 \\
Técnico de enfermagem & 11 & 28,9 & 27 & 71,1 & 38 & 100 \\
Técnico de laboratório & 12 & 31,6 & 26 & 68,4 & 38 & 100 \\
Técnico de patologia clínica & 1 & 2,6 & 37 & 97,4 & 38 & 100 \\
\hline
\end{tabular}

Inicialmente, cabe destacar que apenas 38 laboratórios responderam a questão relacionada à formação necessária para a atuação no setor de coleta.

Neste total, observa-se que o profissional mais requisitado para trabalhar no setor de coleta de exames é o auxiliar de enfermagem, referido por $31(81,6 \%)$ laboratórios. Em seguida, aparece o técnico de laboratório, referido por $12(31,6 \%)$ serviços. O técnico de enfermagem aparece quase na mesma proporção, ou seja, em $11(28,9 \%)$ instituições. Em relação ao nível superior, o enfermeiro é o profissional mais referido, constando em 8 (21,1\%) laboratórios, enquanto o biomédico é citado em 5 (13,2\%) instituições. 


\section{ANÁLISE DE DADOS}

No setor de coleta de exames, o processo de trabalho tem como finalidade a coleta de amostra biológica para processamento, cujo resultado contribui para o diagnóstico médico. Nesse processo, o objeto de trabalho, que é a matéria a ser transformada, é a amostra biológica e os instrumentos são todos os materiais específicos, as diferentes técnicas de coleta, a observação e a comunicação com os usuários.

Considerando esta caracterização genérica do processo de trabalho nos setores de coleta de exames para análise clínica, os resultados encontrados nesta pesquisa foram apresentados contemplando os três tópicos investigados: a particularização dos laboratórios, dos recursos humanos e das atividades desenvolvidas pelos trabalhadores do setor de coleta de exames.

A caracterização dos laboratórios busca apresentar o contexto em que o trabalho é executado; a distinção dos recursos humanos, por sua vez, traz a dimensão do agente do trabalho e as atividades consistem na expressão mais concreta do próprio processo de trabalho pesquisado. 


\section{A) - CARACTERIZAÇÃO DOS LABORATÓRIOS ESTUDADOS}

Inicialmente, vale destacar que a caracterização dos laboratórios estudados reflete apenas a realidade encontrada na amostra, pois trabalhouse com uma amostra por conveniência, ou seja, com os serviços que responderam ao instrumento de coleta de dados e não foram identificados dados na literatura que permitam descrever a população de laboratórios de análises clínicas do Município de São Paulo.

Os resultados mostram que, dentre os laboratórios estudados, predominam as instituições independentes, ou seja, que não pertencem a uma rede de filiais, com $36(80 \%)$ do total. Quanto à natureza jurídica, contata-se que a maioria 30 (66,7\%) é particular e 15 (33,3\%) pública.

Estes dados corroboram com as informações fornecidas pelo Anuário Estatístico de Saúde do Brasil (Ministério da Saúde, 2002), ao mostrar que $13 \%$ do total de estabelecimentos de saúde no País são serviços de apoio à diagnose e terapia, com predomínio do setor privado e marcante iniqüidade na distribuição geográfica, pois observa-se maior concentração na Região Sudeste (55\%).

Nos serviços pesquisados, $22(48,9 \%)$ foram fundados nas décadas de 1980 e 1990. No início de 1980, houve um grande desenvolvimento dos laboratórios, especialmente, nos aspectos relacionados às práticas seguras de coleta, manuseio e transporte de material, decorrentes do grande avanço tecnológico e do aparecimento da Síndrome da Imunodeficiência Adquirida que surge no início dos anos de 1980. Além disso, no começo de 1990, a 
expansão da assistência da saúde por meio do SUS aumentaram a demanda por exames de laboratórios (Hirata, Monteiro, Magliari, 2002).

Quanto ao regime de atendimento, 18 (40\%) dos laboratórios atendem somente em regime de não internação, ou seja, ambulatorialmente, com um predomínio de horário de atendimento da coleta compreendido entre manhã e tarde em $24(53,3 \%)$ e a maioria $27(60 \%)$ possui atendimento sob o regime de internação e não internação conjuntamente, no período de funcionamento da coleta nas 24 horas em $19(70,4 \%)$ dos serviços.

No entanto, chama atenção que em 8 (29,6\%) dos serviços com regime de internação, o setor de coleta de exames só trabalham durante o dia e, em $4(14,8 \%)$ só no período da manhã, pois a necessidade desse tipo de atendimento no interior de um hospital pode ocorrer a qualquer momento, ininterruptamente nas 24 horas.

Os laboratórios que possuem ambos os regimes de atendimento, estão relacionados às unidades hospitalares, para as quais os serviços prestados pelos laboratórios são de grande importância, como referido acima, durante as 24 horas.

Além disso, sabe-se que os trabalhadores do setor de coleta de exames, até pela prática diária, têm maior habilidade no desenvolvimento da atividade de coleta de exames, favorecendo uma análise confiável e conseqüentemente, um resultado fidedigno. Mas, nos horários em que os trabalhadores da coleta não estão presentes, a atividade de coleta dos 
exames passa a ser exercida pelos trabalhadores de enfermagem das unidades de internação.

Esta rotina pode acarretar problemas, como a coleta da amostra por pessoal pouco treinado, que pode apresentar dificuldades ou erros técnicos na obtenção das amostras, bem como não possuir conhecimento específico sobre o preparo que cada exame requer. Um exemplo disso é a coleta de sangue para análise dos fatores de coagulação, cujo garroteamento prolongado, a coleta por via heparinizada ou a dificuldade na punção são fatores suficientes para comprometer a qualidade da amostra e, conseqüentemente, dos resultados.

Estes fatos favorecem um atraso na tomada da conduta terapêutica, visto que em alguns casos será necessário proceder a uma nova coleta ou o setor técnico do laboratório precisará contatar o responsável pelo paciente para discutir se os resultados obtidos condizem com seu quadro clínico, ou ainda, possibilitará uma tomada de decisão pautada em resultados que não refletem a real condição clínica do paciente, o que deve ser evitado à medida que compromete a qualidade da assistência.

A respeito do tipo de cliente dos laboratórios estudados, a maioria das instituições 27 (60\%) atende a uma demanda interna e externa e executa basicamente as análises de hematologia, bioquímica, urinálise, parasitologia, imunologia e microbiologia. Exames mais complexos como a genética, citogenética, citometria de fluxo, entre outros, necessitam de tecnologia e habilidade técnica mais especializada e talvez por isso cada um deles são executados em apenas $1(2,2 \%)$ instituição. 
No que se refere ao programa educacional dos serviços, $37(82,2 \%)$ fazem treinamento de pessoal de coleta com carga horária variável em horas e, em meses, e 4 (8,9\%) instituições não possuem uma carga horária definida. Nesse sentido, convém destacar que 7 (15,6\%) desses serviços não fazem treinamento dos trabalhadores da coleta de exames, nem admissional, nem no decorrer da atuação em serviço, ou seja, nas reciclagens.

Entre os serviços que realizam o treinamento, $20(44,4 \%)$ executam esta atividade apenas em um dado momento e não continuamente, tal como preconizado pela abordagem da educação continuada ou educação permanente em serviço. Por outro lado, 7 (15,6\%) laboratórios assinalam a periodicidade com que oferecem treinamento, seja mensal ou anual.

Quanto à distinção entre ambas as modalidades de educação em serviço, considera-se o que foi apontado por Peduzzi et al., (2003), pois segundo os autores, educação continuada é um conjunto de práticas educacionais planejadas como, por exemplo, os treinamentos e as reciclagens que visam a promover o desenvolvimento do trabalhador a fim de auxiliá-lo na atuação mais efetiva e eficaz em seu trabalho.

Por sua vez, o conceito de educação permanente é mais abrangente, conforme propõe um processo permanente de educação em serviço, no qual a aprendizagem se produz em torno do processo de trabalho como eixo norteador.

A responsabilidade pelo treinamento é do profissional enfermeiro em $11(24,4 \%)$ dos laboratórios e do biomédico em $6(13,3 \%)$ deles. Em dois 
serviços, o enfermeiro compartilha a responsabilidade pelo treinamento com outro profissional de nível médio, o auxiliar de enfermagem, e com um agente denominado "fornecedor de seringa" sobre o qual não foi possível supor a escolaridade. Ainda relacionado ao programa educacional, chama atenção o fato de uma instituição confiar o treinamento a uma empresa de artigos hospitalares sem a participação de algum profissional da instituição e, em outra, a responsabilidade ser atribuída a um profissional de nível médio, um técnico de laboratório.

Parte-se do pressuposto de que a educação permanente é essencial ao bom desempenho de todos os profissionais, pois quanto melhor a qualificação técnica do trabalhador, melhores serão os resultados produzidos em seu trabalho, tanto qualitativo como quantitativamente.

No entanto, na amostra estudada, observa-se a existência de problemas nessa área, pois foi detectada a execução de treinamento sob a responsabilidade de trabalhadores de nível médio, bem como a total ausência de treinamento em serviço para a coleta de exames, como foi encontrado em 7 (15,6\%) dos serviços pesquisados.

A não continuidade do treinamento em serviço, sob a forma de educação permanente, pode acarretar o uso de técnicas não atualizadas ou o emprego errôneo de novos materiais de coleta. Por outro lado, a preocupação demonstrada por algumas instituições com o treinamento de pessoal vai ao encontro das exigências dos sistemas de qualidade de serviço, que requerem uma carga horária e periodicidade previamente definidas. 
Assim, destaca-se que dos 7 (15,6\%) laboratórios que informaram uma periodicidade do treinamento duas instituições possuem o certificado de qualidade ISO 9000.

A coleta domiciliar é uma atividade prevista pelos laboratórios de análises clínicas e $23(51,1 \%)$ instituições estudadas realizam-na. No entanto, esta atividade é executada com maior freqüência sob a responsabilidade do biomédico $5(11,1 \%)$ e do enfermeiros $4(8,9 \%)$.

A atividade, também, está sob a responsabilidade de profissionais de nível médio e, em $1(2,2 \%)$ serviço pesquisado, encontra-se o técnico de laboratório desempenhando esta função e, em outras $2(4,4 \%)$ instituições, são os auxiliares de enfermagem seus responsáveis. Em 2 (4,4\%) serviços, são terceiros que respondem por esta ação, o que caracteriza a terceirização da coleta domiciliar.

Esta ação requer uma infra-estrutura específica, tanto material como de pessoal regida por normas previstas na Portaria $n^{\circ}$ CVS-01 de janeiro de 2000, que trata das condições de funcionamento dos laboratórios de análises clínicas, patologia clínica e congêneres, na qual a responsabilidade pela coleta domiciliar é conferida a um profissional de nível superior (São Paulo, 2000).

Portanto, observa-se que a presença de profissionais de nível médio coordenando as atividades de coleta domiciliar contraria o que foi estabelecido na referida portaria, assim como expõem o cliente a potenciais danos e riscos à saúde. Destaca-se que a discussão sobre a exposição a riscos e danos será retomada em maior profundidade adiante. 
Quanto à execução da coleta domiciliar por terceiros, convém ressaltar o processo de terceirização que vem ocorrendo nos serviços de saúde do País, mais intensamente a partir dos anos 90 do século XX e, especialmente, nas instituições de SADT (Cherchiglia, 1999).

Embora, nesta pesquisa não se buscasse investigar esta temática, visto que o objeto de estudo refere-se à caracterização do processo de trabalho no setor de coleta de exames, conhecer a dinâmica interna e técnica do processo cotidiano do trabalho, e não no plano mais macroscópico da organização da prestação de serviços, na fase de identificação do universo de estudo, observou-se a presença marcante da terceirização, pois $49(13,8 \%)$ dos 196 laboratórios selecionados, inicialmente, eram terceirizados.

Como assinalado no referencial teórico, a terceirização vem sendo estudada na área da saúde, pois não somente os serviços de apoio tal como lavanderia, nutrição e outros vêm sendo terceirizados, mas também a força de trabalho, ou seja, a inserção dos trabalhadores vem ocorrendo por meio desse processo.

\section{B) - CARACTERIZAÇÃO DOS RECURSOS HUMANOS}

Quanto aos recursos humanos existentes nos setores de coleta de exames dos laboratórios estudados, os auxiliares de enfermagem estão 
presentes em $35(77,8 \%)$ instituições, representando a categoria profissional que prevalece.

Quando considerados, em particular, os trabalhadores de nível médio, como os auxiliares de patologia clínica e de laboratório com uma formação mais específica que o auxiliar de enfermagem na área de análises clínicas, foram identificados que estes fazem parte do quadro dos recursos humanos em $19(42,2 \%)$ e $5(11,1 \%)$ laboratórios, respectivamente.

O fato de existir um número maior de auxiliares de enfermagem atuando nessa área de trabalho, pode decorrer da existência de maior número de escolas de auxiliares de enfermagem quando comparadas com a oferta de cursos de auxiliar de patologia clínica e/ou auxiliar de laboratório.

Enquanto os auxiliares de enfermagem constituem a maioria dos trabalhadores denominados na categoria auxiliares, ou seja, com os auxiliares de patologia clínica e auxiliares de laboratório, observa-se o contrário entre os trabalhadores de nível médio denominados na categoria técnicos. Ao se considerar isto nas instituições estudadas, o técnico de laboratório é referido com maior freqüência em 16 (35,6\%) serviços, seguido pelo técnico de patologia clínica em $8(17,8 \%)$ laboratórios e, por último, o técnico de enfermagem em 6 (13,3\%) instituições.

Por um lado, convém ressaltar que o profissional técnico de enfermagem é a categoria mais recente na força de trabalho de enfermagem no País, o que talvez explique e justifique sua baixa freqüência nos laboratórios. Por outro lado, os laboratórios, sob o ponto de vista financeiro, consideram mais interessante possuir em seus quadros auxiliares de 
enfermagem realizando a coleta de exames, visto que para este trabalhador o mercado de trabalho pratica uma remuneração de menor valor. Embora ambos, auxiliares e técnicos de enfermagem, constituam profissões distintas, segundo a Lei do Exercício Profissional de Enfermagem (Lei $\mathrm{N}^{\circ}$ 7.498/86) (Brasil, 1986), pesquisas recentes apontam evidências empíricas sobre a ausência de diferenças entre os trabalhos efetivamente executados por estes agentes nos serviços de saúde brasileiros (Ministério da Saúde, 2003; Peduzzi, Anselmi, 2003).

Em estudo recente desenvolvido pelo Ministério da Saúde (Brasil, 2003), a expressiva contratação de técnicos de enfermagem como auxiliares de enfermagem, o não investimento público na qualificação e formação do técnico de enfermagem são apontados, bem como a expansão dessa modalidade de educação profissional sem a criação de postos de trabalho correspondentes. Desta forma, o estudo sinaliza para a constante imprecisão conceitual e de avaliação a respeito do que constituem, efetivamente, as competências desse trabalhador no interior das equipes de enfermagem e de saúde.

$\mathrm{Na}$ coleta de exames nas instituições pesquisadas, o espaço de atuação é ocupado, predominantemente, pelo auxiliar de enfermagem. Entende-se que isto ocorre por ser mais acessível aos laboratórios do ponto de vista econômico, como já apontado acima, e porque cabe ao auxiliar de enfermagem a execução de tarefas mais manuais da assistência de enfermagem. 
No entanto, as mudanças ocorridas no mundo do trabalho desde os anos 70 do século $\mathrm{XX}$, dada à forte incorporação tecnológica traduzida no desenvolvimento da automação, tecnologias microeletrônicas e robótica introduziram novos padrões de gestão do trabalho que visam ao aumento da produtividade e para isso necessitam de trabalhadores com maior qualificação técnica, polivalência para execução das tarefas diversificadas e multiqualificadas, com iniciativa, capacidade de inovação, de cooperação na execução do trabalho em grupo e de organização do ambiente de trabalho, bem como ter habilidades cognitivas de abstração, análise simbólica e comunicação; ter competência para avaliação do produto de seu trabalho e tomada de decisões visando a melhoria do domínio de técnicas necessárias de seu cotidiano, conforme apontam Antunes (1995) e Peduzzi (1998, 2002).

Estas mudanças também estão cada vez mais presentes nos laboratórios de análises clínicas, cuja automação dos procedimentos analíticos pressupõe um preparo técnico-científico maior, e de acordo com Hirata, Monteiro, Magliari (2002, p. 432):

Na década de 1930, a maior parte das dosagens (medidas) em química clínica era feita por métodos gravimétricos (peso), volumétricos e manométricos. Muitos resultados eram apenas semiquantitativos, o aparelho básico era a balança analítica, e a informação obtida muito limitada. A introdução do calorímetro fotoelétrico da radiação visiva, em substituição do comparador de cores, foi o primeiro dos avanços na aparelhagem do laboratório de química clínica.

A introdução do fotômetro de chama para a dosagem do sódio e do potássio no soro sangüíneo, 
vem dos métodos gravimétricos lentos, inexatos e incômodos, foi outra conquista no princípio da década de 1940 - o espectrofotômetro, que podia trabalhar na faixa do ultravioleta, abriu perspectivas aos laboratórios clínicos.

Nos últimos anos da década de 1950, o sistema auto Analyser, lançado pela Technicon Company, nos Estados Unidos teve notável influência, verificada até os nossos dias. No princípio dos anos 1960, os sistemas analíticos de canais múltiplos foram lançados no mercado, e esse envolvimento tecnológico constituiu outro grande progresso no campo da química clínica. $O$ volume de trabalho no laboratório clínico cresceu rapidamente, como conseqüência das novas possibilidades de se fazer exames em laboratório. $O$ sistema de análise individual (ou descontínua) foi também introduzido na década de 1960 melhorou a eficiência de se fazer exames de emergência, com resultados mais exatos. Também nos anos 1960, os espectrofotômetros de absorção atômica e os cromatógrafos gasosos, concebidos para dosagens químicas, começaram a aparecer nos laboratórios clínicos. Na década de 1970, o radioimunoensaio, a cromatografia líquida de alta especificação, os eletrodos seletivos e os aparelhos controlados por microprocessadores passaram a ser usados nos laboratórios de química clínica.

No que se refere aos recursos humanos de nível superior, os profissionais predominantes nos serviços estudados são o biomédico que aparece em $23(51,1 \%)$ instituições; o enfermeiro e o biólogo apresentam praticamente a mesma freqüência, contando em 15 (33,3\%) e 14 (31,1\%) nos laboratórios pesquisados, respectivamente. O médico e o farmacêutico- 
bioquímico são os profissionais menos freqüentes nas instituições estudadas, sendo referidos, cada um deles, em 12 (26,7\%) laboratórios.

A existência de outros trabalhadores sem qualificação técnica formal e regular atuando no setor de coleta de exames chama a tenção, pois são apontados em $3(6,7 \%)$ instituições, e quando consideradas as ações desenvolvidas por estes agentes no setor de coleta de exames aparecem em $13(35,1 \%)$ laboratórios, realizando atividades de recepção e encaminhamento das amostras coletadas.

Quanto aos recursos humanos de enfermagem no País, dados do COFEN, referentes ao ano de 2002, mostram que o maior contingente é o de auxiliares de enfermagem, representando 63,9\% do total (Silva, Peduzzi, 2003).

Nota-se que nos setores de coleta dos laboratórios de análises clínicas, o profissional de enfermagem mais freqüente é o auxiliar de enfermagem, abarcando $35(77,8 \%)$ da totalidade de trabalhadores atuantes na coleta.

No que se refere aos enfermeiros e técnicos de enfermagem, a força de trabalho de enfermagem brasileira, segundo dados do IBGE referentes ao ano de 1999, é de $13 \%$ e 9,1\%, respectivamente (Ministério da Saúde, 2002); mais uma vez coincide com as informações obtidas neste estudo, no qual se observam $33,3 \%$ de enfermeiros e $13,3 \%$ de técnicos de enfermagem. O quadro de atendentes de enfermagem, ainda conforme dados do COFEN no ano de 2002 , é de $8,2 \%$ da força de trabalho brasileira (Silva, Peduzzi, 2003) e, nos laboratórios estudados, verificou-se um total de 
$6,7 \%$ de trabalhadores sem qualificação técnica e formal. Esta relação está sendo assinalada, embora, neste estudo, os trabalhadores em qualificação técnica formal não tenham sido identificados, especificamente, como atendentes de enfermagem.

\section{C) - CARACTERIZAÇÃO DAS ATIVIDADES DESENVOLVIDAS}

Como foi assinalado anteriormente na apresentação dos resultados, as atividades desenvolvidas no setor de coleta de exames dos laboratórios de análises clínicas, foram agrupadas de modo a distinguir as de natureza assistencial e gerencial.

Assim sendo, na caracterização das atividades realizadas pelos recursos humanos de enfermagem, observa-se que o gerenciamento é realizado predominantemente pelo enfermeiro e, em menor freqüência, pelo técnico de enfermagem e auxiliar de enfermagem.

Nas atividades assistenciais, observa-se uma tendência oposta, ou seja, estas são executadas com maior freqüência pelos auxiliares de enfermagem e técnicos de enfermagem.

Portanto, os resultados desta pesquisa confirmam aqueles encontrados em outros estudos que apontam para o trabalho majoritariamente gerencial do enfermeiro e com predominância assistencial para o pessoal de enfermagem de nível médio. 
Nesse sentido, vale destacar os trabalhos pioneiros realizados por Almeida; Rocha (1986) e Castellanos (1987) que analisam o processo de trabalho de caráter gerencial do enfermeiro brasileiro.

Almeida, Rocha (1986) referem que a enfermeira, com freqüência, assume uma posição de gerente da assistência de enfermagem e da organização institucional, porque esta precisa de um agente que conheça a essência do trabalho de enfermagem, mas, não necessariamente para executá-lo.

Castellanos (1987) ao investigar o processo de trabalho do enfermeiro evidencia a heterogeneidade da enfermagem brasileira, conforme concentra as atividades gerenciais e de ensino no profissional enfermeiro e as atividades de "cuidado direto", tal como denominadas pela pesquisadora, nos demais agentes, ou seja, auxiliares, técnicos e atendentes de enfermagem.

Em estudo posterior, as autoras citam que, na organização tecnológica do trabalho de enfermagem, o processo de trabalho administrar, que tem como objeto a organização da assistência, é o mais presente no cotidiano do trabalho do enfermeiro, embora ainda seja negado pela maioria desses profissionais ao evocarem a "volta ao cuidado direto" (Castellanos et al., 1989).

Alguns estudos desenvolvidos sobre o trabalho da enfermagem na rede básica de saúde, também, obtêm resultados nesta mesma direção, apontando para uma separação entre as dimensões assistencial e gerencial, particularmente, no trabalho da enfermeira, com uma presença maior deste 
agente no gerenciamento do cuidado ou na administração dos serviços (Villa, Mishima, Rocha, 1997; Fracolli, 1999; Mishima et al., 1997; Peduzzi, 2000).

Assim, nota-se que o enfermeiro assume as atividades mais intelectuais, relacionadas a planejamento, organização, supervisão, avaliação do cuidado e/ou dos serviços, enquanto o pessoal de enfermagem de nível técnico e médio, cujo trabalho tem um caráter mais manual, responde pela maioria das atividades assistenciais e do cuidado de enfermagem. Os enfermeiros centram suas ações no objetivo de planejar a assistência e criar condições para que esta seja realizada pelos demais membros da equipe o que configura a separação entre as dimensões intelectual e manual do trabalho de enfermagem (Almeida e Rocha, 1986, Silva, 1986; Melo 1986, Peduzzi, 1998).

Ao analisarem as contradições existentes no processo de trabalho de enfermagem, Peduzzi, Anselmi (2002) identificam uma cisão entre as duas dimensões - assistencial e gerencial, conforme o enfermeiro planeja o cuidado e os demais agentes executam-no sem participação no momento de concepção do plano de cuidado, o que pode comprometer a qualidade da assistência de enfermagem, pois o núcleo duro desse trabalho é o cuidado.

Na presente pesquisa, tal como foi apontado por Castellanos (1987), também, observa-se uma maior participação do enfermeiro no desenvolvimento das atividades de ensino, visto que este profissional realiza atividades de treinamento em 16 (35,6\%) laboratórios, enquanto o auxiliar de enfermagem e o técnico de enfermagem executam esta ação, 
respectivamente em $3(6,7 \%)$ e $2(4,4 \%)$ serviços. Destaca-se que ambos os profissionais, o técnico e o auxiliar de enfermagem estão envolvidos com a atividade de treinamento, no entanto esta caberia somente ao técnico de enfermagem, pois, segundo o preconizado pela Lei do Exercício Profissional de Enfermagem, este agente pode colaborar com o enfermeiro em atividades de gerenciamento da equipe de enfermagem.

Nas atividades executadas pelos trabalhadores sem qualificação técnica formal e regular, observa-se o predomínio de ações de natureza assistencial e apenas em 1 (2,2\%) laboratório estes agentes realizam ações que estão relacionadas ao gerenciamento, especificamente, à coordenação do trabalho. No entanto, nenhum desses trabalhadores realiza atividades de treinamento em serviço, nem mesmo o agente que responde pela coordenação.

No que diz respeito aos profissionais de nível superior, excluído o enfermeiro, que foi tratado anteriormente, os demais desenvolvem tanto atividades assistenciais como gerenciais, contudo predominando da dimensão de gerenciamento.

Assim como os enfermeiros, os demais profissionais de nível superior, também, fazem de modo majoritário ações de cunho gerencial.

Mais uma vez evidencia-se a divisão de trabalho manual e intelectual entre os trabalhadores de nível médio e os de nível universitário, cabendo aos últimos a execução do trabalho mais intelectual que abriga a concepção e o planejamento do que deve ser executado pelos demais. 
Para Aguiar (2001), o saber produzido pelo do trabalho é distribuído de forma desigual entre os variados segmentos de trabalhadores, o que permite a reprodução da divisão social do trabalho, também, no processo de apropriação do conhecimento por parte dos agentes do trabalho.

Nesse processo, os trabalhadores que exercem atividades de caráter mais intelectual, tais como as ações gerenciais, fazem parte da sua formação nas instituições de ensino superior e, aqueles que se destinam à execução de atividades de caráter mais manual, irão qualificar-se nos próprios serviços ou em cursos de curta duração.

É interessante destacar que, apesar de estar em menor número nos laboratórios, o enfermeiro é o que mais participa do treinamento em serviço, percebe-se que isto está relacionado à tradição consagrada do papel educador desse profissional, visto que a atividade de educação é historicamente inerente ao trabalho do enfermeiro, desde sua institucionalização com área profissional.

Desde o surgimento da enfermagem moderna, instala-se uma hierarquia entre as ladies-nurses que assumiam as funções de educação e supervisão, e as nurses que se ocupavam do cuidado direto ao doente, dando origem à divisão do trabalho na enfermagem, já referida anteriormente (Almeida, Rocha, 1986; Melo, 1986; Silva, 1986).

Outro aspecto relevante observado na análise dos resultados referese à presença marcante de ações de enfermagem no trabalho cotidiano realizado nos setores de coleta de exames, tais como: punção venosa, orientações para o preparo de exames, manipulação de cateteres, 
sondagens, coleta de secreções e realização de curativos em feridas, após a coleta de material biológico e outras. Mas tais atividades, também, são executadas por outros trabalhadores de nível médio e superior que dividem este campo de atuação com a enfermagem.

Este aspecto da análise está relacionado ao que Girardi, Seixas (2002), denominam como dilemas da regulamentação profissional na área da saúde, apontando tensões entre atos que são reservados de forma exclusiva ou privativa para determinada profissão e atos compartilhados entre agentes de diversas áreas profissionais. Os autores apresentam um novo paradigma para a regulamentação das profissões, especialmente, na área da saúde, baseado na proteção do público contra efeitos prejudiciais da prática das profissões, ou seja, deve prevalecer a defesa dos interesses públicos no sentido da ampliação do acesso, eficiência econômica, plena utilização das potencialidades e competências dos recursos humanos, em um ambiente em que a proteção e o bem-estar da clientela devem ser constantemente avaliados e assegurados.

Como é o campo de prática que define, em termos gerais, o que a profissão faz e como faz, a regulação profissional considera que cada profissão possui um campo exclusivo em que há atos privativos por lei e atos compartilhados com agentes de outras categorias profissionais.

No setor de coleta de exames dos laboratórios, as ações desenvolvidas pelos agentes de nível superior são compartilhadas entre a enfermagem, biomedicina, farmácia-bioquímica, biologia e a medicina. Por outro lado, as ações realizadas pelos trabalhadores de nível médio são 
divididas entre os auxiliares e técnicos de enfermagem, patologia clínica e de laboratório.

Assim sendo, o compartilhamento das atividades de coleta de exames entre agentes de enfermagem e outros trabalhadores deve ser analisado na perspectiva dos interesses dos usuários do serviço, isto é, buscando evitar a exposição da clientela a riscos e potenciais danos à saúde acarretados pela execução dessas ações por trabalhadores sem a necessária qualificação técnica.

Se, por um lado, a possibilidade efetiva de compartilhar atividades pode trazer benefícios aos usuários conforme amplia o acesso e a produtividade no atendimento; por outro lado pode provocar conflitos entre os diferentes trabalhadores.

Estes conflitos tendem a ser menos intensos entre os agentes de nível médio, para os quais há um conjunto mais circunscrito e padronizado de atividades a serem realizadas. Mas, tornam-se mais intensos e explícitos nas relações entre os profissionais de nível superior que respondem por ações de planejamento, organização, supervisão e avaliação dos serviços prestados, que envolvem tomadas de decisões em situações de maior incerteza e menos delimitação de fronteiras, predispondo a maiores e mais freqüentes tensões na divisão do trabalho.

Outra realidade dos laboratórios de análises clínicas é que a tecnologia de ponta está concentrada no setor técnico, ou seja, no setor de análise da amostra, no qual foi possível a incorporação da microeletrônica e da automação, determinando o grau de modernidade e o reconhecimento 
social que os laboratórios possuem, o que vem acompanhado da necessidade de um alto grau de qualificação técnico-científica dos respectivos profissionais.

No setor de análises, encontram-se, basicamente, profissionais de nível superior, pois há exames cujos resultados só podem ser confirmados por profissionais especializados e os maiores investimentos acadêmicos sob a forma de cursos de atualização e de pós-graduação lato sensu e sensu stricto, além das reuniões científicas, cujo enfoque é predominantemente relacionado à análise.

No setor de coleta de exames, executa-se um trabalho centrado em atividades de caráter manual, de modo que este tende a ter menor valorização técnica e social por referência ao setor de análises, bem como a concentrar um maior número de trabalhadores de nível médio.

No entanto, sabe-se que o setor de coleta tem importância fundamental para o laboratório, pois representa o início do processo de análises clínicas e um erro nesta fase pré-analítica compromete o processo inteiro, podendo abalar até a credibilidade dos resultados fornecidos.

Vale destacar que os trabalhadores de enfermagem, auxiliares, técnicos e enfermeiros estão atuando no setor de coleta de exames, contexto no qual se produz um trabalho de menor valoração social, por trabalhadores com menos autoridade técnica, tal como referido acima. Portanto, no setor de coleta de exames de laboratórios de análises clínicas reproduz-se a problemática relacionada à ausência de visibilidade e à não 
valorização social do trabalho de enfermagem que está inserida justamente no setor de menor expressão no interior dos laboratórios.

A não valorização do trabalho de enfermagem é experimentada concretamente no dia-a-dia de trabalho pelos sujeitos deste estudo - os trabalhadores de enfermagem, que realizam ações silenciosas e quase invisíveis, de bastidores, sem reconhecimento social.

Por outro lado, o cliente/paciente leva em consideração o contato direto com o agente executor da coleta, pois para ele a execução da técnica com a melhor precisão e qualidade possíveis é importante.

Um exemplo clássico dessa valorização é a coleta da punção venosa, que é causadora de estresse por ser um procedimento doloroso, pois nesse procedimento a medida de qualidade do cliente/paciente é o quanto o agente executor da coleta conseguiu puncionar com sucesso na primeira tentativa sem causar danos como hematoma, bem como a interação com o profissional durante a execução da técnica.

Até o momento, a análise apresentada vai ao encontro do que afirma Peduzzi (1998), que a divisão amplia o número de trabalhadores parciais e especializados, desde o médico e demais profissionais universitários ao pessoal auxiliar de nível médio, tanto na enfermagem como na área de apoio diagnóstico e terapêutico, até os trabalhadores empíricos, sem formação formal e regular específica para o setor saúde, treinados em serviço.

Nesse processo de divisão, não apenas a divisão técnica e pormenorizada de trabalhos é reproduzida, mas, a desigual valoração social desses estudos, que é evidenciada pela distinção e elitização do trabalho do 
profissional médico em relação aos demais profissionais de saúde, pois o maior valor social é atribuído ao médico, decorrente da hegemonia do modelo biomédico.

Outro ponto a ser ressaltado é o fato de que o técnico de enfermagem e o auxiliar de enfermagem, no setor de coleta de exames, desenvolvem basicamente as mesmas atividades, sem distinção no trabalho executado por ambos os agentes. Este resultado também é confirmado por outros estudos que assinalam a ausência de diferenças no trabalho desenvolvido pelos auxiliares e técnicos de enfermagem (Ministério da Saúde, 2003; Peduzzi, Anselmi, 2003).

A Associação Brasileira de Enfermagem e o Ministério da Saúde realizaram uma pesquisa que mostra a expressiva contratação de técnicos de enfermagem pelos serviços de saúde como auxiliares de enfermagem, a expansão da formação dos técnicos de enfermagem sem a respectiva criação de postos de trabalho e a imprecisão ou indefinição das atividades do técnico que variam, pois dependem dos aspectos relacionados à instituição, ao turno de trabalho e ao supervisor da unidade (Ministério da Saúde, 2003).

Outro estudo recente desenvolvido por Peduzzi, Anselmi (2003), corrobora os achados da pesquisa referida acima, à medida que não observa diferenças entre os auxiliares e técnicos de enfermagem que atuam em uma maternidade, ambos executam as mesmas ações, podendo o auxiliar de enfermagem realizar atividades de maior complexidade que o 
técnico, desde que esteja inserido nos serviços, há mais tempo e acumule, no entender da respectiva chefia, maior experiência prática de trabalho.

A não diferenciação das atividades dos auxiliares e técnicos de enfermagem pode ser explicada com base na filosofia e na política de recursos humanos que cada instituição adota, pois o técnico, embora tenha uma formação mais específica, na prática, é contratado para executar as mesmas ações do auxiliar de enfermagem, especialmente, nos setores de coleta, onde a atuação tem caráter manual e corresponde a um conjunto de atividades que podem ser estandardizadas e, portanto, submetidas a um controle mais rigoroso.

Por outro lado, isto revela um subaproveitamento das potencialidades que o técnico de enfermagem poderia ter na execução de atividades gerenciais, como colaborador com o profissional enfermeiro, o que o distingue do auxiliar de enfermagem tanto na Lei do Exercício Profissional de Enfermagem, como nas Diretrizes Curriculares da Educação Profissional de Nível Médio (anexo I) (Brasil, 1986; Conselho Nacional da Educação, 2002).

As competências gerenciais do técnico de enfermagem são aproveitadas por apenas $1(2,2 \%)$ laboratório estudado, sob a forma de atividades de coordenação e por $2(4,4 \%)$ serviços em atividades de supervisão e teste de materiais utilizados na coleta, bem como no treinamento em serviço.

No que se refere às atividades assistenciais, também, há distinção entre técnicos e auxiliares de enfermagem na perspectiva da Lei do Exercício Profissional, à medida que cabe aos técnicos a prestação de 
cuidados aos pacientes mais graves, auxiliando o enfermeiro. No entanto, no atendimento oferecido no setor de coleta de exames, em regime ambulatorial ou de internação, a presença de pacientes de maior complexidade é eventual e mesmo em sua presença os cuidados de maior complexidade clínica caberão a outra equipe e não à equipe da coleta, ficando assim quase anuladas as diferenças entre o trabalho do auxiliar e do técnico de enfermagem na área de atuação em estudo.

Este contexto permite analisar que, apesar da Lei do Exercício Profissional fazer distinção das diferentes categorias profissionais de enfermagem, na prática a legislação não é validada em sua totalidade, visto que o técnico de enfermagem e o auxiliar de enfermagem executam as mesmas ações nos laboratórios de análises clínicas.

Nesta pesquisa, os resultados encontrados mostram uma distorção das atividades previstas para cada categoria profissional, pois nos laboratórios estudados a atividade de gasometria arterial, que é privativa do enfermeiro, é executada pelo técnico de enfermagem em $1(2,2 \%)$ serviço e pelo auxiliar de enfermagem em $3(6,7 \%)$ instituições. Encontra-se, também, o auxiliar de enfermagem executando atividades de supervisão, coordenação e planejamento das ações de enfermagem em 1 (2,2\%) laboratório.

Estas atividades requerem o domínio de um saber técnico-científico referente à anatomia, fisiologia, microbiologia e outros, assim como conhecimentos sobre administração e gerenciamento em saúde, em um grau de profundidade, que não é contemplado nos cursos de auxiliares e de 
técnicos de enfermagem. Ou seja, ações assistenciais como a gasometria arterial e atividades gerenciais de planejamento, organização e monitoramento do trabalho requerem formação de nível superior.

Os trabalhadores sem qualificação técnica regular e formal também realizam coleta de exames laboratoriais de menor complexidade e coleta domiciliar em 1 (2,2\%) instituição. Esta situação traz ainda maior preocupação em termos de exposição dos usuários a riscos ou potenciais danos à saúde, pois estes agentes não tiveram a oportunidade de acesso à educação profissional, embora possam ter acumulado experiência prática ao longo do tempo. Esta não é uma exceção desses serviços, visto que muitos estabelecimentos de saúde empregam um expressivo contingente de trabalhadores de enfermagem sem qualificação técnica formal.

Segundo dados do Ministério da Saúde, em 1998, os atendentes de enfermagem representavam quase $30 \%$ da força de trabalho de enfermagem no País, o que desencadeou a implantação do Projeto de Profissionalização dos Trabalhadores da Área de Enfermagem (PROFAE) que vem possibilitando, desde meados do ano 2000, a qualificação profissional desses trabalhadores (Ministério da Saúde, 1999).

Assim sendo, no momento atual, observa-se um decréscimo mais acentuado dos trabalhadores de enfermagem sem qualificação técnica inseridos nos serviços de saúde (Castro, 2002), embora ainda persistam, tal como se observa nesta pesquisa.

Quanto a formação profissional para trabalhar no setor de coleta de exames, entre os laboratórios estudados, verifica-se que 31 (81,6\%) deles 
informaram que, dos trabalhadores de nível médio, o profissional mais requisitado é o auxiliar de enfermagem, seguido pelo técnico de laboratório que é citado por $12(31,6 \%)$ serviços. O técnico de enfermagem aparece quase na mesma proporção que o técnico de laboratório em 11 (28,9\%) instituições.

No que diz respeito aos profissionais de nível superior, o enfermeiro é o mais mencionado, aparecendo em $8(21,1 \%)$ laboratórios, e o biomédico vem, em seguida, referido por $5(13,2 \%)$ serviços. No entanto, este resultado não coincide com o quadro de pessoal que os laboratórios informaram possuir.

A divisão das atividades assistenciais e gerenciais entre os trabalhadores de enfermagem também foi investigada de forma mais direta ao se perguntar ativamente sobre isto no instrumento de coleta de dados, pois importava identificar se os próprios profissionais faziam esta distinção. Nesse sentido, observa-se que 19 (42,2\%) laboratórios referem que não há esta divisão, porém, 16 (35,6\%) outros relataram sua existência.

Este resultado corrobora aquele apresentado anteriormente na Tabela 24, à medida que confirma o enfermeiro respondendo predominantemente por atividades gerenciais, enquanto os auxiliares e técnicos de enfermagem executam, sobretudo, ações de natureza assistenciais, dentro da estrutura dos laboratórios.

Nesta questão, entende-se que foi observada uma tendência dos serviços responderem o que o Conselho Federal e os Conselhos Regionais de Enfermagem prevêem como sendo responsabilidade de cada categoria 
profissional de enfermagem, pois, mesmo nos laboratórios que não dispunham de pessoal de enfermagem, foi assinalado que o enfermeiro faz gerenciamento e o técnico de enfermagem e o auxiliar de enfermagem realizam, predominantemente, assistência.

Quanto ao terceiro objetivo da pesquisa, que se refere a conhecer a inserção da enfermagem na estrutura organizacional, observa-se que, no organograma das instituições estudadas, a enfermagem está subordinada à chefia do próprio laboratório em 13 (28,9\%) serviços, seguida pela subordinação à direção do serviço em 11 (24,4\%) instituições e à área de enfermagem em $8(17,8 \%)$ delas.

Isto revela que a enfermagem está subordinada a outras áreas de trabalho, o que lhe confere escassa autonomia quanto à sua inserção na estrutura institucional. Este resultado é consistente e coerente com outros aspectos analisados que dizem respeito à indiferenciação entre ações de enfermagem e de outros profissionais, ausência de diferenças entre os agentes da própria enfermagem, especialmente, entre o auxiliar e o técnico de enfermagem, Assim como a pouca visibilidade e valorização social da prática de enfermagem. 


\section{CONSIDERAÇÕES FINAIS}

Ao investigar a caracterização do trabalho de enfermagem em laboratório de análises clínicas, os resultados evidenciaram que:

Quanto à caracterização dos laboratórios, chama atenção o aspecto relacionado ao treinamento, pois em $15,6 \%$ dos serviços estudados esta atividade não é desenvolvida e, dentre os que a realizam, $44,4 \%$ fazem isoladamente e não de forma continuada ou permanente. Por outro lado, também, merece destaque que a execução desta atividade está, sobretudo sob a responsabilidade do enfermeiro, visto que este resultado corrobora o predomínio da dimensão gerencial no processo de trabalho do enfermeiro, bem como pelo seu tradicional envolvimento com a execução de ações educativas na equipe de trabalho.

Quanto à caracterização dos recursos humanos que atuam no setor de coleta de exames, o profissional predominante é, indiscutivelmente, o auxiliar de enfermagem, visto que é referido por $77,8 \%$ dos serviços pesquisados. Por sua vez, o enfermeiro aparece em $33,3 \%$ dos laboratórios e o técnico de enfermagem em $13,3 \%$ das instituições.

Este quadro de recursos humanos de enfermagem reproduz a distribuição da força de trabalho de enfermagem no País, pois segundo dados do IBGE (Ministério da Saúde, 2002) esta se compõe de 62,8\% de 
auxiliares de enfermagem, $13 \%$ de enfermeiros e $9,1 \%$ de técnicos de enfermagem. Embora dados recentes do Conselho Federal de Enfermagem (Ministério da Saúde, 2003) mostrem um crescimento dos técnicos de enfermagem que já ultrapassa a porcentagem de enfermeiros, este é um fenômeno recente que vem ocorrendo nos últimos três anos (Silva, Peduzzi, 2003).

Cabe considerar as diferenças existentes entre os dados das duas fontes, IBGE e COFEN, pois ambos utilizam distintas técnicas de coleta de dados, visto que o IBGE procede ao levantamento das informações sobre todos os empregos formais, com carteira de trabalho assinada e o Conselho Federal de Enfermagem registrar todos os profissionais formados independente de sua efetiva inserção no mercado de trabalho.

$\mathrm{Na}$ caracterização das atividades desenvolvidas pelos trabalhadores de enfermagem no setor de coleta de exames, esta pesquisa confirma as evidências de outros estudos, à medida que mostra uma divisão de trabalho inequívoca entre as três categorias profissionais que compõem a força de trabalho da área de enfermagem - auxiliar de enfermagem, técnico de enfermagem e enfermeiro.

Assim sendo, os auxiliares de enfermagem executam quase, exclusivamente, ações assistenciais. Para os técnicos de enfermagem também predominam as atividades assistenciais, embora os informantes tenham apontado a divisão do trabalho assistencial e gerencial na equipe de enfermagem, e o resultado assinale ambas as modalidades, de forma mais 
eqüitativa para o técnico. Por outro lado, os enfermeiros concentram seu trabalho na dimensão gerencial.

Nota-se uma situação de trabalho, na qual os auxiliares executam o cuidado direto na coleta de exames, o enfermeiro gerencia o processo e os técnicos de enfermagem participam de ambos os momentos, tanto na execução como na coordenação do trabalho.

Quanto aos demais profissionais de nível universitário, estes como o enfermeiro, realizam maior porcentagem de ações gerenciais, incluindo o planejamento das ações de enfermagem, coordenação e supervisão da equipe, bem como previsão e provisão de pessoal. Portanto, nota-se que esses profissionais ou respondem integralmente ou participam do gerenciamento da equipe de enfermagem, o que contraria as determinações da regulação profissional da área que prevê a coordenação do trabalho de enfermagem sob a responsabilidade do enfermeiro.

Se, por um lado, há agentes da enfermagem respondendo a outros profissionais não enfermeiros, contrariando a Resolução COFEN-146, por outro lado, os laboratórios de pequeno porte com baixa demanda alegam não possuírem condições financeiras de manter um enfermeiro contratado para responder pelo pessoal de enfermagem no setor de coleta.

Assim, essas instituições optam por atribuir esta responsabilidade a outros profissionais, inclusive, de nível médio. Isto mostra que a referida Resolução ainda não foi socialmente legitimada em sua totalidade, pois a realidade de alguns laboratórios de análises clínicas não permite o cumprimento desta norma. 
Nesse sentido, lembra-se o novo paradigma da regulação profissional abordado na análise do material empírico, à medida que prioriza a defesa do interesse público e não dos interesses das corporações profissionais, o que implica considerar, sobretudo, a garantia de acesso e qualidade aos serviços prestados, livre de qualquer risco, à população.

Além da participação de outros profissionais no gerenciamento das atividades de enfermagem, também, observam-se outras categorias profissionais externas à enfermagem, executando ações de enfermagem, tais como: punção venosa, coleta de secreções e realização de curativos e outras.

A ausência de diferenças entre o trabalho executado pelo auxiliar e pelo técnico de enfermagem, também, foi identificada, à exceção de uma maior responsabilização do último por ações gerenciais.

Portanto, fica evidente a necessidade de um amplo debate sobre a regulação do trabalho em saúde e em enfermagem, bem como do trabalho no setor de coleta de exames de análises clínicas. Este debate deve ser travado, não no sentido de buscar estabelecer fronteiras rígidas entre os diversos trabalhos especializados, mas, para garantir maior clareza quanto à esfera de responsabilidade de cada área profissional, atendendo, simultaneamente, aos esquemas dinâmicos e flexíveis de atribuições no mercado de trabalho atual, particularmente, aos trabalhadores nas categorias de auxiliares e técnicos que apresentam um leque muito diversificado de denominações. 
Outro aspecto que merece ampla discussão no campo da saúde e da enfermagem, diz respeito à representação social e à efetiva inserção dos trabalhadores de enfermagem nas práticas de saúde, visto que esta pesquisa, assim, como outros estudos demonstram que o trabalho de enfermagem ainda apresenta pouca visibilidade e valor na divisão social do trabalho. Estes agentes ocupam-se de atividades que respondem à necessidade social de cuidados, nesse sentido, são imprescindíveis ao bemestar e ao enfrentamento do sofrimento, da dor e dos agravos à saúde, mas são poucos reconhecidos socialmente.

Por fim, destacam-se os limites desta investigação no tratamento e na compreensão dos dois últimos aspectos acima referidos, a regulação profissional e a valorização do trabalho de enfermagem que emergem dada a abordagem do objeto de estudo feita pela via do processo de trabalho. De outro lado, é interessante observar que a análise de situações microscópicas e particulares, tal como o trabalho de enfermagem no setor de coleta de exames, permite identificar problemáticas mais amplas, tecendo uma teia entre o universo micro e o macro do próprio objeto de pesquisa. 
ANEXOS

\section{ANEXO I - ANÁLISE DOCUMENTAL}

O setor de coleta de exames do laboratório de análises clínicas é um campo de atuação que a enfermagem divide com outros profissionais da saúde, destacando-se ao nível médio, o técnico de laboratório e o técnico de patologia clínica. Convém salientar que, alguns cursos são modulares e, se o estudante cumprir determinada carga horária, recebe o título de auxiliar de laboratório ou auxiliar de patologia clínica, e o curso completo confere-lhe o título de técnico nestas áreas.

Diante do fato, considerou-se necessário realizar uma análise documental sobre a formação desses profissionais a fim de identificar as semelhanças e diferenças existentes entre eles, e conhecer quais são as competências/habilidades que capacitam a atuação nesse campo.

A partir dos Referenciais Curriculares Nacionais para a Educação Profissional de Nível Técnicos para a Área da Saúde do Ministério da Educação foram obtidos os cenários, delimitações, interfaces, funções e subfunções, gerais e específicas das subáreas de Enfermagem e Biodiagnóstico, bem como a descrição das competências, habilidades e 
bases tecnológicas exigidas para cada uma delas. O técnico de laboratório e de patologia clínica estão inseridos na subárea de Biodiagnóstico.

O nível técnico para a análise foi escolhido porque na Portaria $n^{\circ}$ CVS-01, já mencionada anteriormente, não há referência a outro profissional do nível intermediário, além do auxiliar de enfermagem; quanto ao nível técnico, ela cita os técnicos de enfermagem, os técnicos de laboratório e o de patologia clínica.

A seguir, as informações documentais apresentadas estão baseadas na publicação dos Referenciais Curriculares Nacionais para a Educação Profissional de Nível Técnico para a Área da Saúde do Ministério da Educação (Ministério da Educação e Cultura, 2000).

\section{CENÁRIO, TENDÊNCIAS e DESAFIOS}

Subárea de Biodiagnóstico

A subárea de Biodiagnóstico desenvolve atividades pertinentes às análises microbiológicas, morfológicas, químicas e físicas de fluídos e tecidos orgânicos em Laboratórios de Análises Clínicas. Compreende a orientação prévia do cliente/paciente, a coleta e processamento de amostras biológicas até a execução de exames laboratoriais, por meio da operação de equipamentos da área.

Atualmente, o diagnóstico, o tratamento de patologias e o monitoramento da saúde incluem, dentre outros, os dados e informações obtidos por intermédio das análises realizadas em amostras biológicas. 
A importância desses procedimentos no processo de produção dos cuidados de saúde justifica a emergente preocupação com o aprimoramento e atualização dos recursos humanos, de modo a acompanhar os avanços científicos, tecnológicos e mecatrônicos da área.

O cenário interno da subárea mostra um quadro de recursos humanos, no qual o maior contingente é constituído de profissionais de nível médio e básico sem formação específica, orientados e treinados em serviço pelos profissionais que respondem pelos encargos técnicos dos setores. Este fato denuncia uma demanda por técnicos que atendam às exigências de mercado e correspondam ao perfil exigido pelo processo de trabalho na subárea de Biodiagnóstico.

Subárea da Enfermagem

O processo de trabalho na subárea da Enfermagem está centrado nas ações do cuidar. Um cuidar fundamentado no saber, no fazer e no sentir, voltado ao atendimento das necessidades de saúde do paciente/cliente/comunidade nas diferentes fases do ciclo vital e comprometido com a proteção e promoção da vida.

No entanto, a atividade de enfermagem ainda é, basicamente, realizada no espaço hospitalar, público ou privado, sob a influência do modelo médico-assistencial hegemônico do País, o modelo biomédico.

Segundo os Referenciais Curriculares Nacionais para a Educação Profissional de Nível Técnico para a Área da Saúde do Ministério da Educação,considerando que $65 \%$ da força de trabalho em saúde é constituída de trabalhadores da Enfermagem desenvolvendo ações em 
todas as áreas da saúde, fica claramente definida a importância da Enfermagem no panorama geral da assistência à Saúde. Gaidzinski (1991) cita que nos hospitais, o pessoal de enfermagem representa $60 \%$ do quadro de trabalhadores destas instituições.

Dados mais atuais foram publicados pelo Ministério da Saúde (2001) na revista Formação do Projeto de Profissionalização dos Trabalhadores da Área da Saúde (PROFAE) mostram que, em 1992, dos empregos do setor saúde, $50 \%$ eram ocupados por trabalhadores da enfermagem.

\section{DELIMITAÇÃO E INTERFACES}

Subárea de Biodiagnóstico

As bases científicas que constituem insumos para a apropriação de competências técnico-operacionais no processo de trabalho em Biodiagnóstico encontram-se nas ciências da natureza, especialmente, nos estudos de biologia, microbiologia e parasitologia, citologia, química, física e matemática. Os estudos de informática e língua estrangeira moderna constituem as bases instrumentais necessárias à adequada utilização das ferramentas tecnológicas disponíveis nos dias de hoje, nos quais se destaca a mecatrônica.

Os conhecimentos de língua portuguesa necessários à adequada comunicação escrita e verbal e à leitura e interpretação de textos técnicos e legais constituem, também, importante base instrumental ao processo de trabalho na subárea. 
Nas ciências humanas, mais especificamente na psicologia, sociologia e filosofia, repousam as bases instrumentais que permitirão a aquisição das competências sociocomunicativas e relacionais, sob crivo ético.

A subárea do Biodiagnóstico estabelece interface com as subáreas de hemoterapia e enfermagem. Com a primeira destas, a interface evidencia-se por meio dos procedimentos de controle aos quais o sangue e os hemocomponentes são submetidos e que constituem práticas de Biodiagnóstico; já com a Enfermagem esta correlação reside nos procedimentos de coleta de amostras e na orientação e/ou preparo dos clientes/pacientes para a coleta.

\section{Subárea de Enfermagem}

As ações da subárea são delimitadas pela Lei do Exercício Profissional que rege a atuação dos diferentes níveis profissionais que compõem a equipe de Enfermagem.

A subárea de Enfermagem estabelece interface com as ciências da natureza, da educação básica, dos estudos de biologia, anatomia e fisiologia humanas, higiene, microbiologia e parasitologia, química, física e da matemática e suas técnicas de onde extrai as bases científicas para as ações pertinentes aos procedimentos de administração e controle de medicamentos, utilização e manuseio de materiais e equipamentos específicos e para a realização das múltiplas técnicas de trabalho utilizadas no processo de assistência. 
Estas são também as bases científicas para a compreensão do processo saúde-doença, no aspecto dos fatores determinantes e condicionantes do mesmo, da fisiopatologia dos agravos à saúde, da epidemiologia dos processos mórbidos e da relevância da Biossegurança em todas as ações dos profissionais da subárea.

Das ciências humanas, obtém-se a sustentação do cuidar/assistir o paciente/cliente/comunidade, por meio dos estudos de psicologia, sociologia, antropologia e filosofia. Nestes reside a base científica das competências de caráter ético, sociocomunicativo e relacional que deverão permear todo o trabalho do "cuidar" e, ainda, as relações em equipe.

$\mathrm{Na}$ área de linguagens e códigos, encontram-se as bases instrumentais que fundamentarão, por intermédio dos conhecimentos de língua portuguesa, a comunicação verbal e não-verbal com o cliente/ paciente e equipe, o registro correto e adequado de dados, a leitura e interpretação de prescrições e textos técnicos. $\mathrm{Na}$ aplicação dos conhecimentos de informática, baseia-se o pleno e correto uso dos sistemas de informação e a adequada utilização das ferramentas tecnológicas disponíveis.

A Enfermagem estabelece interface com a quase totalidade das subáreas da Saúde, uma vez que o processo de trabalho da mesma inclui o cuidar/cuidado em todos os seus aspectos, considerando a totalidade das necessidades do ser humano, no conceito de saúde e nos pressupostos do SUS. 


\section{MATRIZES DE REFERÊNCIA E NÚCLEO DA ÁREA}

As matrizes de referência curriculares resultaram da análise das subfunções do núcleo de área da saúde e foram agrupadas em cinco grandes categorias de ação. São eles:

- Apoio ao diagnóstico: inclui as ações e procedimentos que auxiliam no estabelecimento do diagnóstico do cliente/paciente, na identificação de causas de agravos à saúde em ambientes coletivos e na definição das necessidades de saúde de determinado indivíduo ou grupo populacional.

- Educação para a saúde: reúne as ações que visam à manutenção da saúde da população sadia, por meio de ações educativas empreendidas com o cliente/comunidade, objetivando a adoção de práticas de vida saudável e estimulando o autocuidado.

- Proteção e prevenção: conjunto de ações que objetivam proteger e preservar a saúde, prevenir moléstias e eliminar ou minimizar riscos ao cliente/paciente/comunidade.

- Recuperação/reabilitação: ações que têm o objetivo de recuperar a saúde e/ou reabilitar as funções afetadas em conseqüência de agravos e doenças, visando a recuperação física e o reajustamento social com vistas à melhoria da qualidade de vida do cliente/paciente.

- Gestão em saúde: função voltada à eficiência e eficácia dos diversos processos de trabalho, à garantia da qualidade do serviço prestado e à viabilidade de negócio como empreendimento econômico.

Algumas destas matrizes de referência, também, denominadas funções são subdivididas em subfunções, conforme a Fig.2. 
As subfunções que agrupam competências comuns passaram a constituir o núcleo da Área de Saúde, cujo objetivo é conferir um perfil inicial comum a todos os profissionais da área e, além disso, facilitar ao aluno a construção de "itinerários" de formação profissional que atendam às suas expectativas e perspectivas de trabalho. As competências específicas constituem, por sua vez, subfunções também específicas que variam, de acordo com as profissões.

As subfunções do núcleo da Área em número de cinco, incluem, portanto, as competências gerais que deverão ser apropriadas por qualquer técnico de nível médio em saúde, conforme consta na Resolução 4/99 do Conselho Nacional de Educação.

Nessa concepção as subfunções de Educação para o autocuidado, Promoção da Saúde e Segurança no Trabalho, Biossegurança nas ações de saúde, Prestação de Primeiros Socorros e Organização do processo de Trabalho em Saúde, que estão destacadas na Fig.2, constituem o núcleo da área da saúde, e por isso não serão aprofundadas neste trabalho.

Figura 2 - Núcleo da Área da Saúde, segundo funções e subfunções

\begin{tabular}{|l|l|l|}
\hline \multicolumn{1}{|c|}{ FUNÇÕES } & \multicolumn{1}{|c|}{ SUBFUNÇÕES } \\
\hline $\begin{array}{l}\text { 1.Apoio ao } \\
\text { Diagnóstico }\end{array}$ & \multicolumn{1}{|c|}{- -- } \\
\hline $\begin{array}{l}\text { 2. Educação } \\
\text { para a Saúde }\end{array}$ & $\begin{array}{l}\text { 2.1 Educação para o } \\
\text { Autocuidado }\end{array}$ & \multicolumn{1}{|c|}{--} \\
\hline $\begin{array}{l}\text { 3. Proteção e } \\
\text { Prevenção }\end{array}$ & $\begin{array}{l}\text { 3.1 Promoção da Saúde e } \\
\text { Segurança no Trabalho }\end{array}$ & $\begin{array}{l}\text { 3.2 Biossegurança nas } \\
\text { ações de } \\
\text { saúde }\end{array}$ \\
\hline $\begin{array}{l}\text { 4.Recuperação/ } \\
\text { reabilitação }\end{array}$ & $\begin{array}{l}\text { 4.1 Prestação de Primeiros } \\
\text { Socorros }\end{array}$ & \multicolumn{1}{|c}{} \\
\hline $\begin{array}{l}\text { 5. Gestão em } \\
\text { saúde }\end{array}$ & $\begin{array}{l}\text { 5.1 Organização do Processo de } \\
\text { trabalho em Saúde }\end{array}$ \\
\hline
\end{tabular}


A seguir, nas Figuras 3 e 4 aparecem destacadas em cinza as subfunções que compõem o núcleo comum da área da saúde, comuns aos profissionais da saúde e as subfunções específicas das subáreas de Biodiagnóstico e de Enfermagem.

Figura 3 - Subfunções específicas da Subárea de Biodiagnóstico, segundo funções e subfunções

\begin{tabular}{|c|c|c|c|}
\hline FUNÇÕES & SUBFUNÇÕES & & \\
\hline $\begin{array}{l}1 \quad \text { Apoio ao } \\
\text { Diagnóstico }\end{array}$ & $\begin{array}{l}\text { 1.1: Coleta de amostras } \\
\text { biológicas }\end{array}$ & $\begin{array}{l}\text { 1.2: Manipulação de } \\
\text { amostras biológicas }\end{array}$ & $\begin{array}{l}\text { 1.3: Execução de } \\
\text { exames laboratoriais }\end{array}$ \\
\hline $\begin{array}{l}2 \text { Educação para } \\
\text { a Saúde }\end{array}$ & $\begin{array}{l}\text { 2.1: Educação para o } \\
\text { autocuidado }\end{array}$ & -- & -- \\
\hline $\begin{array}{l}3 \text { Proteção e } \\
\text { Prevenção }\end{array}$ & $\begin{array}{l}\text { 3.1: Promoção da saúde e } \\
\text { segurança no trabalho. }\end{array}$ & $\begin{array}{l}3.2 \text { Biossegurança nas } \\
\text { ações }\end{array}$ & $\begin{array}{l}\text { 3.3: Operação dos } \\
\text { equipamentos }\end{array}$ \\
\hline $\begin{array}{l}4 \text { Recuperação/ } \\
\text { Reabilitação }\end{array}$ & $\begin{array}{l}\text { 4.1: Prestação de } \\
\text { primeiros socorros }\end{array}$ & -- & -- \\
\hline $\begin{array}{l}5 \text { Gestão em } \\
\text { saúde }\end{array}$ & $\begin{array}{l}\text { 5.1: Organização do } \\
\text { Processo de trabalho }\end{array}$ & $\begin{array}{l}\text { 5.2: Organização do } \\
\text { Processo de trabalho em } \\
\text { Biodiagnóstico }\end{array}$ & -- \\
\hline
\end{tabular}


Figura 4 - Subfunções específicas da Subárea de Enfermagem, segundo funções e subfunções

\begin{tabular}{|c|c|c|c|c|c|c|c|}
\hline \multirow[b]{2}{*}{$\begin{array}{l}\text { FUNÇÕES } \\
1 . \\
\text { Apoio ao } \\
\text { diagnós- } \\
\text { tico }\end{array}$} & \multicolumn{7}{|c|}{ SUBFUNÇÕES } \\
\hline & $\begin{array}{l}1.1 \\
\text { Prepara- } \\
\text { ção e } \\
\text { acompa- } \\
\text { nhamento } \\
\text { de } \\
\text { exames } \\
\text { diagnósti- } \\
\text { cos }\end{array}$ & -- & -- & -- & -- & -- & -- \\
\hline $\begin{array}{l}2 . \\
\text { Educação } \\
\text { para a } \\
\text { saúde }\end{array}$ & $\begin{array}{l}2.1 \\
\text { Educação } \\
\text { para o } \\
\text { autocuida } \\
\text { do }\end{array}$ & -- & -- & -- & -- & -- & -- \\
\hline $\begin{array}{l}3 . \\
\text { Proteção e } \\
\text { prevenção }\end{array}$ & $\begin{array}{l}3.1 \\
\text { Promoção } \\
\text { da Saúde } \\
\text { e } \\
\text { Seguran- } \\
\text { ça no } \\
\text { trabalho }\end{array}$ & $\begin{array}{l}3.2 \\
\text { Biossegu- } \\
\text { rança nas } \\
\text { ações de } \\
\text { saúde }\end{array}$ & \begin{tabular}{|l|}
3.3 \\
Promoção \\
da \\
biossegu- \\
rança nas \\
ações de \\
Enferma- \\
gem \\
\end{tabular} & $\begin{array}{l}3.4 \\
\text { Assistên- } \\
\text { cia em } \\
\text { Saúde } \\
\text { Coletiva }\end{array}$ & -- & -- & -- \\
\hline $\begin{array}{l}4 . \\
\text { Recupe- } \\
\text { ração / } \\
\text { Reabili- } \\
\text { tação }\end{array}$ & $\begin{array}{l}4.1 \\
\text { Prestação } \\
\text { de } \\
\text { Primeiros } \\
\text { Socorros }\end{array}$ & $\begin{array}{l}4.2 \\
\text { Assistên- } \\
\text { cia a } \\
\text { clientes/ } \\
\text { pacientes } \\
\text { em } \\
\text { tratamen- } \\
\text { to clínico }\end{array}$ & $\begin{array}{l}4.3 \\
\text { Assistên- } \\
\text { cia a } \\
\text { clientes/ } \\
\text { pacientes } \\
\text { em } \\
\text { tratamen- } \\
\text { to } \\
\text { cirúrgico }\end{array}$ & $\begin{array}{l}4.4 \\
\text { Assistên- } \\
\text { cia em } \\
\text { saúde } \\
\text { mental }\end{array}$ & $\begin{array}{l}4.5 \\
\text { Assistên- } \\
\text { cia a } \\
\text { clientes/ } \\
\text { pacientes } \\
\text { em } \\
\text { situações } \\
\text { de } \\
\text { urgência e } \\
\text { emergên- } \\
\text { cia }\end{array}$ & $\begin{array}{l}4.6 \\
\text { Assistên- } \\
\text { cia à } \\
\text { criança, } \\
\text { ao adoles- } \\
\text { cente } \\
\text { jovem e à } \\
\text { mulher }\end{array}$ & $\begin{array}{l}4.7 \\
\text { Assistên- } \\
\text { cia a } \\
\text { pacientes } \\
\text { em estado } \\
\text { grave }\end{array}$ \\
\hline $\begin{array}{l}5 . \\
\text { Gestão }\end{array}$ & $\begin{array}{l}5.1 \\
\text { Organiza- } \\
\text { ção do } \\
\text { processo } \\
\text { de } \\
\text { Trabalho } \\
\text { em saúde }\end{array}$ & $\begin{array}{l}5.2 \\
\text { Organiza- } \\
\text { ção do } \\
\text { Processo } \\
\text { de } \\
\text { trabalho } \\
\text { em } \\
\text { Enferma- } \\
\text { gem }\end{array}$ & -- & -- & -- & -- & -- \\
\hline
\end{tabular}


Diante das Fig. 3 e 4, observamos que apesar das subáreas de Biodiagnóstico e Enfermagem possuírem as subfunções comuns aos demais profissionais da área da saúde, referentes ao núcleo da área, estas competências e habilidades gerais não são suficientes para a atuação no setor de coleta de exames do laboratório de análises clínicas.

Para tal atuação, a função Apoio ao Diagnóstico possui a subfunção $n^{\circ} 1.1$ que, na subárea de Biodiagnóstico recebeu o nome de Coleta de amostras biológicas e na Enfermagem, de Preparação e acompanhamento de exames diagnósticos. Esta subfunção visa ao desenvolvimento de habilidades e competências específicas para o trabalho na coleta do laboratório de análises clínicas, como pode ser observado nas Fig. 3 e 4.

\section{FUNÇÃO 1 - APOIO AO DIAGNÓSTICO}

\section{SUBÁREA: BIODIAGNÓSTICO}

\section{SUBFUNÇÃO 1.1 Coleta de amostras biológicas}

Esta subfunção reúne atividades de preparo do cliente/paciente, a escolha do material, o desenvolvimento de técnicas adequadas ao estado fisiopatológico do cliente/paciente, a escolha da região da coleta, quando não indicada pelo profissional requisitante do exame e sua realização propriamente dita. Compreende ainda as orientações relativas ao aspecto nutricional, ingestão de medicamentos, álcool, drogas de abuso, assepsia, repouso, jejum, quantidade de material a ser colhido ou momento adequado de coleta (quando realizado pelo próprio cliente/paciente), que devem ser 
fornecidas para que o resultado das análises seja fiel às condições fisiopatológicas.

Competências

- Interpretar corretamente requisições médicas e de outros profissionais assim como siglas, abreviações e a sinonímia utilizada nos exames laboratoriais para evitar erros;

- Identificar e selecionar os materiais e acessórios necessários para a coleta das diversas amostras biológicas;

- Selecionar e caracterizar, anticoagulantes e conservantes, de acordo com cada caso específico;

- Selecionar o campo ou local da coleta de amostras, levando em consideração as condições fisiopatológicas do cliente/paciente e respeitando as normas/exigências para a coleta de amostras biológicas;

- Correlacionar características dos recipientes com suas finalidades, identificando as amostras coletadas;

- Caracterizar, identificar os cuidados a serem tomados, antes e depois da coleta de amostras para exames laboratoriais, de acordo com cada caso;

- Reconhecer a importância da vacinação e sua interferência nos resultados laboratoriais;

- Caracterizar e reconhecer os valores éticos a serem usados pelos profissionais do laboratório;

- Identificar e avaliar as condições do cliente/paciente no momento da coleta; com o objetivo de evitar possíveis erros nos resultados dos exames. 


\section{Habilidades}

- Coletar os diferentes materiais biológicos para exames laboratoriais, em quantidade suficiente, demonstrando domínio da técnica de coleta relativa a cada material;

- Utilizar os materiais e acessórios necessários para coleta dos diversos tipos amostras biológicas;

- Utilizar adequadamente anticoagulantes e conservantes;

- Identificar frascos de amostras coletadas;

- Informar ao cliente/paciente os cuidados a serem tomados, antes da coleta de amostras para exames laboratoriais, de acordo com cada caso;

- Orientar o cliente/paciente sobre a interferência da vacinação nos resultados dos exames laboratoriais;

- Aplicar os preceitos éticos durante a realização das atividades laboratoriais;

- Utilizar técnicas de relacionamento humano para o bom atendimento ao cliente/paciente;

- Colher amostras dos diferentes materiais biológicos para exames laboratoriais, de acordo com a técnica;

- Utilizar a terminologia técnica da área de laboratório de biodiagnóstico.

Bases Tecnológicas

- Técnicas básicas para a qualidade, a confiabilidade e a segurança de resultados de exames;

- Princípios de garantia de qualidade e qualidade total;

- NBRs relacionadas à atividade laboratorial de biodiagnóstico; 
- Normas ISO relacionadas à atividade;

- Noções de assepsia: anti-sépticos, desinfetantes e métodos de esterilização;

- Ética profissional;

- Mecanismo de ação de reagentes, conservantes e anticoagulantes;

- Técnicas para coleta de amostras biológicas;

- Fontes de obtenção e metabolismo de nutrientes: glicídios, lipídios, e proteínas (dieta);

- Hormoniologia clínica: variação de taxas hormonais;

- Noções de Farmacocinética e Farmacodinâmica (mecanismo de ação dos medicamentos);

- Reações imunológicas (reação antígeno-anticorpo);

- Siglas, abreviações e sinonímias dos exames e termos técnicos relacionados ao laboratório de análises clínicas;

- Nomes e símbolos das unidades do Sistema de Unidades de medidas aplicáveis à área;

- Manuais de instalação e utilização de aparelhos;

- Noções de informática para utilização de banco de dados: rótulos e etiquetas;

- Técnicas de atendimento ao cliente/paciente. 
SUBFUNÇÃO 1.2 Manipulação de amostras biológicas

Relaciona-se às atividades de acondicionamento e armazenamento de reagentes químicos e amostras biológicas, tanto nas áreas internas ao laboratório como no transporte externo destes materiais, obedecendo às regras de biossegurança para 0 transporte de substâncias infectocontagiosas e substâncias químicas, bem como a manutenção da qualidade e validade destes produtos e amostras biológicas.

SUBFUNÇÃO 1.3 Execução de exames laboratoriais

Compreende as ações específicas para a execução de exames laboratoriais, desde o recebimento das amostras, até a avaliação e liberação dos resultados das análises executadas, sem a intenção de emitir laudo (laudar) ou diagnosticar.

\section{SUBÁREA: ENFERMAGEM}

SUBFUNÇÃO 1.1 Preparação e acompanhamento de exames diagnósticos Compreende as atividades executadas antes, durante e após exames com fins de diagnóstico.

\section{Competências}

- Selecionar materiais e equipamentos necessários ao exame clínico geral e especializado, assim como verificar seu funcionamento;

- Identificar e caracterizar as medidas antropométricas e sinais vitais e reconhecer a importância das mesmas na avaliação da saúde do cliente/paciente; 
- Identificar e caracterizar as posições corretas para exames;

- Definir as características das técnicas de enfermagem relacionadas à higiene, conforto e à segurança do cliente/paciente e de coleta de material para exame;

- Enumerar, definir e caracterizar os principais exames reconhecendo materiais e equipamentos utilizados;

- Conhecer as técnicas de acondicionamento identificação, guarda, conservação e encaminhamento dos materiais coletados;

- Conhecer e caracterizar os principais exames e os cuidados de enfermagem necessários à sua realização.

Habilidades

- Preparar material e local necessários, auxiliar e/ou proceder à coleta de material para o exame;

- Informar, orientar, encaminhar, preparar, apoiar e posicionar o cliente/paciente, antes e durante o exame a ser realizado;

- Executar técnicas de mensuração antropométricas (peso, altura) e verificar sinais vitais;

- Encaminhar o cliente/ paciente no retorno ao local de espera, ou leito apoiando-o quando necessário;

- Operar equipamentos e manusear materiais necessários ao exame;

- Registrar e anotar ocorrências e os cuidados prestados, de acordo com as exigências e normas;

- Acondicionar, identificar corretamente o material coletado encaminhandoo ao laboratório de destino; 
- Posicionar o cliente/paciente, de acordo com o exame a que irá submeter-se.

Bases Tecnológicas

- Materiais necessários ao exame clínico geral e especializados.

- Medidas antropométricas;

- Técnica de verificação de peso, altura e sinais vitais;

- Sinais vitais (parâmetros normais);

- Noções básicas de exames clínicos e exame físico;

- Posições para exames;

- Técnicas básicas de Enfermagem em higiene, conforto e segurança do paciente;

- Normas técnicas sobre funcionamento de aparelhos e equipamentos específicos;

- Normas e rotinas de anotações e registros em formulários padronizados;

- Noções básicas sobre os principais exames laboratoriais, radiológicos e especializados;

- Materiais e equipamentos utilizados;

- Noções de bioquímica;

- Normas técnicas e rotinas sobre coleta de materiais para exames.

A Enfermagem não possui as subfunções 1.2 Manipulação de amostras biológicas e a 1.3 Execução de exames laboratoriais.

No que diz respeito à subfunção 1.1 Coleta de amostras biológicas, destacamos as competências, habilidades e bases tecnológicas, por ser esta a subfunção comum à Enfermagem e ao Biodiagnóstico que Ihes conferem 
adjetivos para trabalharem no setor de coleta de exames. Observa-se que ambas subáreas têm competências, habilidades e bases tecnológicas muito semelhantes para executar adequadamente esta subfunção.

Apesar de terem abordagens diferentes na execução desta atividade, pois além do material analisado no documento, segundo nossa experiência de trabalho no setor de coleta de exames de um laboratório clínico, a Enfermagem dá ênfase maior ao cuidado, pois, no Biodiagnóstico, a ênfase está nos aspectos mais técnicos da coleta dos exames: observação dos anticoagulantes e conservantes, siglas e abreviações, normas de qualidade, manuais de instalação e utilização de equipamentos.

Apesar de cada profissional ter seu enfoque de atuação moldado pela formação acadêmica, tanto o cuidado e a ênfase na interação, quanto aos aspectos mais estritamente técnicos da coleta de exames, são qualidades necessárias a todos os profissionais que atuam na coleta de exames laboratoriais para que a amostra seja coletada corretamente, propiciando resultados e, conseqüentemente, tratamentos seguros.

Relacionado às subfunções 1.2 Manipulação de amostras biológicas e a 1.3 Execução de exames laboratoriais, o técnico de laboratório e de patologia clínica desenvolvem atividades específicas da profissão, ao contrário do técnico de enfermagem que se detém à coleta da amostra biológica e a alguns pontos da manipulação das amostras referentes ao transporte e armazenamento. Além disso, a Lei do Exercício Profissional da Enfermagem não prevê a manipulação em nível analítico das amostras coletadas. 
A seguir, são comparadas as outras funções e subfunções das subáreas em questão, a fim de se obter o perfil dos profissionais técnicos em enfermagem e em biodiagnóstico.

\section{FUNÇÃO 2 - EDUCAÇÃO PARA A SAÚDE}

SUBFUNÇÃO 2.1 Educação para o autocuidado

Comum às subáreas de Biodiagnóstico e de Enfermagem.

\section{FUNÇÃO 3 - PROTEÇÃO E PREVENÇÃO}

SUBFUNÇÃO 3.1 Promoção da saúde e segurança do trabalho SUBFUNÇÃO 3.2 Biossegurança nas ações de saúde

Estas duas subfunções são comuns às subáreas de Biodiagnóstico e de Enfermagem.

\section{SUBÁREA: BIODIAGNÓSTICO}

SUBFUNÇÃO 3.3 Operação dos equipamentos próprios da área

As atividades de controle de qualidade para validação das análises executadas fazem parte dessa subfunção, a partir da realização de pequenos reparos em equipamentos, controle estatístico dos resultados, calibração rotineira destes equipamentos visando à regularidade dos exames laboratoriais, bem como a manutenção, limpeza e desinfecção.

SUBÁREA: ENFERMAGEM

SUBFUNÇÃO 3.3 Promoção da Biossegurança nas ações de enfermagem 
Atividades relativas ao tratamento dado aos indivíduos, ao meio ambiente, aos materiais e equipamentos e ao uso de técnicas específicas com o objetivo de prevenir e controlar infecções.

Os tratamentos dados aos materiais incluem os métodos de descontaminação, limpeza, preparo, desinfecção e esterilização e são realizados no domicílio, em qualquer unidade de saúde e, especificamente, nos Centros de material e esterilização.

Nesta subfunção, há uma diferença entre a formação dos profissionais das subáreas analisadas, a começar pelo nome da subfunção que no Biodiagnóstico recebe o título de Operação dos equipamentos próprios da área e na Enfermagem, Promoção da Biossegurança nas ações de enfermagem.

Segundo nossa interpretação do documento analisado, na subárea de Biodiagnóstico, o enfoque está na segurança de operação dos equipamentos e nos resultados confiáveis, bem como o domínio dos equipamentos e aparelhos utilizados na rotina do laboratório, enquanto na subárea de Enfermagem a atenção está voltada para a segurança do trabalhador de enfermagem, conhecimentos e execução de técnicas relacionadas à prevenção de infecções.

SUBFUNÇÃO 3.4 Assistência em Saúde Coletiva

É a atenção de enfermagem prestada ao indivíduo nas diferentes faixas etárias, famílias, grupos e comunidade, relacionados à: 
- Educação para saúde sobre medidas de proteção à saúde, prevenção de doenças prevalentes, endemias, epidemias, doenças preveníveis por imunizações, riscos e agravos à saúde; atendimento às necessidades básicas do indivíduo, efeito de medicamentos, de vacinas, de imunobiológicos;

- Cuidados com administração, manuseio, conservação e controle destes;

- Identificação precoce de sinais e sintomas de desequilíbrio orgânico, emocional e social e causas de riscos e agravos à saúde;

- Registro de fatores detectados que provocam desequilíbrio da saúde individual e coletiva, com vistas a traçar o perfil epidemiológico da comunidade, e interagir com a mesma em busca de soluções em nível local, regional e ou central para obter êxito nas condutas em defesa da saúde e melhoria da qualidade de vida.

A subárea de Biodiagnóstico não possui a subfunção 3.4 Assistência em saúde coletiva.

Esta subfunção não é desenvolvida pelos técnicos da subárea de Biodiagnóstico, talvez, por sua função estar basicamente voltada aos equipamentos e aparelhos do laboratório de análises clínicas, ao contrário da enfermagem, que tem seu objeto de trabalho centrado no cuidar, e por isso tem esta disciplina em sua formação acadêmica.

\section{FUNÇÃO 4. RECUPERAÇÃO / REABILITAÇÃO}

SUBFUNÇÃO 4.1 Prestação de primeiros socorros

Comum às subáreas de Biodiagnóstico e de Enfermagem. 
SUBÁREA: BIODIAGNÓSTICO

SUBFUNÇÃO 4.2 Assistência a clientes/pacientes em tratamento clínico SUBFUNÇÃO 4.3 Assistência a clientes/pacientes em tratamento cirúrgico SUBFUNÇÃO 4.4 Assistência em saúde mental SUBFUNÇÃO 4.5 Assistência a clientes/pacientes em situações de urgência e emergência

SUBFUNÇÃO 4.6 Assistência à criança, ao adolescente/jovem e à mulher SUBFUNÇÃO 4.7 Assistência a pacientes em estado grave A subárea de Biodiagnóstico não prevê estas subfunções.

\section{SUBÁREA: ENFERMAGEM}

SUBFUNÇÃO 4.2 Assistência a clientes/pacientes em tratamento clínico

É a atenção de enfermagem às necessidades básicas do cliente/paciente nas diferentes faixas etárias, em especial, adultos e idosos, com afecções agudas ou crônicas em tratamento clínico, visando a efetivar o tratamento, evitar complicações, manter ao máximo a capacidade funcional e a adaptação às limitações conseqüentes da doença, além de promover o autocuidado.

As ações de enfermagem poderão desenvolver-se no domicílio, serviços de saúde e unidades de referência. 
SUBFUNÇÃO 4.3 Assistência a clientes/pacientes em tratamento cirúrgico

É a atenção de enfermagem às necessidades básicas dos clientes/pacientes nas diferentes faixas etárias em tratamento cirúrgico, nos períodos pré, trans e pós-operatórios, compreendendo:

Aplicação de princípios científicos e execução de procedimentos que minimizem os riscos cirúrgicos;

Incentivo ao autocuidado; promoção de apoio e segurança, reabilitação com vistas à rápida reintegração sociofamiliar. As ações de enfermagem poderão ser realizadas, no domicílio, nos serviços de saúde e, especialmente, nas unidades de referência.

SUBFUNÇÃO 4.4 Assistência em saúde mental

É a atenção de enfermagem às necessidades básicas do cliente/paciente, visando à promoção/manutenção e à recuperação de sua integridade mental, emocional e o equilíbrio na relação com o meio em que vive. Esta atenção relaciona-se a: conhecimento dos sinais e sintomas dos quadros agudos e crônicos dos transtornos mentais; estabelecimento de comunicação adequada com os portadores de transtornos mentais e usuários de diferentes drogas; identificação das alternativas de tratamento; interpretação e aplicação das normas do exercício profissional de enfermagem relativas à saúde mental e psiquiátrica; registro de ocorrências, observações, procedimentos e cuidados realizados; interação com os familiares do cliente/paciente e com os profissionais da equipe de saúde e de enfermagem em defesa dos princípios da assistência à saúde mental. As 
ações são desenvolvidas no domicílio, em serviços de saúde e, especialmente, nas unidades de referência.

SUBFUNÇÃO 4.5 Assistência a clientes/pacientes em situações de urgência e emergência

É a atenção de enfermagem a indivíduos nas diferentes faixas etárias, vítimas de acidentes e agravos à saúde e que necessitam cuidados em caráter de urgência e emergência. Os cuidados são prestados nos serviços de saúde, unidades móveis de atendimento e de referência em urgência e emergência, visando a eliminar e/ou minimizar os riscos de vida, evitar complicações, corrigir com a máxima urgência as causas e os efeitos dos agravos existentes.

SUBFUNÇÃO 4.6 Assistência à criança, ao adolescente/jovem e à mulher Refere-se à atenção de enfermagem que tem como enfoque especial:

- a criança sadia e portadora de patologias, monitorando seu crescimento e desenvolvimento nos períodos perinatal, de lactância, infantil, préescolar, escolar, pré-adolescência e adolescência;

- a promoção da saúde do jovem/adolescente, a prevenção/intervenção em comportamento de risco associados à violência, drogas, álcool, acidentes, suicídios, exploração sexual e comercial, delinqüência, comportamento sexual de risco, doenças sexualmente transmissíveis, gravidez e aborto. 
- a saúde da mulher abrangendo aspectos ginecológicos, de reprodução (obstétricos), de planejamento familiar, de prevenção de câncer cérvicouterino, de mama e de climatério.

Esses cuidados são prestados no domicílio, nos serviços de saúde, na escola e no ambiente de trabalho.

SUBFUNÇÃO 4.7 Assistência à pacientes em estado grave

É a atenção às necessidades básicas de pacientes em qualquer faixa etária, que estejam em estado grave e/ou agonizante. Os cuidados são prestados nas unidades de internação e, especialmente, em Unidade de Tratamento Intensivo - UTI geral, unidades coronariana, de diálise, de queimados e outras visando ao conforto físico, mental e espiritual, eliminar e/ou minimizar riscos e agravos, promover recuperação isenta de seqüelas, orientar e apoiar familiares durante a internação e no preparo para alta.

As subfunções 4.2 Assistência a clientes/pacientes em tratamento clínico; 4.3 Assistência a clientes/pacientes em tratamento cirúrgico; 4.4 Assistência em saúde mental; 4.5 Assistência a clientes/pacientes em situações de urgência e emergência; 4.6 Assistência à criança, ao adolescente/jovem e à mulher; 4.7 Assistência a Pacientes em estado grave não são desenvolvidos pelos técnicos da subárea de Biodiagnóstico, talvez, porque, seu objeto de trabalho está voltado diretamente à análise das amostras biológicas. 
Como o enfoque da enfermagem está centrado no cuidado, esta desenvolve as ações relacionadas à assistência ao paciente/cliente clínico e cirúrgico, em saúde mental, ao paciente em situação de urgência, à criança/adolescente/mulher e ao paciente em estado grave, pois tem competências, habilidades e bases tecnológicas voltadas à assistência de enfermagem.

\section{FUNÇÃO 5 - GESTÃO EM SAÚDE}

SUBFUNÇÃO 5.1 Organização do processo de trabalho em saúde

Comum às subáreas de Biodiagnóstico e de Enfermagem.

\section{SUBÁREA: BIODIAGNÓSTICO}

SUBFUNÇÃO 5.2 Organização do Processo de Trabalho em Laboratório de Biodiagnóstico

Esta subfunção compreende as atividades organizacionais como previsão e provisão, realização de compras de reagentes, vidrarias e materiais de consumo, realização de mapas e relatórios com finalidade estatística, elaboração de cadastros de fornecedores e clientes, implantação e manutenção de rotinas que tornem o laboratório eficiente e eficaz, bem como todas as atividades que tenham como finalidade o funcionamento adequado do laboratório de análises clínicas.

SUBÁREA: ENFERMAGEM

SUBFUNÇÃO 5.2- Processo de Trabalho em Enfermagem 
Visa a discutir a dinâmica do processo de trabalho na atenção de enfermagem individual, coletiva e na pesquisa, com a perspectiva de formar uma postura pessoal e profissional coerente com a cidadania.

Nesta subfunção, cada profissional de Biodiagnóstico e de Enfermagem aprendem e desenvolvem ações pertinentes ao processo de trabalho de sua subárea de atuação, bem como conhece os aspectos históricos, éticos, de pesquisa e de postura profissional.

Diante dos Referenciais Curriculares Nacionais para a Educação Profissional de Nível Técnico da Área de Saúde, observam-se semelhanças, especificidades e interfaces das subáreas de Biodiagnóstico e de Enfermagem, já iniciadas na formação profissional.

O cenário da subárea de Biodiagnóstico possui, também, um quadro de recursos humanos composto por trabalhadores que, conforme a Portaria $\mathrm{n}^{\circ}$ CVS-01, pertencem ao nível médio, também chamado de intermediário, pois não possuem formação específica sobre a subárea e são treinados em serviço pelos responsáveis técnicos do setor onde atuam ou vão atuar. 
ANEXO II : Tabela de Dígitos Casuais ou Aleatórios*

\begin{tabular}{|c|c|c|c|c|}
\hline 0347437386 & 3696473661 & 4698637162 & 3326168045 & 6011141095 \\
\hline 9774246762 & 4281145720 & 4253323732 & 2707360751 & 2451798973 \\
\hline 1676622766 & 5650267107 & 3290797853 & 1355385859 & 8897541410 \\
\hline 1256859926 & 9696682731 & 0503729315 & 5712101421 & 8826498176 \\
\hline 559563564 & 3854824622 & 3162430990 & 0618443253 & 2383013030 \\
\hline 1622779439 & 4954435482 & 1737932378 & 8735209643 & 8426349164 \\
\hline 442175331 & 5724550688 & 7704744767 & 2176335025 & 8392120676 \\
\hline 6301637859 & 1695556719 & 9810507175 & 1286735807 & 4439523879 \\
\hline 3321123429 & 7864560782 & 5242074438 & 1551001342 & 9966027954 \\
\hline 5760863244 & 0947279654 & 4917460962 & 9052847727 & 0802734328 \\
\hline 1818079246 & 4417165809 & 7983861962 & 0676500310 & 5523640505 \\
\hline 2662389775 & 8416074499 & 8311463224 & 2014858845 & 1093728871 \\
\hline 2342406474 & 8297777781 & 0745321408 & 3298940772 & 9385791075 \\
\hline 5236281995 & 5092261197 & 0056763138 & 8022025353 & 8660420453 \\
\hline 785943512 & 8339500830 & 4234079688 & 5442068798 & 3585294839 \\
\hline 7029171213 & 4033203826 & 1389510374 & 1776371304 & 0774211930 \\
\hline 5662183735 & 9683508775 & 9712259347 & 7033240354 & 9777464480 \\
\hline 9949572277 & 8842954572 & 1664361600 & 0443186679 & 9477242190 \\
\hline 1608150472 & 3327143409 & 4559346849 & 1272073445 & 9927729514 \\
\hline 3116933243 & 5027898719 & 2015370049 & 5285666044 & 3868881180 \\
\hline 6834301370 & 5574307740 & 4422788426 & 0433460952 & 6807970657 \\
\hline 7457256576 & 5929976860 & 7191386754 & 1358182476 & 1554559552 \\
\hline 2742378653 & 4855906572 & 9657693610 & 9646924245 & 9760490491 \\
\hline 0039682961 & 6637322030 & 7784570329 & 1045650426 & 1104966724 \\
\hline 2994989424 & 6849691082 & 5375919330 & 3425205727 & 4048735192 \\
\hline 1690826659 & 8362641112 & 6719007174 & 6047212968 & 0202370331 \\
\hline 1127947506 & 0609197466 & 0294373402 & 7670903086 & 3845943038 \\
\hline 3524101620 & 3332512638 & 7978450491 & 1692535616 & 0275509598 \\
\hline 3823168638 & 4238970150 & 8775668141 & 4001749162 & 4851840832 \\
\hline 3196259147 & 9644334913 & 3486825391 & 0052434885 & 2755268962 \\
\hline 6667406714 & 6405719586 & 1105650968 & 7683203790 & 5716001166 \\
\hline 1490844511 & 7573880590 & 5227411486 & 2298122208 & 0752749580 \\
\hline 6805511800 & 3396027519 & 0760629355 & 5933824390 & 4937384459 \\
\hline 2046787390 & 9751401402 & 0402333108 & 3954164936 & 4795931330 \\
\hline 6419589779 & 1506159320 & 0190107506 & 4078788962 & 0267741733 \\
\hline 0526937060 & 2235851513 & 9203515977 & 5956780683 & 5291057074 \\
\hline 0797108823 & 0998429964 & 6171629915 & 0651291693 & 5805770951 \\
\hline 6871868585 & 5487664754 & 7332081112 & 4495926316 & 2956242948 \\
\hline 2699616553 & 5837788070 & 4210506742 & 3217558574 & 9444671694 \\
\hline 1465526875 & 8759362241 & 2678630655 & 1308270150 & 1529393943 \\
\hline 1753775871 & 7141615072 & 1241949626 & 4495273699 & 0296743083 \\
\hline 9026592119 & 2352233312 & 9693021839 & 0702183607 & 2599327023 \\
\hline 4123525599 & 3104496996 & 1047484588 & 1341438920 & 9717144917 \\
\hline 6020508169 & 3199736868 & 3581330376 & 2430124860 & 1899107234 \\
\hline 9125380590 & 9458284136 & 4537590309 & 9035572912 & 8262546560 \\
\hline 3450577437 & 9880330091 & 0977931982 & 7494800404 & 4507316649 \\
\hline 8522043943 & 7381539479 & 3362468628 & 0831544631 & 5394133847 \\
\hline 0979137748 & 7382972221 & 0503272483 & 7289440560 & 3580399488 \\
\hline 8875801814 & 2295754249 & 3932822249 & 0248077037 & 1604616787 \\
\hline 9096237000 & 3900030690 & 5585783836 & 9437306932 & 9089007633 \\
\hline
\end{tabular}


(Continuação)

\begin{tabular}{|c|c|c|c|c|}
\hline 5374239967 & 6132286984 & 9462678624 & 9833411995 & 4753533809 \\
\hline 6338068654 & 9900652694 & 0282902307 & 7962678060 & 7591128119 \\
\hline 3530582146 & 0672171094 & 2521317596 & 4928240049 & 5565797807 \\
\hline 6343368269 & 6551183788 & 6138441245 & 3292858865 & 5434818535 \\
\hline 9825375526 & 0191828146 & 7471129497 & 2402713707 & 0392186675 \\
\hline 0263211769 & 7150808956 & 3815701148 & 4340458698 & 0083269103 \\
\hline 6455222182 & 4822280600 & 6154134391 & 8278122329 & 0666241227 \\
\hline 8507261389 & 0110078204 & 5963693603 & 6911158380 & 1329541928 \\
\hline 5854162415 & 5154448200 & 6261650469 & 3818651897 & 8572134921 \\
\hline 3485278487 & 6148645626 & 9018481326 & 3770154257 & 6565803907 \\
\hline 0392182746 & 5799169656 & 3033728522 & 8464385698 & 9901309864 \\
\hline 6295302759 & 3775416648 & 8697806145 & 2353040163 & 4576086427 \\
\hline 0845931522 & 60217546910 & 9877278542 & 2888610884 & 6962034273 \\
\hline 0708551840 & 4544751390 & 2494966102 & 5755668315 & 7342371161 \\
\hline 0185899566 & 5110193488 & 1584971975 & 1276394378 & 6463910825 \\
\hline $728471 \quad 1435$ & 1911584926 & 5011171776 & 8631572018 & 9560784675 \\
\hline 8878281684 & 1352539453 & 7545693096 & 7389657031 & 9917434876 \\
\hline 4517756557 & $28401972 \quad 12$ & 2512747567 & 6040608119 & 2462016116 \\
\hline 9676281254 & 2201119425 & 7196161688 & 6864367445 & 1959508892 \\
\hline 4331677230 & 2402940863 & 3832366602 & 6936382539 & 4803451522 \\
\hline 5044664421 & 6606580562 & 6815543502 & 4235489632 & 1452415248 \\
\hline 2266221586 & 2663754199 & 5842367224 & 5837521851 & 0337183911 \\
\hline 9624401451 & 2322308857 & 9567472983 & 9469400607 & 1816367886 \\
\hline 3173916119 & 6020729348 & 9857072369 & 6595396958 & 5680301944 \\
\hline 7860739984 & 4389943645 & 5669470741 & 9022910712 & 7835340872 \\
\hline 8437906156 & 7010239805 & 8511347660 & 7648453460 & 0164183996 \\
\hline 3667100823 & 9893350886 & 9929762981 & 3334915893 & 6314523252 \\
\hline 0728590748 & 8964588975 & 8385622789 & 3014785627 & 8663598002 \\
\hline 1015838760 & 7924316656 & 2148240693 & 9198940549 & 0147593800 \\
\hline 5519689765 & 0373521656 & 0053559027 & 3342293887 & 2213888334 \\
\hline 5381291339 & 3501207134 & $62337482 \quad 14$ & 5373190903 & 5654295693 \\
\hline 5186326892 & 3398746699 & 4014719458 & 4594193881 & 1444998107 \\
\hline 3591702913 & 8003540727 & 9694783266 & 5095527433 & 1380556254 \\
\hline 3771679513 & 2002449594 & 6485040572 & 0132907614 & 5389746041 \\
\hline 9366138327 & 9279646472 & 2854965384 & 4814529894 & 5607938930 \\
\hline 0296084565 & 1305004184 & 9307547259 & 2145570977 & 1948562744 \\
\hline 4983434835 & 8288336996 & 7236041976 & 4745151860 & 8211089597 \\
\hline 8460716246 & 4080813037 & 3439230538 & 2515357130 & 8812572177 \\
\hline 1817308871 & 4491148847 & 8923306315 & 5634204789 & 9982932498 \\
\hline 7969106178 & 7132769562 & 8700225840 & 9254017525 & 4311719931 \\
\hline 7593365783 & 5620148211 & 7421979065 & 9642686386 & 7454132694 \\
\hline 3830922903 & 0628813938 & 6225068463 & 6129089367 & 0432920809 \\
\hline 5129501034 & 3157759580 & 5197027477 & 7615484944 & 1855637709 \\
\hline 2131388624 & 3779815374 & 7324161033 & 5283909476 & 7047145436 \\
\hline 2901238788 & 5802393767 & 4210142092 & 1655234245 & 5496091106 \\
\hline 9533952200 & 1874720018 & 3879586932 & 8176802692 & 8280842539 \\
\hline 9084607980 & 2436598738 & 8207538935 & 9635237918 & 0598900735 \\
\hline 4640629882 & 5497205695 & 1574800832 & 1646705080 & 6772164279 \\
\hline 2031890343 & 3846826872 & 3214829970 & 8060471897 & 6349302130 \\
\hline 7159730550 & 0822237177 & 9101932049 & 8296592694 & 6639679860 \\
\hline
\end{tabular}


(Continuação)

\begin{tabular}{|c|c|c|c|c|}
\hline 2217686584 & 6895239235 & 8702225751 & 6109439506 & 5824820347 \\
\hline 1936275946 & 1379933755 & 3977327709 & 8552053062 & 4783516274 \\
\hline 1677230277 & 0961872521 & 2806242593 & 1671135978 & 2305474725 \\
\hline 7843767161 & 2044903264 & 9767639961 & 4638039322 & 6981219921 \\
\hline 0328282608 & 7337320405 & 6930160905 & 8869582899 & 3507447547 \\
\hline 9322536439 & 0710637635 & 8703047988 & 0813138551 & 5534577269 \\
\hline 7876585474 & 9238709692 & 5206797945 & 8263182744 & 6966921909 \\
\hline 2368352600 & 9953936128 & 5270054834 & 5665056186 & 9092107080 \\
\hline 1539257099 & 9386527765 & 1533590528 & 2287260747 & 8696982906 \\
\hline 5871963024 & 1846233427 & 8513992444 & 4918097949 & 7416322302 \\
\hline 5735273372 & 2453639409 & 4110764791 & 4404954966 & 3960045981 \\
\hline 4850865448 & 2206347252 & 8221156520 & 3329947111 & 1591291203 \\
\hline 6196489503 & 0716393366 & 9856105679 & 7721302712 & 9049222362 \\
\hline 3693894126 & 2970836351 & 9974205236 & 8709411509 & 9860160303 \\
\hline 1887004231 & 5790120207 & 2347371731 & 5408018863 & 3941889210 \\
\hline 8856532759 & 3335726747 & 7734554570 & 0818273890 & 1695867075 \\
\hline 0972958429 & 4941310670 & 4238064518 & 6484733165 & 5253379715 \\
\hline 1296881731 & 6519690283 & 6075869068 & 2464193551 & 5661873912 \\
\hline 8594572416 & 9209843876 & 2200276985 & 2981947870 & 2194479012 \\
\hline 3864435998 & 9877876807 & 9151676244 & 4098059378 & 2332654118 \\
\hline 5344094272 & 0041867979 & 6847220020 & 3555315151 & 0083632255 \\
\hline 4076662684 & 5799999037 & 3663320858 & 3740136897 & 8764810783 \\
\hline 0217791805 & 1259525702 & 2207904703 & 2814113079 & 2069224098 \\
\hline 9517820653 & 3151109646 & 9206880777 & 5611508169 & 4023725139 \\
\hline 3576224292 & 9611834480 & 3468354877 & 3342409060 & 7396539786 \\
\hline 2629135641 & 8547046608 & 3472575913 & 8243804615 & 3826617004 \\
\hline 7780207582 & 7282329990 & 6395737663 & 8973449905 & 4867264318 \\
\hline 4640664452 & 9136744353 & 3082135400 & 7845639835 & 5503366768 \\
\hline 3756081809 & 7753844647 & 3191189558. & 2416741153 & 4410138557 \\
\hline 6165616866 & 3727473919 & 8483700748 & 5321400671 & 9506798854 \\
\hline 9343696407 & 3418045235 & 5627092486 & 6185538345 & 1990709900 \\
\hline 2196601299 & 1120994518 & 4813935534 & 1837794990 & 6597382046 \\
\hline 9520479797 & 2737832871 & 0006414174 & 4589093984 & 5167115249 \\
\hline 9786217873 & 1065819259 & 5876171497 & 0476621617 & 1795704580 \\
\hline 6992063413 & 5971741732 & 2755102419 & 2371821374 & 6352520141 \\
\hline 0431172156 & 3373991987 & 2672392767 & 5377576893 & 6061972261 \\
\hline 6106980391 & 8714774396 & 4300659850 & 4560330107 & 9899465047 \\
\hline 8593858688 & 7287086240 & 1606108920 & 2321347497 & 7638032963 \\
\hline 2174324745 & 7396079452 & 0965907747 & 2576161933 & 5305705330 \\
\hline 1569538280 & 7996235310 & 6539071629 & 4533024370 & 0287404145 \\
\hline 0289080449 & 2021146886 & 8763939517 & 1129019580 & 3514973533 \\
\hline 8718158979 & 8543017273 & 0861745169 & 8974398215 & 9451334167 \\
\hline 9883719422 & 5997509952 & 0852850840 & 8780616531 & 9151803244 \\
\hline 1008582166 & 7268492931 & 8985844606 & 5973198523 & 6509297563 \\
\hline 4790561008 & 8802842783 & 4229722319 & 6656456579 & 2071532025 \\
\hline 2285616890 & 4964928544 & 1640128988 & 5014498106 & 0182774512 \\
\hline 6780437933 & 1283114116 & 2558196870 & 7702540052 & 5343371526 \\
\hline 2762509672 & 7944614015 & 1453406539 & 2731585028 & 1139033425 \\
\hline 3378808715 & 3830063821 & 1447470726 & 5496875332 & 4036409676 \\
\hline 1313926699 & 4724495774 & 3225436217 & 1097116984 & 9963223298 \\
\hline
\end{tabular}


(Continuação)

\begin{tabular}{|c|c|c|c|c|}
\hline 1027539623 & 7150543623 & 5431048298 & 0414121509 & 2678254717 \\
\hline 2841506188 & 6485272018 & 8336360556 & 3971650962 & 9476621189 \\
\hline 3421425702 & 5919189748 & 8030033098 & 0524677007 & 8497508746 \\
\hline 6181772323 & 8282115408 & 5328705896 & 4407395543 & 4234433928 \\
\hline 6115181354 & 1686202688 & 9074805509 & 1453905117 & 5201630159 \\
\hline 9176216464 & 4491133297 & 7531626654 & 8480327577 & 5608257029 \\
\hline 0097790806 & 3730285985 & 5356685340 & 0174395973 & 3019998548 \\
\hline 3646183494 & 7520802777 & 7891691600 & 0843187368 & 6769613425 \\
\hline 8898996050 & 6595794294 & 9362408996 & 4356477166 & 4676296702 \\
\hline 0437598721 & 0502032417 & 4797815651 & 9234860182 & 5551331291 \\
\hline 6362063441 & 9421785509 & 7276451694 & 2995818383 & 7988019730 \\
\hline 7847235390 & 3441924571 & 0923707007 & 1238927943 & 1485114723 \\
\hline 8768621543 & 5314365925 & 5447337015 & 5924484035 & 5003429936 \\
\hline 4760921077 & 8859531152 & 6625690704 & 4868647106 & 6165702212 \\
\hline 5688875941 & 6528046753 & 9579883731 & 5041069476 & 8183171633 \\
\hline 0257458667 & 7343073448 & 4426879329 & 7709616784 & 0669447775 \\
\hline 3154141317 & 4862119060 & 6812936428 & 4624791676 & 1460255101 \\
\hline 2850164336 & 2897855899 & 6722527623 & 2470365454 & 5928617196 \\
\hline 6329626650 & 0263455238 & 6763475475 & 8324784320 & 9263134748 \\
\hline 4565582651 & 7696593872 & 8657457146 & 4467761455 & 4488016212 \\
\hline 3965366370 & 7745855051 & 7413393522 & 3053360295 & 4934887361 \\
\hline 7371981604 & 2918945123 & 7651948486 & 7993963863 & 0858255894 \\
\hline 7220562011 & 7265710886 & 7957951391 & 9748726648 & 0971172489 \\
\hline 7517269976 & 8937207001 & 7731619546 & 2697057351 & 5333187287 \\
\hline 3748608229 & 8130153914 & 4838759329 & 0687377848 & 4556008447 \\
\hline 6808028072 & 8371463049 & 8917958829 & 0239560346 & 9774065617 \\
\hline 1423986167 & 7052850150 & 0184027843 & 1062981941 & 1883994799 \\
\hline 4908962144 & 2527994128 & 0741083466 & 1942743991 & 4196537872 \\
\hline 7837060843 & 6361624229 & 3968951096 & 0924230062 & 5612807316 \\
\hline 3721341768 & 6896832356 & 3284601531 & 4473673477 & 9115797458 \\
\hline 1429093404 & 8783075507 & 7658308364 & 8729255884 & 8650600025 \\
\hline 5843280636 & 4952835114 & 4756912934 & 0587310695 & 1245570909 \\
\hline 1043672970 & 8062800342 & 1080213884 & 9056350309 & 4312744914 \\
\hline 4438883954 & 8697374422 & 0095013176 & 1716295663 & 3878944981 \\
\hline 9069591951 & 8539528513 & 0728370761 & 1116362703 & 7886720495 \\
\hline 4147102562 & 9705310361 & 2026363162 & 6869869544 & 8495484645 \\
\hline 9194146319 & 7589114711 & 3156341909 & 7957923659 & 1493878140 \\
\hline 8006541866 & 0918940619 & 9840071781 & 2245448411 & 2462204231 \\
\hline 6772776348 & 8408315558 & 2433457758 & 8045679382 & 7570160824 \\
\hline 5940241327 & 7926888630 & 0131601039 & 5358477093 & 8581563938 \\
\hline 0590358995 & 0161169694 & 5078136936 & 3768533731 & 7126350371 \\
\hline 4443806998 & 4668051482 & 9078500562 & 7779135744 & 5960103966 \\
\hline 6181319682 & 0057256059 & 4672601877 & 5566126211 & 0899556457 \\
\hline 4288071005 & 2498656321 & 4721618832 & 2780302160 & 1092353612 \\
\hline 7794300539 & 2810990027 & 1273739912 & 4999579482 & 9688571791 \\
\hline 7883197616 & 9411688426 & 2354208685 & 2386669907 & 3637349209 \\
\hline 8776596181 & 4363646161 & 6576369590 & 1848274568 & 2723653072 \\
\hline 9143059647 & 5578999524 & 3755857878 & 0148411910 & 3519540773 \\
\hline 8497777273 & 0962066572 & 8712490360 & 4115207627 & 5047022916 \\
\hline 8741607683 & 4488960780 & 8305833896 & 7370668190 & 3056104859 \\
\hline
\end{tabular}


(Continuação)

\begin{tabular}{|c|c|c|c|c|}
\hline 2889658708 & 1350630423 & 2547579113 & 5262241994 & 9167485710 \\
\hline 3029436542 & 7866285580 & 4746419008 & 5598781070 & 4992051207 \\
\hline 9574626053 & 5157322227 & 1272722777 & 4467322313 & 6795077630 \\
\hline 0185549672 & 6686656460 & 5659753675 & 4644336371 & 5450064475 \\
\hline 1091469686 & 1983524753 & 6500519351 & 3080051929 & 5623271903 \\
\hline 0533180851 & 5178572617 & 3487962395 & 8999933979 & 1128941552 \\
\hline 0443133700 & 7968962660 & 7039836656 & 6203558657 & 7755336202 \\
\hline 0585402524 & 7352937050 & 4821477463 & 1727275126 & 3596290045 \\
\hline 8490906577 & 6399256902 & 0904033578 & 1979950721 & 0284485197 \\
\hline 2855530948 & 8628300235 & 7130320647 & 9374218633 & 4990216974 \\
\hline 8983406980 & 9796475997 & 5633248736 & 1718169046 & 7527285213 \\
\hline 7320960568 & 9341699607 & 9750817959 & 4237138183 & 9242850431 \\
\hline 1089077621 & 4024743642 & 4033044624 & 3563023161 & 3459433696 \\
\hline 9150277837 & 0606162598 & 1778803685 & 2641776337 & 7163949433 \\
\hline 0345446688 & 9781260389 & 3946672117 & 9810393315 & 6163002592 \\
\hline 8941589163 & 6599599784 & 9014796155 & 5616888760 & 3215996743 \\
\hline 1343009726 & 1691213241 & 6022667217 & 3185336907 & 6849204329 \\
\hline 7171005172 & 6203892632 & 3527991825 & 7812030970 & 5093193556 \\
\hline 1928150041 & 9227734038 & 3711057516 & 9881993729 & 9220323967 \\
\hline 5638309230 & 4551946904 & 0084143637 & 9566390109 & 2168409579 \\
\hline 3927528911 & 0081062848 & 1208057526 & 0335630577 & 1381206758 \\
\hline 7313285801 & 0506422407 & 6060299993 & 7293780436 & 2576015403 \\
\hline 8160845157 & 1268465589 & 6009718789 & 7081109591 & 8379682066 \\
\hline 0562980785 & 0779266961 & 6785723741 & 8579764823 & 6158870805 \\
\hline 6297162918 & 5216162356 & 6295809763 & 3225340336 & 4884603765 \\
\hline 3113632108 & 1601925821 & 4879747372 & 0864809138 & 0728666159 \\
\hline 9738353419 & 8984053447 & 8809315488 & 9796860169 & 4613956596 \\
\hline 3211783382 & 5199984439 & 1275106036 & 8066399497 & 4236311659 \\
\hline 8199133705 & 0812603923 & 6173848918 & 2602043795 & 9618690630 \\
\hline 4574000305 & 6999472652 & 4806300018 & 0330285559 & 6610714405 \\
\hline 1184136901 & 8891287950 & 7142149655 & 9859960136 & 8877904559 \\
\hline 1466128722 & 5945270851 & 8564238541 & 6472085944 & 6798366556 \\
\hline 4025678782 & 8427173037 & 4869490258 & 9802505811 & 9539063563 \\
\hline 4448974943 & 6545534107 & 1483467411 & 7666636008 & 9054336584 \\
\hline 4194540657 & 4828018384 & 0911219173 & 9728447406 & 2230956972 \\
\hline 0712155884 & 9318318345 & 5452622991 & 5358546605 & 4719639275 \\
\hline 6427904352 & 1826329683 & 5058452757 & 1496396485 & 7387967623 \\
\hline 8071864103 & 4562634088 & 3569341094 & 3222520474 & 6963218341 \\
\hline 2706080992 & 2622592827 & 3858221479 & 2432123842 & 3356909257 \\
\hline 5468972054 & 3326740330 & 7422191348 & 3028019249 & 5861522703 \\
\hline 0292656899 & 0553152670 & 0469226407 & 0473257482 & 7835222188 \\
\hline 8352577862 & 9861704822 & 6850645575 & 4270320960 & 5870614397 \\
\hline 8282763133 & 8513413810 & 1647614377 & 8327197041 & 3478776025 \\
\hline 3861340949 & 0441660976 & 2050734095 & 2477957320 & 4742806103 \\
\hline 0101118838 & 0310168224 & 3958201239 & 8277021888 & 3311491516 \\
\hline 2166143828 & 5408180704 & 9217633675 & 3314111178 & 9730536238 \\
\hline 3229306959 & 6850333147 & 1564887527 & 0451416196 & 8662936671 \\
\hline 0459216547 & 3990898677 & 4686868886 & 5009132491 & 5480677866 \\
\hline 3864500736 & 5650459425 & 4828483051 & 6073730387 & 6847371084 \\
\hline 4833508353 & 5977645990 & 5892625018 & 9309458906 & 1326988629 \\
\hline
\end{tabular}




\section{(Continuação)}

\begin{tabular}{|c|c|c|c|c|}
\hline 2519648284 & 6274299224 & 6103912248 & 6494631507 & 6685120027 \\
\hline 2302414604 & 4431524307 & 4406030934 & 1983946294 & 4828015192 \\
\hline 5585669628 & 2830625883 & 6568624245 & 1308604628 & 9568455243 \\
\hline 6845196959 & 3514825680 & 2206522639 & 5978987614 & 3609030186 \\
\hline 6931462985 & 1888269554 & 0102140305 & 4800264385 & 3393814595 \\
\hline 3731612898 & 9461470310 & 6780844126 & 8884596914 & 7732828189 \\
\hline 6642192494 & 1313386996 & 7669762413 & 4383101324 & 1832848504 \\
\hline 3365781235 & 9159113844 & 2331487574 & 0530084632 & 9004935616 \\
\hline 7632061935 & 2295301929 & 5774432090 & 2025367069 & 3832110101 \\
\hline 4333420259 & 2039849561 & 5822040299 & 9978788382 & 4367163895 \\
\hline 2831934394 & 8773193847 & 5436909810 & 8343322626 & 2200905922 \\
\hline 9719216334 & 6933170302 & 1115504608 & 4269601742 & 1468611448 \\
\hline 8280371420 & 5639598963 & 3390384450 & 7822871088 & 0658873967 \\
\hline 0368031360 & 6413093711 & 8602574199 & 3166606564 & 0303025897 \\
\hline 6516581101 & 9878806323 & 0737662056 & 2096067980 & 3339404942 \\
\hline 2465585704 & 1862852824 & 2645178276 & 3965017391 & 5037493873 \\
\hline 0272640775 & 8566483873 & 7510965931 & 4878580888 & 7208545717 \\
\hline 7916786399 & 4361006642 & 7626711433 & 3386767166 & 3785055607 \\
\hline 0475149339 & 6852168334 & 6409446258 & 4832722695 & 3267354971 \\
\hline 4064645760 & 9700129133 & 2214730111 & 8397689565 & 6777809887 \\
\hline 0627073426 & 0152486957 & 1917535596 & 0241038933 & 8685730232 \\
\hline 6240038710 & 9688224694 & 3556609420 & 6073048498 & 9645184707 \\
\hline 0098481897 & 9151632795 & 7425840307 & 8829047984 & 0371137826 \\
\hline 5064191891 & 9855834609 & 4966411245 & 4149368343 & 5375351339 \\
\hline 3854522578 & 0198008985 & 8612228925 & 1010711945 & 8884770007 \\
\hline 4686809778 & 6512646470 & 5841054908 & 6868885400 & 8161618041 \\
\hline 9072929310 & 0912819363 & 6930020426 & 9236486945 & 9199080765 \\
\hline 6621417760 & 9935726122 & 5240746729 & 9750713979 & 5782148806 \\
\hline 8705465276 & 8996342237 & 2711570419 & 5793083569 & 0751199266 \\
\hline 4690610306 & 8985332280 & 3489122937 & 4471384037 & 1549555108 \\
\hline 1188530609 & 8183339829 & 9127594309 & 7072514973 & 3597258341 \\
\hline 1105920697 & 6882340883 & 2540584064 & 5642785406 & 6096961282 \\
\hline 3394242028 & 6242071263 & 3439029231 & 8061684419 & 0992147349 \\
\hline 2489747561 & 6102733685 & 6728504985 & 3779950266 & 7319762813 \\
\hline 1519746723 & 6138937368 & 7623155820 & 3536828259 & 0133481766 \\
\hline 0564127088 & 8058350688 & 7348273943 & 4340133545 & 5510543850 \\
\hline 5749364406 & 7493553926 & 2770987668 & 7836262406 & 4324564080 \\
\hline 7782969697 & 6042171848 & 1634921952 & 9884484292 & 8319067778 \\
\hline 2410700651 & 5962379542 & 5367149529 & 8465430730 & 7754001542 \\
\hline 5000077823 & 4954368514 & 1850541882 & 2379807137 & 6062954030 \\
\hline 4437762196 & 3703089864 & 9085594364 & 1779965235 & 2105225930 \\
\hline 9057551747 & 5326792038 & 6990586403 & 3348329154 & 6844902425 \\
\hline 5074646742 & 9528127323 & 3254986494 & 8217181714 & 5510616429 \\
\hline 4404702202 & 8431646408 & 5255042429 & 9195438114 & 6613184744 \\
\hline 3274616473 & 2146514477 & 7248920005 & 8359896506 & 5376705878 \\
\hline 7573517049 & 1253675154 & 3810116773 & 2232614375 & 3161222111 \\
\hline 7618361634 & 1628258298 & 6426705487 & 4948551139 & 9425208085 \\
\hline 0017377181 & 6421911582 & 8104145211 & 3907306077 & 3918278568 \\
\hline 5495575504 & 1277407014 & 7986615750 & 5249417346 & 0563349233 \\
\hline 6999955463 & 4437335317 & 3806583793 & 4710623128 & 6359404032 \\
\hline
\end{tabular}

${ }^{*}$ Fonte: Fisher, RA; Yates, F. - Tabelas Estatísticas para Pesquisa em Biologia, Medicina e Agricultura. São Paulo, Polígono-EDUSP, 1971. 


\title{
ANEXO III-O INSTRUMENTO DE COLETA DE DADOS - QUESTIONÁRIO
}

\author{
UNIVERSIDADE DE SÃO PAULO \\ ESCOLA DE ENFERMAGEM \\ PROGRAMA DE PÓS-GRADUAÇÃO NÍVEL MESTRADO
}

\section{- Caracterização do laboratório}

. Nome do laboratório:

Categoria profissional da pessoa que respondeu ao questionário:

. O laboratório: ( ) unidade independente ( ) pertence a uma rede de filiais*

(*solicitamos que sejam fornecidos apenas os dados referentes à esta unidade especificamente)

. Natureza jurídica: ( ) público ( ) privado fundação

. Ano de inauguração do serviço:

. Número médio de pacientes/clientes atendidos por mês:

. Regime de atendimento:

( ) não internação

( ) internação ( ) ambos

. Clientela:

( ) interna

( ) externa

( ) ambas

. Tipos de análise que realiza:
( ) Bioquímica
( ) Hematologia
( ) Imunologia
( ) Microbiologia
( ) Biologia Molecular
( ) Outros

. Há treinamento do pessoal da coleta? $\quad($ ) sim ( ) não

Em caso afirmativo, qual a carga horária:

Profissional responsável:

. Horário de funcionamento do setor de coleta:
no ambulatório:
( ) manhã
( ) tarde
( ) noite
nas unidades de internação:
( ) manhã
( ) tarde
( ) noite

\section{- Caracterização dos recursos humanos}

. Assinalar os profissionais da área da saúde que atuam no setor de coleta de exames e respectivo número:
( ) auxiliar de enfermagem
n. ${ }^{\circ}$
( ) auxiliar de laboratório
n. ${ }^{\circ}$
( ) auxiliar de patologia clínica
n. ${ }^{\circ}$
( ) biólogo
( ) biomédico
n. ${ }^{\circ}$
( ) bioquímico
ก. ${ }^{\circ}$
( ) enfermeiro
n.
( ) farmacêutico
n. ${ }^{\circ}$
( ) médico
n. ${ }^{\circ}$
( ) técnico de enfermagem
n. ${ }^{\circ}$
( ) técnico de patologia clínica $n$.
( ) técnico de laboratório
n. ${ }^{\circ}$
.$^{\circ}$
( ) outro tipo de trabalhadores da coleta de exames sem qualificação técnica formal e
n. ${ }^{\circ}$ regular:
n. ${ }^{\circ}$

.É realizada coleta domiciliar? ( ) sim

( ) não

Caso afirmativo, qual é o profissional coordena esta atividade? 
- Caracterização das atividades desenvolvidas pelos trabalhadores de enfermagem e outros trabalhadores sem qualificação técnica formal e regular:

Assinalar as atividades desenvolvidas pelos trabalhadores da coleta:

\begin{tabular}{|l|l|l|l|l|l|}
\hline \multicolumn{1}{|c|}{ Atividades } & Enfermeiro & $\begin{array}{c}\text { Técnico } \\
\text { de } \\
\text { enferma- } \\
\text { gem }\end{array}$ & $\begin{array}{c}\text { Auxiliar de } \\
\text { enferma- } \\
\text { gem }\end{array}$ & $\begin{array}{c}\text { Trabalhadores } \\
\text { sem } \\
\text { qualificação } \\
\text { técnica * }\end{array}$ & $\begin{array}{c}\text { Outros } \\
\text { trabalhadores } \\
\text { com nível } \\
\text { superior }\end{array}$ \\
\hline $\begin{array}{l}\text { Recepção de amostras } \\
\text { já coletadas }\end{array}$ & & & & \\
\hline $\begin{array}{l}\text { Coleta de exames, em } \\
\text { geral (sangue, urina, } \\
\text { fezes, culturas, } \\
\text { micológicos, etc.) }\end{array}$ & & & & & \\
\hline $\begin{array}{l}\text { Coleta de exames de } \\
\text { maior complexidade } \\
\text { (provas funcionais, teste } \\
\text { do pezinho, etc.) }\end{array}$ & & & & & \\
\hline $\begin{array}{l}\text { Auxílio em } \\
\text { procedimentos médicos } \\
\text { (mielograma, líquor, } \\
\text { etc.) }\end{array}$ & & & & & \\
\hline Gasometria arterial & & & & & \\
\hline $\begin{array}{l}\text { Manipulação de } \\
\text { cateteres centrais }\end{array}$ & & & & & \\
\hline $\begin{array}{l}\text { Orientações sobre os } \\
\text { exames }\end{array}$ & & & & & \\
\hline $\begin{array}{l}\text { Encaminhamento das } \\
\text { amostras coletadas ao } \\
\text { setor técnico }\end{array}$ & & & & & \\
\hline Coleta domiciliar & & & & \\
\hline $\begin{array}{l}\text { Teste de materiais } \\
\text { utilizados na coleta de } \\
\text { exames }\end{array}$ & & & & & \\
\hline Supervisão & & & & \\
\hline Coordenação & & & & \\
\hline $\begin{array}{l}\text { Planejamento das ações } \\
\text { de enfermagem }\end{array}$ & & & & \\
\hline $\begin{array}{l}\text { Participação na seleção } \\
\text { recursos humanos em } \\
\text { enfermagem }\end{array}$ & & & & \\
\hline $\begin{array}{l}\text { Previsão e provisão de } \\
\text { pessoal }\end{array}$ & & & & \\
\hline Elaboração de escalas & & & & \\
\hline Treinamento em serviço & & & & \\
\hline Outros: & & & & \\
\hline Tabalhador quenão tem & & & & \\
\hline
\end{tabular}

* Trabalhador que não tem formação técnica formal em curso reconhecido pela Secretaria do Estado da Educação 
. Há divisão de trabalho assistencial e gerencial entre os trabalhadores de enfermagem?

( ) $\operatorname{sim}$ ( ) não

. Caso afirmativo, assinale o tipo de trabalho que é desenvolvido predominantemente pelos trabalhadores de enfermagem:

\begin{tabular}{|l|l|l|}
\hline \multicolumn{1}{|c|}{ Trabalhadores } & Assistencial & Gerencial \\
\hline Enfermeiro & & \\
\hline Técnicos de enfermagem & & \\
\hline Auxiliares de Enfermagem & & \\
\hline
\end{tabular}

. Inserção da equipe de enfermagem na estrutura organizacional:

( ) subordinação direta à própria área de enfermagem

( ) subordinação direta à área do laboratório

( ) subordinação direta à direção do serviço

. Qual a formação necessária solicitada ao profissional para trabalhar na coleta? 


\title{
ANEXO IV- CARTA DE AUTORIZAÇÃO DA INSTITUIÇÃO
}

\author{
UNIVERSIDADE DE SÃO PAULO \\ ESCOLA DE ENFERMAGEM \\ PROGRAMA DE PÓS-GRADUAÇÃO NÍVEL MESTRADO
}

Ao Sr.

responsável da instituição

Vimos solicitar sua autorização para a coleta de dados para a pesquisa intitulada "Caracterização do trabalho da enfermagem em laboratórios de análises clínicas".Que tem por objetivo geral identificar os aspectos da atuação da enfermagem nos laboratórios de análises clínicas, que permitam caracterizar o processo de trabalho da enfermagem nesse setor. Para tanto, os objetivos específicos são: a) Identificar os trabalhadores da saúde que atuam na coleta de exames dos laboratórios de análises clínicas; b) reconhecer as atividades desempenhadas pelos diferentes agentes da equipe de enfermagem neste setor; c) conhecer a inserção da enfermagem na estrutura organizacional.

O levantamento de dados com o responsável pelo setor de coleta de exames do laboratório será realizado, por meio de questionário anexo.

Saliento o caráter científico do estudo proposto, no qual a sua colaboração é estritamente voluntária, sendo-lhe assegurado retirá-la em qualquer fase da investigação, sem nenhuma penalização ou prejuízo à sua pessoa ou instituição. Também destaco que não haverá identificação pessoal ou institucional, e que as informações fornecidas serão confidenciais.

Desde já asseguramos nosso comprometimento de retorno dos resultados da pesquisa à instituição sob a forma de relatório.

Assinatura de consentimento do responsável:

Assinatura do Pesquisador/Mestrando:

Assinatura do Orientador:

Sob orientação da Profa Dra. Marina Peduzzi

Departamento de Orientação Profissional da Escola de Enfermagem da Universidade de São Paulo. Telefone: (011) 3066-7552 


\title{
ANEXO V - TERMO DE CONSENTIMENTO LIVRE E ESCLARECIDO
}

\author{
UNIVERSIDADE DE SÃO PAULO \\ ESCOLA DE ENFERMAGEM \\ PROGRAMA DE PÓS-GRADUAÇÃO NÍVEL MESTRADO
}

$\mathrm{Eu}$, pertencente à instituição autorizo a

utilização das informações fornecidas por mim ou pela pessoa por mim designada, para a realização da pesquisa intitulada "Caracterização do trabalho de enfermagem em laboratórios de análises clínicas". Esta pesquisa tem por objetivo geral identificar os aspectos da atuação da enfermagem nos laboratórios de análises clínicas, que permitam caracterizar o processo de trabalho da enfermagem nesse setor. Para tanto, os objetivos específicos são: a) Identificar os trabalhadores da saúde que atuam na coleta de exames dos laboratórios de análises clínicas; b) reconhecer as atividades desempenhadas pelos diferentes agentes da equipe de enfermagem neste setor; c) conhecer a inserção da enfermagem na estrutura organizacional.

A coleta de dados com o responsável pelo setor de coleta de exames do laboratório será realizada por meio de questionário anexo.

Tenho conhecimento do caráter científico do estudo proposto, no qual minha colaboração é estritamente voluntária, sendo-me assegurado retirar este consentimento em qualquer fase da investigação, sem nenhuma penalização ou prejuízo à minha pessoa ou instituição. Estou ciente de que não haverá identificação pessoal ou institucional, e que as informações fornecidas serão confidenciais.

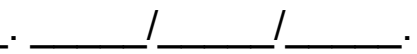

Assinatura de consentimento do responsável:

Assinatura do Pesquisador/Mestrando:

Assinatura do Orientador:

Sob orientação da Profa Dra. Marina Peduzzi

Departamento de Orientação Profissional da Escola de Enfermagem da Universidade de São Paulo. Telefone: (011) 3066-7552 
ANEXO VI - PARECER DE APROVAÇÃO DA COMISSÃO DE ÉTICA DA ESCOLA DE ENFERMAGEM DA UNIVERSIDADE DE SÃO PAULO 


\author{
ANEXO VII - CARTA DE APRESENTAÇÃO \\ UNIVERSIDADE DE SÃO PAULO \\ ESCOLA DE ENFERMAGEM \\ PROGRAMA DE PÓS-GRADUAÇÃO NÍVEL MESTRADO
}

Prezado senhor (a),

Vimos convidá-lo(a) a participar da pesquisa "Caracterização do trabalho da enfermagem em laboratórios de análises clínicas" que está sendo desenvolvida dentro do programa de pós-graduação nível mestrado da Escola de Enfermagem da Universidade de São Paulo.

A sua participação será por meio do preenchimento do questionário anexo, que pode ser feito por sua senhoria ou pelo profissional responsável pelo setor de coleta de exames da instituição.

As informações do questionário serão utilizadas para uma caracterização do trabalho da enfermagem nos setores de coleta dos laboratórios de análises clínicas, onde existir, e conhecer os outros trabalhadores que atuam com a enfermagem nesse campo de atuação.

Trata-se de uma pesquisa científica e as informações a respeito dos laboratórios serão mantidas sob sigilo, bem como a identificação dos informantes.

Seguem, também, em anexos o parecer do Comitê de Ética desta escola com a Carta de Autorização da Instituição e o Termo de Consentimento Livre e Esclarecido. Estes dois últimos estão em duas vias: uma para ser devidamente preenchida e nos enviada, e a outra, para que sua senhoria possa entrar em contato conosco quando achar necessário.

Convém salientar que a sua participação é de suma importância para a realização deste estudo que tem um caráter voluntário, ficando-lhe garantido o direito de retirar-se da pesquisa em qualquer fase da investigação.

Esperamos receber a sua resposta em breve.

Agradecemos a colaboração.

Mestranda: Adriana M. Silva

Orientadora: Prof ${ }^{a}$ Dra. Marina Peduzzi

Qualquer dúvida poderá dirigir-se ao Departamento de Orientação Profissional da Escola de Enfermagem da Universidade de São Paulo. Telefone: (011) 3066-7552 


\section{REFERÊNCIAS BIBLIOGRÁFICAS}

Aguiar ZN. A qualificação dos atendentes de enfermagem: transformações no trabalho e na vida. [dissertação] São Paulo (SP): Escola de enfermagem da USP; 2001.

Almeida MCP, Mishima SM, Peduzzi M. A pesquisa em enfermagem fundamentada no processo de trabalho: em busca da compreensão e qualificação da prática de enfermagem. In: Anais do $51^{\circ}$ Congresso Brasileiro de Enfermagem; 1999 out 2-7; Florianópolis. Florianópolis: ABEn Seção SC; 2000. p. 259-77.

Almeida MCP; Rocha JSY. O saber de enfermagem e sua dimensão prática. São Paulo: Cortez; 1986.

Almeida MCP, Rocha SMM. Considerações sobre a enfermagem enquanto trabalho. In: Almeida MCP, Rocha SMM, organizadoras. O trabalho de enfermagem. São Paulo: Cortez; 1997. p.15-26.

Antunes R. Adeus ao trabalho?: ensaio sobre as metamorfoses e a centralidade do mundo do trabalho. São Paulo: Cortez; 1995. Fordismo, toyotismo e acumulação flexível; p.13-38.

Barbosa PMK, Barbosa VBA, Valera RB. O enfermeiro e o conhecimento sobre a punção arterial. Nursing Bras 2000; 3(26):24-7. (edição brasileira) 
Brasil. Lei n.7.498, de 24 de junho de 1986. Dispõe sobre a regulamentação do exercício da enfermagem e dá outras providências. Diário Oficial da República Federativa do Brasil, Brasília, 26 jun. 1986. Seção 1, p.1.

Caldonha AM. Enfermagem empreendedora - banco de ossos: da implantação à assistência [tese]. Ribeirão Preto (SP): Escola de Enfermagem de Ribeirão Preto | USP, 2002. [resumo]

Cassiani SHB. A coleta de dados nas pesquisas em enfermagem: estratégias, validade e confiabilidade. [dissertação] Ribeirão Preto (SP): Escola de Enfermagem de Ribeirão Preto | USP; 1987.

Castellanos BEP. O trabalho do enfermeiro: a procura e o encontro de um caminho para o seu estudo: da abordagem mecânico-funcionalista à pesquisa emancipatória. [tese]. São Paulo (SP): Escola de Enfermagem da USP; 1987.

Castellanos BEP, Rodrigues AM, Almeida MCP, Rosa MTL, Mendes SASA. Os desafios da enfermagem para os anos 90. In: Programa do $41^{\circ}$ Congresso Brasileiro de Enfermagem; 1989 set 4-7; Florianópolis. Florianópolis: ABEn - Seção - SC; 1989.

Castro JL, organizadora. PROFAE: educação profissional em saúde e cidadania. Brasília (DF): Ministério da Saúde; 2002.

Centro de Vigilância Sanitária - CVS. Relação dos Laboratórios do Município de São Paulo. São Paulo; 2002.

Chein I. Uma introdução à amostragem. In: Selltz $C$, Jahoda $M$, Deutsch $M$, Cook SW. Métodos de pesquisa nas relações sociais. São Paulo: EPU; 1974. Apêndice B; p. 571-611. 
Cherchiglia ML. Terceirização do trabalho nos serviços de saúde: alguns aspectos conceituais, legais e pragmáticos. In: Santana JP, Santos E, Castro JL, Sório RER, Varella RC. Capacitação em desenvolvimento de recursos humanos de saúde CADRHU. Natal: EDUFRN; 1999. p.367-85.

Cochran WG. Técnicas de amostragem. Rio de Janeiro: Fundo de Cultura, 1965. Amostragem sistemática; p. 281-317

Conselho Federal de Enfermagem - COFEN. O exercício de enfermagem nas instituições de saúde do Brasil 1982/1983. Rio de Janeiro: ABEn; 1985.

Conselho Federal de Enfermagem - COFEN. Resolução COFEN 146, de 12 de junho de 1992. Dispõe sobre a obrigatoriedade de haver enfermeiro em todas as unidades de serviço em que são desenvolvidas ações de enfermagem. Rio de Janeiro, 1992. p.112-4.

Conselho Federal de Enfermagem - COFEN. Resolução COFEN 195, de 18 de fevereiro de 1997. Dispõe sobre a solicitação de exames laboratoriais de rotina e complementares por enfermeiro. Rio de Janeiro, 1997. p.169-70.

Conselho Nacional de Educação. Resolução CEB n. 4, 22 de dezembro de 1999. Diretrizes Curriculares Nacionais para a Educação Profissional de Nível Técnico. Câmara de Educação Básica. [on line]. Brasília (DF); 1999. Disponível em: <http://www.mec.gov.br/semtec/educprof/ttp/ceb0499.doc> (30 maio 2002).

Conselho Nacional de Saúde. Resolução n. 196 de 10 de outubro de 1996. Diretrizes e normas regulamentadoras de pesquisas envolvendo seres humanos. Bioética 1996; 4(2 Supl):15-25. 
Costa TF. Exposição dos trabalhadores de enfermagem às substâncias químicas: estudo em um hospital público universitário. [dissertação]. São Paulo (SP): Escola de Enfermagem da USP; 2002. [resumo]

Fischbach TF, editor. Exames laboratoriais e diagnósticos: manual de enfermagem. 5.ed. Rio de Janeiro: Guanabara Koogan; 1996. Responsabilidades dos profissionais nos testes diagnósticos; p. 1-11.

Fracolli LA. Processo de trabalho de gerência: possibilidades e limites frente à reorganização do trabalho na rede básica de saúde em Marília. [tese]. São Paulo (SP): Escola de Enfermagem da USP; 1999.

Fundação Sistema Estadual de Análise de Dados - SEADE. Relação dos Laboratórios do Município de São Paulo. São Paulo; 2002.

Gaidzinski, RR. Dimensionamento de pessoal de enfermagem. In: Kurcgant, P, organizadora. Administração em enfermagem. São Paulo: EPU; 1991. p. 91-6.

Girardi SN, Carvalho CL. Configurações do mercado de trabalho dos assalariados em saúde. In: Formação 2002; 2(6):15-36.

Girardi SN, Cherchiglia ML, Araújo JF. Formas institucionais de terceirização de serviços de saúde na rede hospitalar filantrópica. In: Falcão $A$, organizador. Observatório de recursos humanos em saúde no Brasil: estudos e análises. Rio de Janeiro: FIOCRUZ; 2003. p. 191-25.

Girardi SN, Seixas PH. Dilemas da regulamentação profissional na área da saúde: questões para um governo democrático e inclusionista. In: Formação 2002; 1(5): 29-43 
Graziano KU. Avaliação in vitro da atividade antimicrobiana das pastilhas de paraformaldeído, segundo a metodologia da AOAC, reproduzindo as condições de uso nas instituições de saúde do Brasil [tese]. São Paulo (SP): Escola de Enfermagem da USP; 1999. [resumo].

Gryschek ALFPL. Necessidades de qualificação da equipe de enfermagem para a assistência aos clientes portadores de HIV e da AIDS. Rev Esc Enferm USP 2000; 34(3):288-93. [resumo].

Haddad N. Metodologia de estudos em ciências da saúde: como planejar, analisar e apresentar um trabalho científico. São Paulo: Roca; 2004. Apêndice; p.249-271.

Heckler S, Müller S, Feldens TS, Guimarães VR. Análise e interpretação das dosagens gasométricas, hematológicas e bioquímicas de sangue e urina. Rev Gauch Enferm 1985; 6 (1):83-114.

Hirata EE, Monteiro MC, Magliari MA. Laboratório: nova vigiância e norma. In: Marques MC, Diniz E, Carvalho ML, Pereira SD, organizadores. Casos e fatos da vigilância sanitária sobre a saúde da sociedade. São Paulo: Sobravime | CVS 2002. p.417-33.

Kitahara PH. Seguimento do enfermeiro graduado na Escola de enfermagem da USP: sua inserção em unidades de terapia intensiva. Rev Esc Enferm USP 1999; 33(3):284-93. [resumo].

Kobayashi MK. Caracterização da disciplina noções de administração de enfermagem dos cursos técnicos de enfermagem. [dissertação]. São Paulo (SP): Escola de Enfermagem da USP; 2002. 
Kornhauser A, Sheatsley P. Construção de questionário e processo de entrevista. In: Selltz C, Jahoda M, Deutsch M, Cook SW. Métodos de pesquisa nas relações sociais. São Paulo: EPU; 1974. Apêndice C; p. 61357.

Kottke TE, Trapp MA. The quality of pap test specimens collected by nurses in a brest and cervical cancer screening clinic. Am J Prev Med 1998;14(3):196-200.

Kurcgant $\mathrm{P}$, Massarollo MCKB, Castilho V, Silva VEF. Percepção dos enfermeiros sobre as atividades que desenvolvem em suas unidades de trabalho. Rev Esc Enferm USP 1993; 27(2):229-45.

Liedke ER. Processo de trabalho. In: Cattani AD, organizador. Trabalho e tecnologia: dicionário crítico. Petróplis: Vozes; 1997a. p. 181-3.

Liedke ER. Trabalho. In: Cattani AD, organizador. Trabalho e tecnologia: dicionário crítico. Petrópolis: Vozes; 1997b. p. 269-74.

Lino MM. Satisfação profissional entre enfermeiras de UTI: adaptação transcultural do Index of Work Satisgaction (IWS). [dissertação]. São Paulo (SP): Escola de enfermagem da USP; 1999. [resumo]

Malarkey LM, McMorrow ME. Nurse's manual of laboratory tests and diagnostic procedures. Philadelphia: W.B. Saunders; 1996.

Martins CM, Rezende DT, Lemes BEM, Ferraz LNGB, Baldacci LM, Teixeira MO. Formação técnica em biotecnologia em saúde: relatório final das unidades de produção e serviços. Rio de Janeiro; Fundação Oswaldo Cruz; 1997.

Melo C. Divisão social do trabalho e enfermagem. São Paulo: Cortez; 1986. 
Ministério da Educação e Cultura. Educação Profissional: Referenciais Curriculares Nacionais da Educação Profissional de Nível Técnico.[on line]. Brasília $\quad$ (DF); 2000.2 Disponível em: http://www.mec.gov.br/semtec/educprof/ftp/ReferenciaisCurriculares/saúde.p df (30 maio 2002).

Ministério da Saúde. Projeto de Profissionalização dos Trabalhadores da Área da Enfermagem (PROFAE). Avaliação do impacto da profissionalização dos trabalhadores da área de enfermagem na qualidade dos serviços de saúde. Rev Formação 2001; 1(1):83-90.

Ministério da Saúde. Anuário Estatístico de Saúde do Brasil. Brasília (DF); 2002. Recursos físicos; p. 233-71

Ministério da Saúde. Secretaria de Gestão de Gestão do Trabalho e da Educação na Saúde. Departamento de Gestão da Educação na Saúde. Perfil de ações do técnico de enfermagem no Brasil. Brasília (DF); 2003.

Ministério da Saúde. Secretaria de Políticas de Saúde. Secretaria de Gestão de Investimentos em Saúde. Dossiê: mercado de trabalho no Brasil: PROFAE - Programa de Formação de Trabalhadores na Área de Enfermagem. Brasília (DF); 1999.

Mion Júnior D. Aparelhos, técnicas de medida da pressão arterial e critérios de hipertensão adotados por médicos brasileiros: estudo exploratório. Rev Arquivos Bras Cardiol 2002; 79 (6): 593-600. [resumo].

Mishima SM, Villa TCS, Silva EM, Gomes ELR, Anselmi ML, Pinto IC, Almeida MCP. Organização do processo gerencial no trabalho em saúde pública. In: Almeida MCP, Rocha SMM, organizadoras. O trabalho de enfermagem. São Paulo: Cortez; 1997. p.251-960. 
Moura RAA. Colheita de material para exames de laboratório: assegurando a qualidade dos serviços no laboratório clínico. São Paulo: Atheneu; 1998.

Noca CRS. O atendente e o processo de profissionalização da enfermagem: estudo em hospitais no Município de São Paulo. [dissertação] São Paulo (SP): Faculdade de Saúde Pública da USP; 1999.

Nogueira RP. O processo de produção de serviços de saúde. São Paulo; 1989. [Apostila do Curso de Atualização em Desenvolvimento de Recursos Humanos - CADRAU. Reforma Sanitária e Recursos Humanos. Departamento de Medicina Preventiva FMUSP. Módulo I].

Nogueira RP. Anotações sobre a trajetória e os problemas da pesquisa em recursos humanos de saúde. Rio de Janeiro; 1992. |mimeografado|.

Nogueira RP. O trabalho em saúde hoje: novas formas de organização. In: Negri B, Faria R, Viana AL D'Ávila, organizadores. Recursos humanos em saúde: política, desenvolvimento e mercado de trabalho. Campinas: Ed. da UNICAMP | NEPP; 2002. p. 257-73

Oguisso T. A prevalência do tabagismo entre estudantes de graduação da Escola de Enfermagem da Universidade de São Paulo. Rev Esc Enferm USP 2001; 35(1):19-27. [resumo].

Oliveira MHP, Vinha VHP. Avaliação comparativa entre duas técnicas de colheita de urina para cultura bacteriológica em mulheres. Rev Bras Enferm 1982; 35(1):39-47.

Oliveira MHP, Vinha VHP, Van Grieken EM. Custo operacional de duas técnicas de colheita de urina bacteriológica em mulheres num hospitalescola. Rev Bras Enferm 1983; 36(1):20-4. 
Paim JS. Recursos humanos em saúde no Brasil: problemas crônicos e desafios agudos. São Paulo: Faculdade de Saúde Pública da USP; 1994.

Peduzzi M. Equipe multiprofissional de saúde: a interface entre trabalho e interação. [tese] Campinas (SP): Faculdade de Ciências Médicas da UNICAMP; 1998.

Peduzzi M. A inserção do enfermeiro na equipe de saúde da família na perspectiva de promoção da saúde. In: $1^{\circ}$ Seminário Estadual sobre $O$ Enfermeiro no Programa de Saúde da Família. 2000 nov 9-11; São Paulo. São Paulo: Secretaria do Estado da Saúde; 2000.

Peduzzi M. Laços, compromissos e contradições existentes nas relações de trabalho da enfermagem. In: Anais do $53^{\circ}$ Congresso Brasileiro de Enfermagem. 2001 out 9-14; Curitiba. Curitiba: ABEn - Seção - PR; 2001a.

Peduzzi M. Equipe multiprofissional de saúde: conceito e tipologia. Rev Saúde Pública, 2001b: 35(1)103-9.

Peduzzi, M. Mudanças tecnológicas e seu impacto no processo de trabalho em saúde. Ver. Trabalho, Educação e Saúde 2002; 1(1):75-91.

Peduzzi M, Anselmi ML. O processo de trabalho de enfermagem: a cisão entre o planejamento e execução do cuidado. Rev Bras Enferm 2002; 55(4):392-8.

Peduzzi M, Anselmi ML. O processo de trabalho do auxiliar de enfermagem. . In: Formação 2003; 3(7):73-87.

Peduzzi M, Anselmi ML, Gaidzinski RR, Molesni, JO. Características do contexto de trabalho da enfermagem. In: Formação 2003; 3(7): 5-21.

Peduzzi M, Schraiber LB. A pesquisa na área de recursos humanos em saúde, no Brasil. Rev Interface 2000; (7):149-52. (Notas Breves). 
Pierantoni CR, Varella TC. Classificação brasileira de ocupações - 2002 perspectivas para análise do mercado de trabalho em saúde com o foco na enfermagem. In: Formação 2002; 2(6):55-69.

Ricardi TVR, Halker E, Sato MTGF, Carratu FP. Importância da educação em serviço na diminuição da contaminação das amostras para urocultura. Rev Bras Enferm 1990; 43 (1/4): 44-51.

Sannazzaro CAC. Contribuição para o estudo dos custos unitários de análises bioquímicas quantitativas realizadas pelo processo manual e pelo processo automático no Laboratório de Análises Clínicas do Hospital Universitário da Universidade de São Paulo, em 1989. [tese]. São Paulo (SP): Faculdade de Saúde Pública da USP; 1993.

Santos ALV. O que o paciente hospitalizado sabe sobre seus exames laboratoriais e complementares. Rev Bras Enferm 1973; 26(6):373-8.

São Paulo (Estado). Portaria n ${ }^{\circ}$ CVS-01, de 18 de janeiro de 2000. Dispõe sobre as condições de funcionamento dos laboratórios de análises clínicas, patologia clínica e congêneres. Diário Oficial Estado de São Paulo, São Paulo, 2000; 110(35):1-63.

Schraiber LB, Peduzzi M. Tendências e possibilidades da investigação de recursos humanos em saúde no Brasil. Educ Méd Salud 1993; 27(3):295313.

Silva GB. Enfermagem profissional: análise crítica. São Paulo: Cortez; 1986.

Selltz C, Jahoda M, Deutsch M, Cook SW. Métodos de pesquisa nas relações sociais. São Paulo: EPU; 1974. Planejamento de pesquisa: estudos exploratórios e descritivos; p. 57-90. 
Silva LIMC, Peduzzi M. Os recursos humanos de enfermagem da perspectiva da força de trabalho: análise da produção científica e da composição e distribuição dos trabalhadores de enfermagem. [Relatório de pesquisa]. São Paulo: EEUSP; 2003.

Silvieri MC, Paula NS. Subsídios para o ensino da atuação do enfermeiro em exames e provas de laboratório. Rev Esc Enferm USP 1968; (2):12-9.

Sociedade Brasileira de Análises Clínicas - SBAC. Relação dos Laboratórios do Estado de São Paulo. São Paulo; 2002.

Souza EF, editor. Novo manual de enfermagem: procedimentos e cuidados básicos. 6.ed. Rio de Janeiro: Cultura Médica; 1978. Funções do enfermeiro nos exames complementares; p.157-88.

Telefônica Telecomunicações de São Paulo S.A. Guia de assinantes on-line. São Paulo; 2002. Disponível em <http://www.telefonica.com.br> (15 dez 2002).

Treseler KM. Clinical laboratory and diagnostic tests: significance and nursing implications. 3.ed. Connecticut: Appleton \& Lange; 1995.

Triola MF. Introdução à estatística. 7.ed. Rio de Janeiro: LTC; 1999. Introdução à estatística. p. 1-16

Triviños ANS. Introdução à pesquisa em ciências sociais: a pesquisa qualitativa em educação. São Paulo: Atlas; 1987. Alguns temas no desenvolvimento de uma pesquisa; p.91-115.

Villa TCS, Mishima SM, Rocha SMM. A enfermagem nos serviços de saúde pública do estado de São Paulo. In: Almeida MCP, Rocha SMM, organizadoras. O trabalho de enfermagem. São Paulo: Cortez; 1997. p.2760. 
Witt A. Metodologia de pesquisa: questionário e formulário. São Paulo: Resenha Tributária; 1973. 